\title{
What are the perceptions of stakeholders of an online ESOL programme?: The case of one intermediate school in New Zealand.
}

Annette Tate

A thesis submitted to the Victoria University of Wellington in partial fulfilment of the requirements for the degree of Master of Education. 


\begin{abstract}
Online teaching for English language learners in New Zealand schools is a recent phenomenon. Increasingly complex technologies allow expanding and far reaching options in the teaching practices of English, particularly to those students in remote geographical areas, or in schools with no qualified English as a second language teacher. This qualitative research project investigated the case of one intermediate school that adopted online English language learning to meet the learning needs of their English language learners.

Stakeholders' perceptions of barriers and facilitators to learning were reported and examined. Data indicated research participants formed three distinct groups according to the extent of their involvement in the daily programme; their communication about English language learning and the particular online programme they were using; and their understanding of the purposes and processes of the online English language programme. These three factors influenced stakeholders' perceptions of the value of online English language learning. The more actively stakeholders were involved, communicated about and understood the online English language learning programme, the more they were convinced of its value. These findings suggest that stakeholders who have a more peripheral involvement may benefit from increased opportunities to connect with other stakeholders in the programme. Online English language learning is likely to be enhanced if formal and informal structures are developed to allow stakeholders to develop greater involvement, opportunities for communication and knowledge of the programme.
\end{abstract}




\section{Acknowledgements}

I acknowledge the generous support given to me by the following people.

- Heather Bell, my principal for five years. You challenged and inspired me in equal measures with your constant seeking and love of learning.

- My supervisors Dr Carolyn Tait and Dr Margaret Gleeson. Thank you so much for your clear thinking, gentle guidance and kind communications. I have enjoyed our association.

- The staff and students who welcomed me into their school and participated so willingly in this research.

- Everyone connected with ELLINZ online. Your passion to serve your English language learners is exemplary and inspiring.

- Most especially, my wonderful husband Peter. Thank you for supporting me to pursue my dream and for all the cups of tea.

Teach me knowledge and good judgement, for I trust your commands. Psalm 119v66 (New International Version) 


\section{Table of Contents}

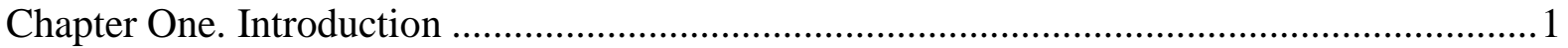

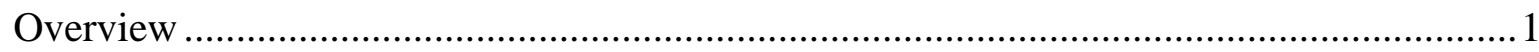

What do English Language Learners Need? .................................................................

English Language Learners' Needs in the New Zealand School Setting..............................2

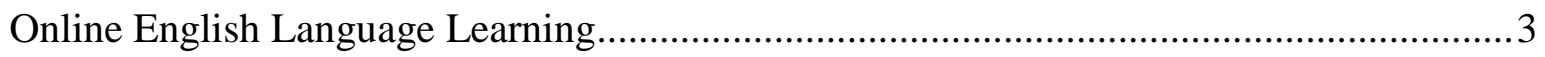

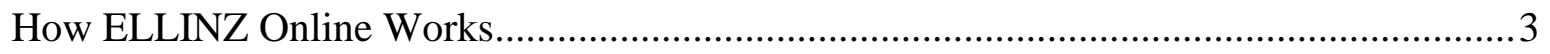

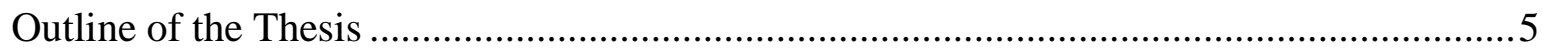

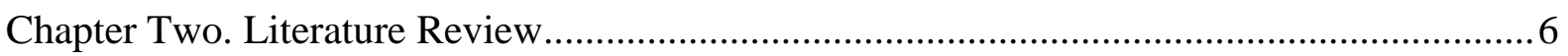

Terminology for English Language Learners ......................................................... 6

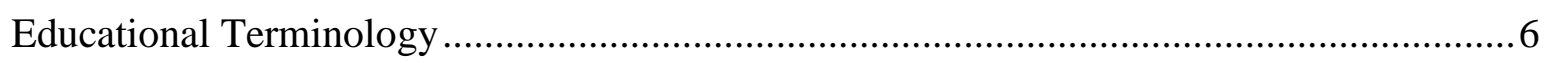

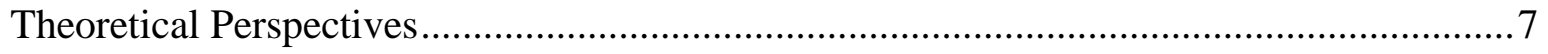

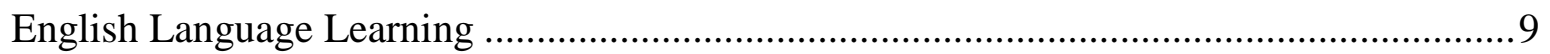

English Language Learning, Online Learning and Online English Language Learning ..... 11

Perceptions of Online Learning and Online English Language Learning .......................... 12

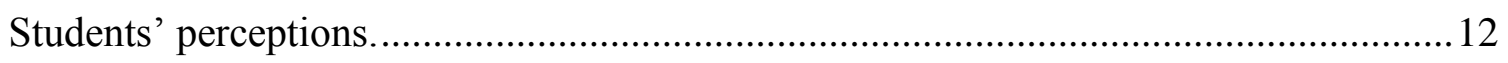

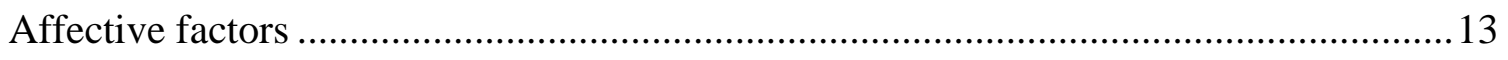

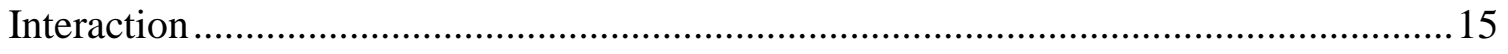

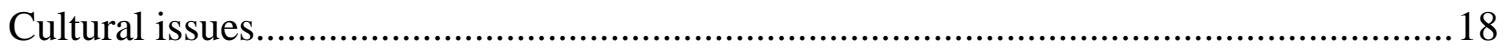

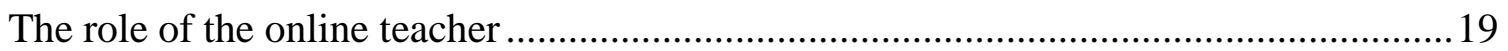

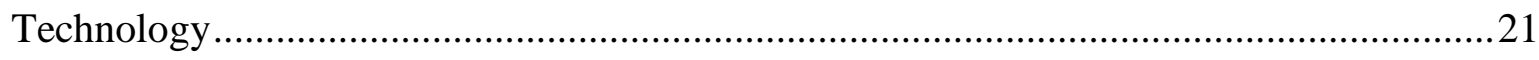

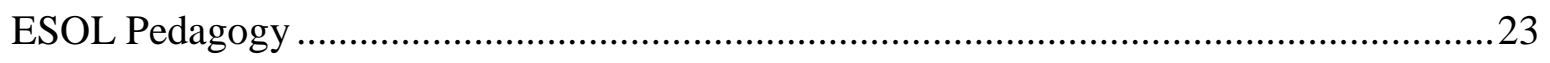

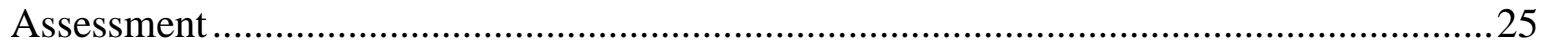

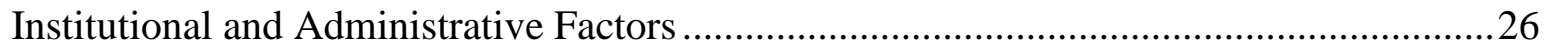

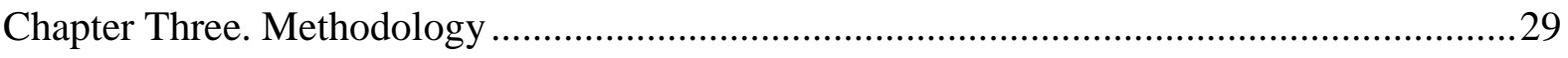

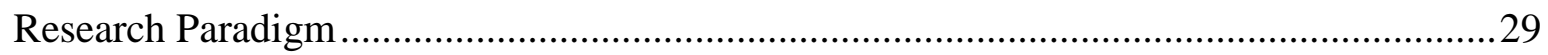

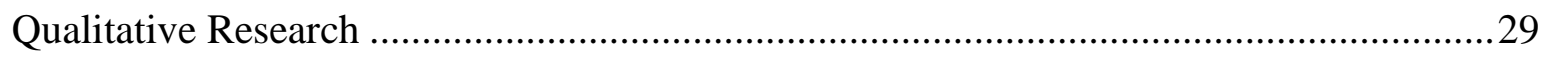

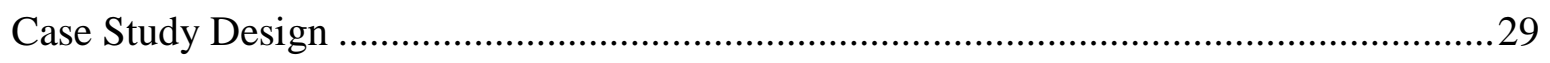

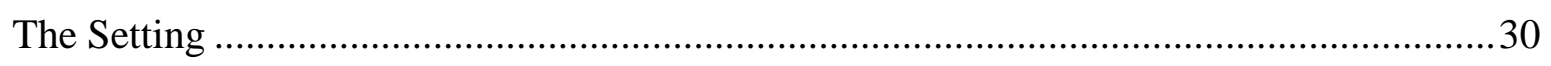

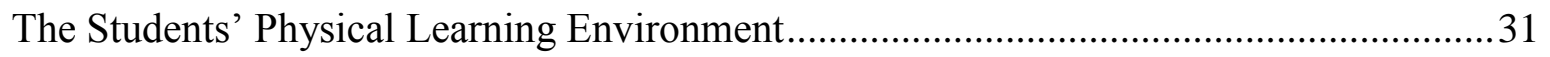

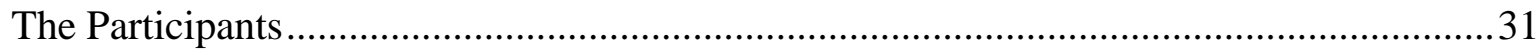

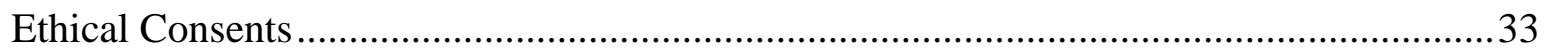

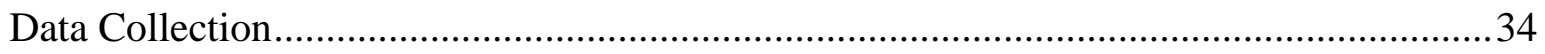




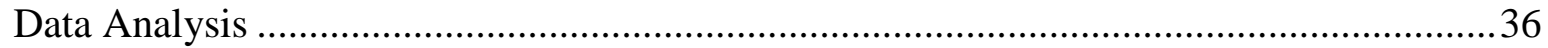

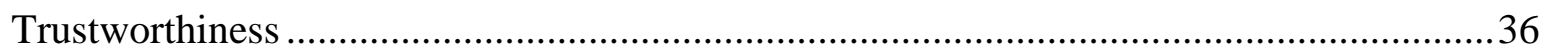

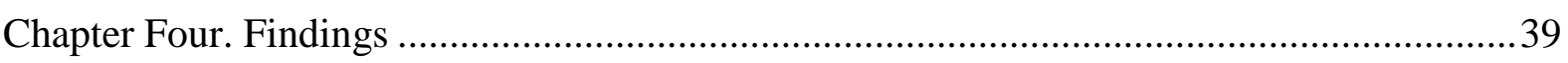

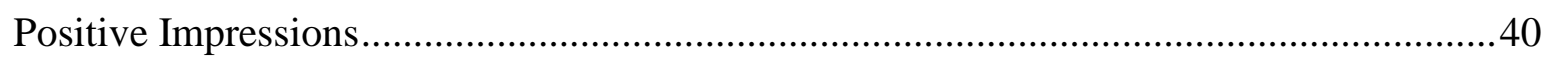

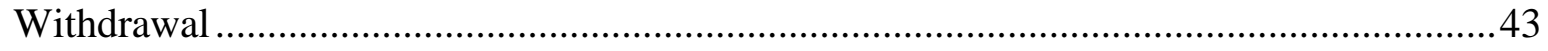

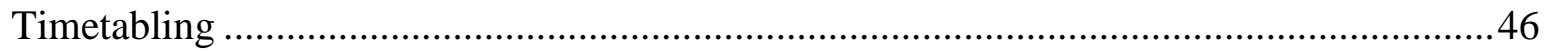

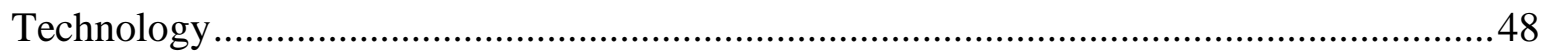

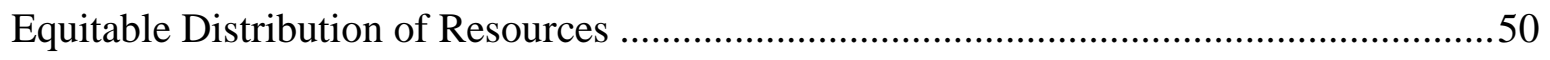

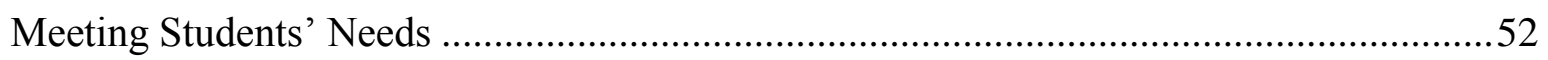

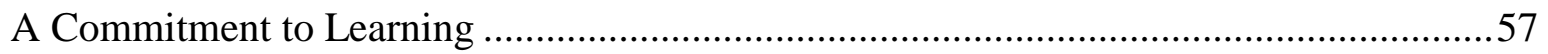

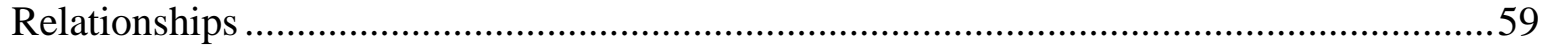

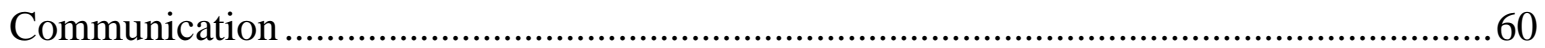

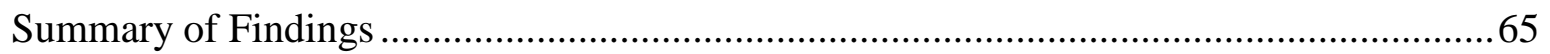

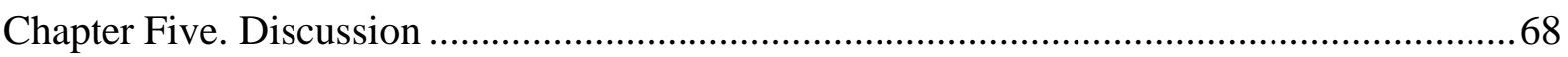

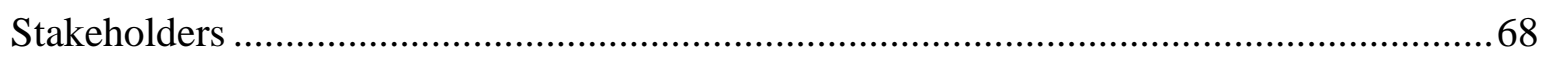

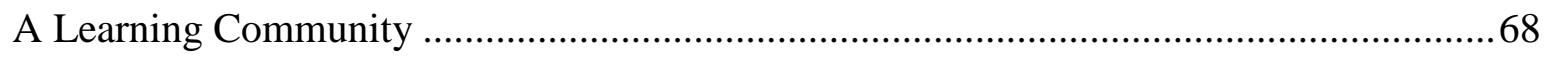

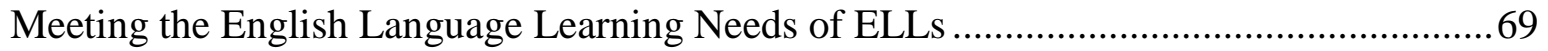

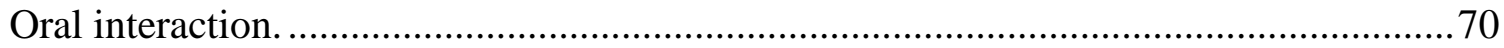

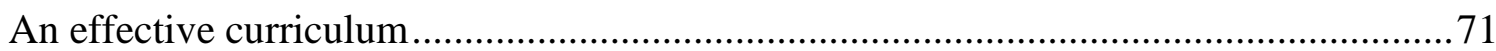

Can Online English Language Learning Meet ELLs’ Learning Needs? ............................72

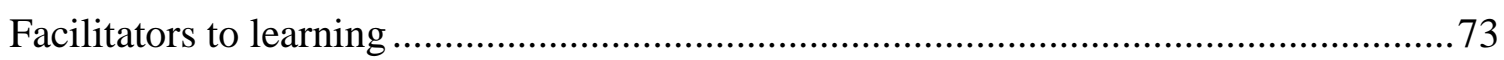

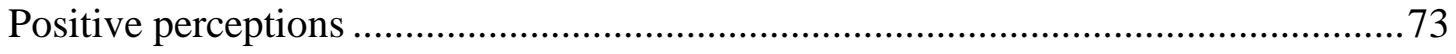

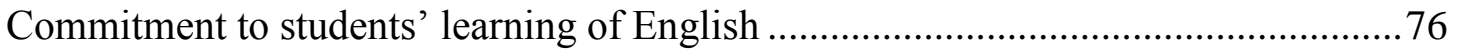

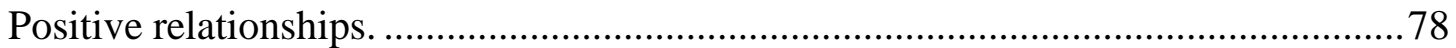

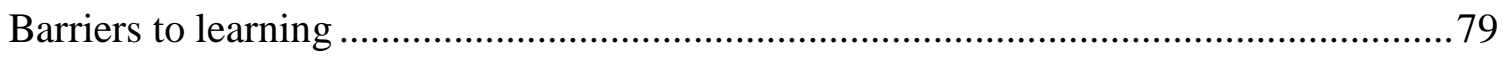

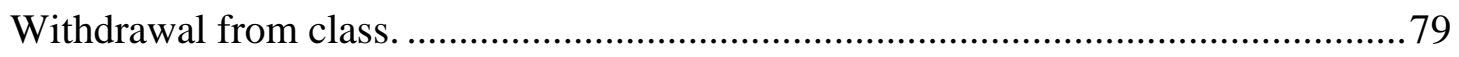

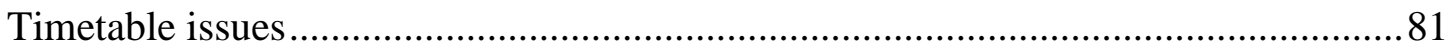

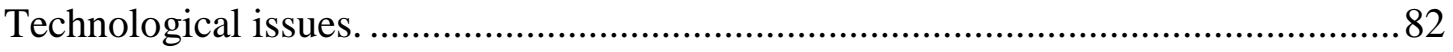

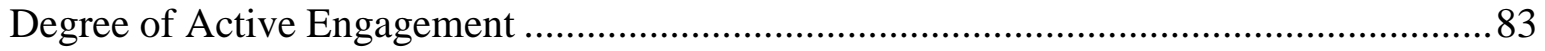

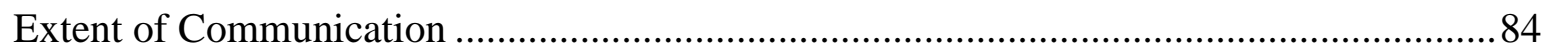

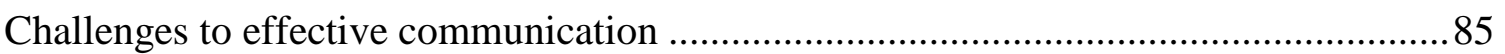

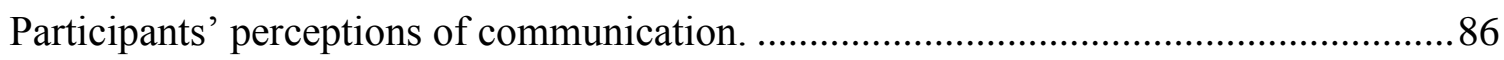

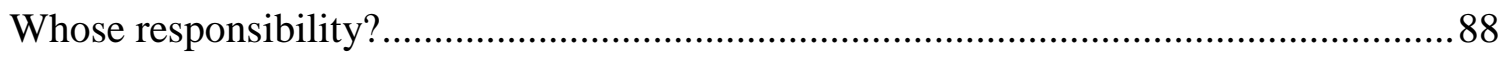




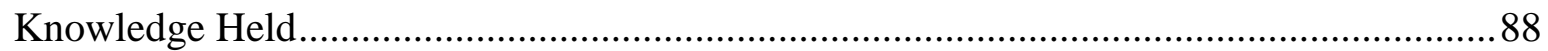

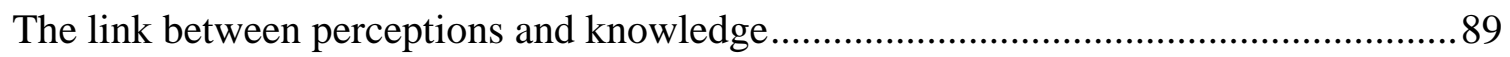

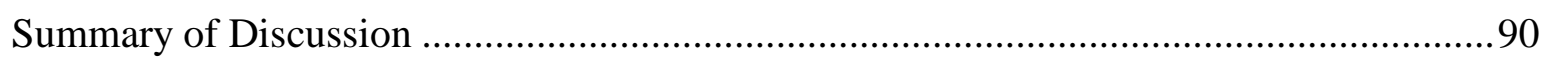

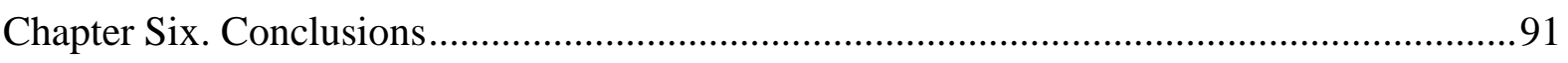

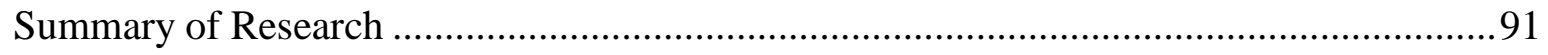

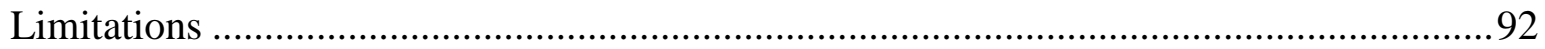

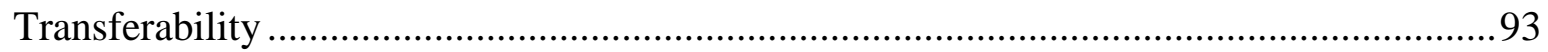

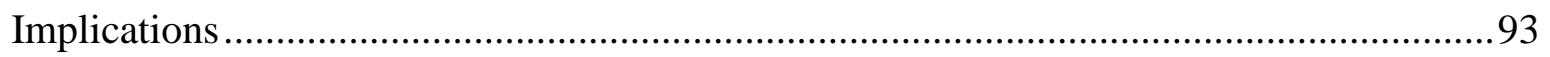

Perspectives to Enhance Programme Effectiveness ......................................................95

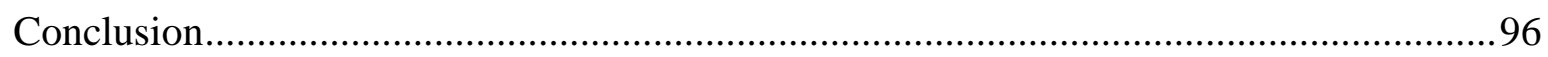

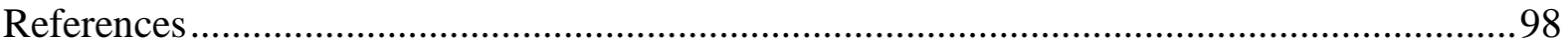

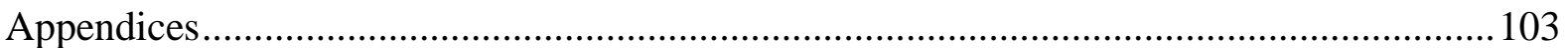

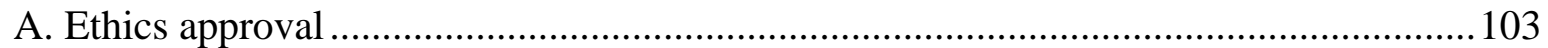

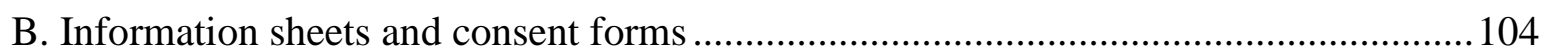

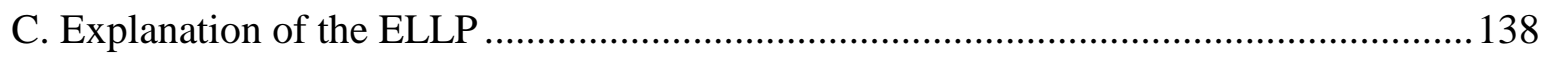

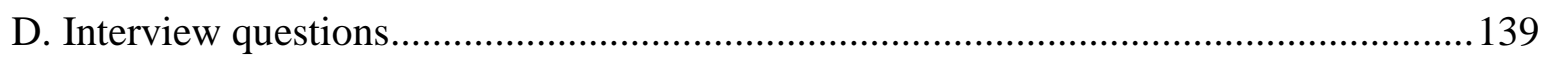

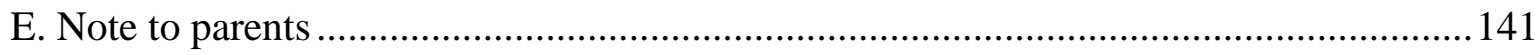

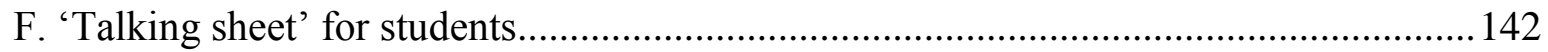

\section{Table of Tables}

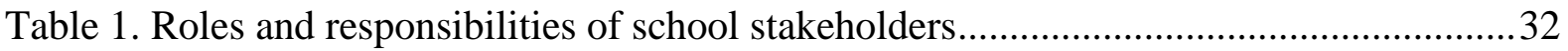

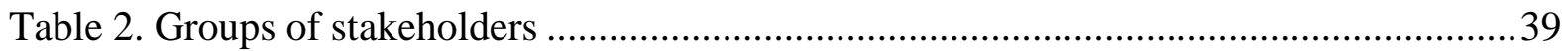

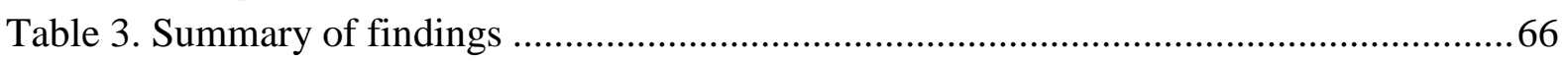




\section{Chapter One. Introduction}

\section{Overview}

Increasing and accelerating world-wide migration patterns have resulted in large numbers of English language learners in schools. In the first half of 2014 over 31,000 students attending New Zealand primary (including intermediate) or secondary schools qualified for English for speakers of other languages (ESOL) funding, (T. Hunter, personal communication, April 2, 2014). These are the students whose English proficiency in reading, writing, listening and speaking measured below the predetermined criteria on the designated funding assessment, making them eligible for the Government funding which assists schools to provide for their learning needs (Ministry of Education, 2004, p. 93). These students are a diverse group; often linguistically, culturally and ethnically dissimilar, yet they are united in their need to learn English. They come from different backgrounds. They are refugees, migrants or the New Zealand born children of migrants. However, these ESOL funded students do not represent the sum of English language learners in New Zealand schools. There are many more whose English language proficiency is above the ESOL funding cut off level, yet has not reached the level of their peers who speak English as their first language.

\section{What do English Language Learners Need?}

Teaching approaches that accelerate the English language development of students draw on a large and relatively recent body of research on second language acquisition (SLA). The study of SLA is a comparatively new discipline, with systematic research being undertaken consistently only since the 1960s. In addition, factors contributing towards successful SLA are multifaceted. Brown (2007) comments 'Many variables are involved in the acquisition process. Language learning is not a set of easy steps that can be programmed into a quick do-it-yourself kit' (p.1).

One variable that has gained increasing prominence amongst researchers is the belief that successful SLA involves not just the learning of linguistic elements such as syntax and vocabulary, but also requires a wider conceptual understanding of the cultural context in which the target language is spoken. Consequently, in order to communicate successfully, English language learners (ELLs) need to not only learn the mechanics of the English language, but also to understand the social and cultural milieu in which they are communicating. 
The importance of the teacher's role in successful English acquisition by learners cannot be overestimated (Echevarria \& Vogt, 2010). The degree to which school aged ELLs successfully learn English depends to a large extent on what happens between the teacher and student in the classroom. Gibbons (2009) suggests knowledge construction and English language skills develop concurrently as a skilled teacher develops the literacy of students in an intellectually challenging curriculum, one in which ELLs "are afforded the opportunities to think creatively, transform information, engage in inquiry-oriented activity and construct their own understandings through participating in substantive conversations and, critically, are given the scaffolding and support to be successful" (p.1).

However, ELLs have long been identified as being at risk of educational failure both in New Zealand and overseas (Cummins, 2001; Fletcher, Parkhill, \& Harris, 2011). The challenge remains for educators to accommodate their learning needs within our classrooms if ELLs are to bridge the academic gap between their performance in an English language environment and that of their English first language (L1) speaking counterparts. Cummins (2001) proposes a theoretical framework in which he suggests language minority students, or ELLs' failure to achieve at school can be attributed to the relationship between educators, and the language minority students and their families. He suggests that language minority students are empowered or disempowered as learners within their school environment to the extent that

1. the minority language and culture are integrated into the school programme;

2. the minority community is invited to participate in the school programme;

3. pedagogical practices of the school promote use of the home language and studentcentred learning; and,

4. assessment practices advocate for minority students rather than viewing lower educational attainment as the student's fault.

The literature suggests both research based pedagogical practice and the optimal sociocultural environment Cummins speaks of are necessary to create the most favourable learning conditions for ELLs.

\section{English Language Learners' Needs in the New Zealand School Setting}

The New Zealand setting presents specific challenges to the equitable provision of ESOL resources. Although the majority of ESOL funded ELLs live in the more densely populated urban areas of New Zealand, there are smaller numbers dispersed geographically throughout the country. While the English language learning needs of these students may be 
significant, there are many schools where the numbers of these students are very small. In the first half of 2014, forty eight percent of the New Zealand schools that received ESOL funding only had between one and nine ESOL funded students in attendance (T. Hunter, personal communication, April 9, 2014). In addition to having small numbers of ELLs on their rolls, schools may not have a teacher who has completed a recognised ESOL teacher qualification on their staff. Even if a suitably qualified person was available schools may not think it financially feasible to employ an ESOL teacher for such small numbers of students.

\section{Online English Language Learning}

Advances in technology over recent decades have resulted in revolutionary changes in the education of English language learners (Chapelle, 2007). Increasingly complex information and communication technologies (ICT) allow expanding and far reaching options in the teaching practices and assessment of English language learners at an accelerating rate (Blake, 2011; Chapelle, 2007; St. Amant, 2007; White, 2006). Internet facilities provide the opportunity for online learning: instruction which can be delivered either in hybrid, or blended classes, where face-to-face teaching occurs alongside online teaching, or fully online classes where the course content is delivered entirely in a virtual setting (Blake, 2011; White, 2006). These different learning environments offer attractive advantages to learners and educational institutions alike, as evidenced by the rapid growth in online courses worldwide (Casey, 2008). Equally they pose a variety of challenges for educators. Online language learning and teaching raises multifaceted issues "...given the presence and interplay of human, institutional and sociocultural influences..." (White, 2006, p. 248).

\section{How ELLINZ Online Works}

ELLINZ online is an online English language learning programme. This Ministry of Education initiative was designed in 2009, trialled in 2010, piloted in 2011 and 2012, and has been in operation since then.

The programme is offered to intermediate and secondary schools within New Zealand including the site of this study. Schools wishing to participate apply to ELLINZ online for selection. Schools are included in the programme if they meet certain selection criteria; namely having ELLs who are assessed as functioning in the foundation or stage one on the English Language Learning Progressions ${ }^{1}$ (ELLP) (Ministry of Education, 2008), and the school is able to provide the technological infrastructure and support from an eTutor to run

\footnotetext{
${ }^{1}$ See appendix A for an explanation of the ELLP.
} 
the programme. Typically, selected schools are not able to provide their English language learners with a qualified ESOL teacher from their own staff.

Teaching is offered online to small groups by an eTeacher (from a different geographical location), and learning is supported within the school by an eTutor during and between synchronous lessons. In a typical lesson a small group of up to eight students is withdrawn from the mainstream classroom for a class of between 40 and 60 minutes. Students work independently and in groups. eTeachers differentiate the learning for different levels to meet the individual learning needs of the students.

The students work with their eTeacher online using communication software such as Skype or Adobe Connect. This software enables web conferencing, user desktop sharing, voice communications, video communication and instant messaging. ELLINZ online uses Moodle as the learning management system to manage the various features of the programme such as discussion forums, wikis and online quizzes. Students and eTeachers use Google Drive to allow file sharing and collaborative editing. An eTutor works alongside students within the school guiding them in various ways. For example, she may clarify instructions, prompt responses from students and encourage the students to stay on task. eTeachers prioritise interaction opportunities for the students, regularly engaging students in paired or group speaking practice before a writing task. In a typical lesson students will listen, speak, read and write, following a set curriculum.

This style of delivery could be described as 'blended learning', as the eTutor supports students within the school alongside the online teaching by the ESOL teacher. However, in this research the ELLINZ online programme will be described as 'online learning' as the eTutor is typically a teacher aide without ESOL teaching qualifications. In addition, the term online learning can refer to a blended course as well as a course taught exclusively online (Blake, 2011).

Most online language teaching and research has been confined to tertiary settings (Felix, 2004, 2008; Oliver, Osborne, \& Brady, 2009). Online English language teaching is a new concept within New Zealand primary, intermediate and secondary schools and I found no studies of online English language learning in New Zealand at primary, intermediate or secondary school levels in the literature. My thesis aims to address this gap, by undertaking a single case study investigating the perceptions of stakeholders of an online English language learning programme in one New Zealand intermediate school. 
I used the terms 'stakeholder' and 'participant' in this study. A stakeholder may be described as a person, group or organization that has interest or concern in an organization (Collins Cobuild Advanced Learner's Dictionary, 2003). In this research, all of the participants, or people who took part in the research, were stakeholders. However, there were some stakeholders who did not participate in this research. Stakeholders who were not research participants included some staff employed in the online English language learning programme, such as the ePrincipals, and the Ministry of Education which funds the programme. These may also be designated as stakeholders, as they have a direct interest in ESOL provision and outcomes for ELLs. Therefore all of the participants were stakeholders but not all stakeholders participated in this research.

My interest in this topic arises from my experience as an ESOL teacher in both face-to-face and online settings. In addition, I have personal experiences from which to draw, as I have studied at tertiary level in the classroom and online too.

\section{Outline of the Thesis}

This thesis is divided into six chapters. It begins with an introduction, and then moves to a literature review, in which I explore the prior research of the two main areas of interest; English language learning and online English language learning, and how they connect. In Chapter Three I outline the methodology, describing the different methods and processes used for gathering data. Findings from the data collected are presented in Chapter Four. In Chapter Five I discuss the findings, linking these to the relevant literature. Finally in Chapter Six I draw conclusions from this case study, and offer implications for teaching and learning. 


\section{Chapter Two. Literature Review}

In this review I investigate empirical studies and theoretical reviews. First, I define key terminology, and discuss theoretical perspectives. I then review the main themes that emerged from the literature. I investigate face-to-face English language learning as a foundation from which to understand online English language learning, and then examine the relationship between online learning and online English language learning. Next, I examine perceptions of online learning under the headings of students' perceptions, affective factors, interaction, cultural issues and the role of the online teacher. I then discuss technology, ESOL pedagogy and assessment. Finally I explore institutional and administrative factors.

\section{Terminology for English Language Learners}

Students learning the English language are described by various terms. These terms can vary depending on the country of origin and also change over time. Some terms for learners include ESOL students, English language learners, linguistic minority students, English as a second language (ESL) students, non English speaking background (NESB), limited English proficient (LEP) and English as an additional language (EAL) (Gibbons, 2009). Although once widely used, terms such as NESB and LEP are now used less often as they tend to highlight perceived deficits in the student and do not take into account the language strengths the learner may have in their home language. Additionally, in New Zealand the term 'English language learner' (ELL) is used increasingly in an attempt to identify the student as a person and not by the learning programme attended. In this research I have used the term English language learner or ELL to identify the student participants.

\section{Educational Terminology}

Distance education is a broad term used to describe any educational courses that are delivered to students who are physically separated from the course provider (Tallent-Runnels et al., 2006; White, 2003). It involves four key aspects: the separation of student and teacher, the use of technical media, two way communication between student and teacher and the involvement of an educational institution (Keegan, 1990).

However, there is uncertainty about accepted terminology in common use. Rice (2006) states 'Distance education, distance learning, e-learning, Web-based instruction, virtual schools, and online learning are all terms used interchangeably to describe this broad, somewhat confusing, and constantly changing field of non-traditional instruction', (p. 426). Blake, (2011) suggests this terminology confusion arises from the percentage of course content that is delivered online. He asserts web-based educational courses can use the internet in varying 
amounts to deliver tuition, with the percentage of the course that is not web-based being delivered in other formats, for example an online course combined with some face-to-face delivery also.

In distance education a variety of delivery formats may be used, such as video conferencing, audio conferencing, entirely web based, web enhanced and blended or hybrid courses where the curriculum is delivered by some web based and some face-to-face instruction.

Elearning refers to any learning that is electronically mediated, with the term online education describing courses delivered entirely on the internet (Tallent-Runnels et al., 2006). Elearning may or may not be delivered on the internet, but online education is exclusively internet based. Classes may be in real time (synchronous) where all students are online and communicating at the same time, or in deferred time (asynchronous) where students work independently at different times on their course work (Tallent-Runnels et al., 2006). Blended or hybrid courses combine online elements with traditional face-to-face teaching. Virtual schooling is the term usually given to distance education programmes targeting primary and secondary level students.

In this research the terms online education, eTeachers and online learning will be used, as the online English language learning programme that is the subject of my study is delivered via the internet by a teacher who is physically separated from the students. For this reason I consider these to be the most appropriate terms to use.

\section{Theoretical Perspectives}

Sociocultural approaches to education have emphasized the centrality of language to children's development and learning. The notion that language, thought and cognitive development are inextricably linked has been an important influence on educational thinking (Lyall, 2008). The view that learning, including language learning, is a collaborative activity and not one that is done in isolation is at the heart of sociocultural theory. This necessitates planned language interaction requiring student to student and student to teacher communications with purposeful learning goals. This kind of learning is described by Gibbons (2009) as a middle ground between 'top down' transmission-type teaching where the teacher assumes responsibility of knowledge transfer to the student and the totally student-led learning where students construct their own knowledge and the teacher acts as facilitator. In an approach that is totally student-led ELLs are not given the explicit overt language teaching that is necessary for them to achieve their potential (Wong-Fillmore \& Snow, 2000). Within a 
sociocultural context, language learning becomes a collaborative social activity, as well as one that is academically driven.

Alongside this concept of collaborative, social learning is the notion of assisted learning; learning alongside and aided by a more skilled partner as the skills of the learner develop. The term that is commonly used in education for assisted learning with a more skilled partner is 'scaffolding' (Wood, Bruner \& Ross, as cited in Gibbons, 2002, p.10). The term scaffolding describes temporary help given during the process of learning. During the process of scaffolding a student's learning, the more skilled person (probably a fellow student or teacher) gives the right amount and the right sort of help for the learner to achieve the task. As the learner's skills develop, the help is reduced and finally removed, just as physical scaffolding is removed once physical work is finished on a building. Appropriate scaffolding for ELLs combines high cognitive challenge on the student together with adequate support to successfully complete the task (Gibbons, 2002).

There is a prevailing theme in the literature highlighting the deficit of research in online language learning (Kaler, 2012; Oliver, Kellogg, \& Patel, 2012; Oliver, Kellogg, Townsend, \& Brady, 2010; Rice, 2006; Tallent-Runnels et al., 2006). The sound theoretical base for English language learning found in the literature is not matched by a corresponding sound theoretical base to online language learning. Mayes, Luebeck, $\mathrm{Ku}$, Akarasriworn and Korkmaz (2011) claim 'Some of the existing frameworks and recommendations are based on research, while many others are built simply on the experiences of online educators' (p. 151). Second language (L2) learning theories, the needs of individual learners and the sociocultural context in which language learning takes place all need to be considered by researchers (Ibarz $\&$ Webb, 2007). Rice (2006) suggests the complexities of online learning contribute to the confusion in the field, along with 'a lack of a theoretical rationale for most distance education research' (p.440). In addition, Tallent-Runnels et. al. (2006) state "We found no comprehensive theory or model that informed studies of online instruction" (p.115). Furthermore, White (2006) calls for new tools, methods and approaches suitable for the new theories of distance language learning. This lack of a sound theoretical base extends to online English language course design also. Yague (as cited in Ibarz \& Webb, 2007) suggests this deficit weakens online English language courses and renders them less effective than they might be. 
Despite the pervasive theme of a lack of a strong theoretical base for online learning, sociocultural theory guides both English language learning literature and online English language learning literature. As previously mentioned, sociocultural theory suggests that learning of language is constructed through socially mediated interaction. This theory is derived from Vygotsky's (1962) concept of the Zone of Proximal Development. The Zone of Proximal Development describes the gap between what a learner can achieve unaided, and what that same learner may achieve jointly with a more skilled 'expert', within a social setting. Sociocultural theory suggests that language learning is not discrete and cannot be separated from the social setting in which it occurs. It is from this hypothesis most of the online language learning pedagogy arises. Engagement between and among learners, with the emphasis on collaboration and participation allows learners to use and learn language within an authentic social setting (Beckett, Amaro-Jiménez, \& Beckett, 2010; Blake, 2007, 2011; Oliver et al., 2012). By establishing relationships and negotiating linguistic exchanges within their learning community, language learners can gain expertise through socialisation (Beckett et al., 2010). The move from teacher directed learning toward interactive based learning that emphasizes the communicative and social aspects of learning has been enabled by newer technologies (Tallent-Runnels et al., 2006), which focus on participation (Blake, 2011). White (2006) comments on this trend, stating there is a shift from teaching materials "...to a concern with communication and learning as a social process supported largely by ICT" (p.249). Oral collaboration is an important part of this shift.

Sociocultural theory has underpinned the course foundation and implementation of the online English language learning programme that is the subject of this research, and therefore forms the theoretical basis of this case study. I will now consider English language learning in a face-to-face context as a foundation from which to understand online English language learning.

\section{English Language Learning}

The quality of instruction is a high priority when educating English language learners (Calderon, Sanchez, \& Slavin, 2011). ELLs need an educational environment that places high cognitive expectations with corresponding high levels of support on the student. Best practice for ELLs suggests language and literacy support be given alongside core curriculum teaching within a classroom that is culturally responsive and relevant to the unique needs of the individual students (Gibbons, 2009). Specific classroom teaching practices to develop students' oral abilities, utilise prior knowledge, explicitly teach vocabulary, make meaning 
explicit and assess fairly will foster engagement and maximise ELLs' learning opportunities (Echevarria \& Vogt, 2010). Also, explicit teaching practices need to be maintained by systemic supports such as school leadership and structure, teacher professional development, parent and family supports and monitoring of outcomes (Calderon et al., 2011).

Within the sociocultural paradigm, overarching principles guide teachers to choose approaches and materials to suit the particular needs of their students within their own unique setting. Structured pedagogy that does not take into account the individuality of learners does not provide the flexibility to allow maximum language learning attainment (Blake, 2011). In a positive learning environment for ELLs, teachers need to adopt teaching approaches that will be of educational benefit to their students. Teachers consider which strategies they can consciously adopt and build into their teaching repertoire that will then lead to students developing the language skills as well as the curriculum content required to meet their educational goals.

One approach is to structure learning experiences based on interactive, collaborative oral experiences. Classroom discourse has the potential to generate a rich learning context for all learners, including English language learners. Wells (as cited in Gibbons, 2009) suggests the two functions of spoken language in the classroom are to provide a bridge to written literacy and to make sense of new knowledge. These are both functions essential to learning the English language and learning across the curriculum.

Talk is therefore seen as a bridge to learning, particularly learning the academic language in which English language learners need satisfactory proficiency before they can progress successfully through our schooling and tertiary educational systems. Students in this particular online English language learning programme function at the foundation stage or stage one of the ELLP in oral language development. At these stages ELLs' oral expression would range from speaking in single words to using non-standard sentence constructions and formulaic phrases. Their comprehension of spoken English would range from understanding individual words to understanding simple sentences (Ministry of Education, 2008). By contrast, according to the Literacy Learning Progressions ${ }^{2}$, L1 speakers in their first year of school in New Zealand are expected to use oral language to offer opinions, respond orally to text, use an increasing variety of verb forms correctly, ask questions and participate in

\footnotetext{
${ }^{2}$ The Literacy Learning Progressions are a reference for teachers describing what students need to know at specific stages of their schooling.
} 
discussions (Ministry of Education, 2010). Therefore ELLs at the foundation stage or stage one on the ELLP need to make significant progress in English to even begin to function at the curriculum levels of their peers. How ELLs talk, how much they talk, how the talk is set up and monitored and what they talk about will all have a profound influence on their learning.

I will now discuss the connection between English language learning, online learning and online English language learning.

\section{English Language Learning, Online Learning and Online English Language Learning} English language learning is the umbrella under which online English language learning sits. Online English language learning may be described as a subset of English language learning. Another significant consideration for this review however, is that of online learning, learning that occurs online but in any subject area, as some of the research literature from online learning informed this review. The three areas of English language learning, online learning and online English language learning have similarities and differences in practice. Just as best-practice teaching approaches and skills used in face-to-face teaching may be different to those used in online teaching, so best-practice teaching approaches and skills used in online teaching may differ to those used in online language teaching (Compton, 2009).

Effective teaching practice is based on a sound theoretical base. Teachers need to be able to make defensible choices about their underlying beliefs in both the methodology and the technologies used in their teaching practice. The bases from which these choices are made guide practice, and are therefore extremely important. Gibbons (2009) asserts '...teachers are critical in making good ideas context responsive-that is, making them relevant to their own unique situations and to the needs of their students' (p.3).

Students learning online do not seem to do better or worse than those who are learning in a classroom face-to-face (Blake, 2011; Diaz \& Entonado, 2009; Liu \& Cavanaugh, 2011; Tallent-Runnels et al., 2006). However, research suggests that the quality of instruction whether in an online or face-to-face environment is a crucial factor influencing student achievement (Mayes et al., 2011; Rice, 2006; Ushida, 2005).

I will now investigate students' perceptions of online learning and online English language learning. Reviewing the perceptions of students is relevant since I gathered the perceptions of the research participants as the findings in this thesis. 


\section{Perceptions of Online Learning and Online English Language Learning}

Students' perceptions. Students' perceptions of online learning are generally positive (Antón, 2011; Kaler, 2012). There is a preference by learners for a blended or hybrid course delivery: course delivery that is part online, part face-to-face. In my study the students learn online with face-to-face support from an eTutor, conditions that are very similar to those in which positive perceptions are reported. In a study examining the conditions in which Native American high school students adapt successfully to an online environment, Kaler (2012) found student perceptions of online learning to be positive. Students in this study reported learning online gave them increased challenge, freedom and independence over traditional face-to-face tuition. Ushida (2005) investigated students' motivation and attitudes in the study of French or Spanish in an online setting. Her research addressed the factors affecting patterns of students' motivation and attitude, and how these factors influenced learning. In findings similar to Kaler's, the study showed positive results overall. Students reported relatively positive and stable levels of motivation and attitudes during their course. Ushida suggests factors contributing toward the positive response may have been that students self selected the course and that all were confident computer users prior to course commencement.

However Oliver et al. (2012), in a comparison of reported differences between high school online foreign language students and high school students learning other subjects online, found the foreign language students had significantly less positive perceptions of their online courses in several key areas than their counterparts. These areas were overall success in the online environment, teacher preparation, teaching, course/assignment instructions and level of group collaboration. Recommendations from students and teachers involved in this study included improving some aspects of teaching (for example providing timely feedback), increasing collaboration and providing suitable support for learners. Nevertheless, the students in Oliver et al.'s study were L1 speakers learning a foreign language within an English speaking context, whereas the students in my study are ELLs learning English in order to progress academically in an English speaking context.

In a study of primary school students in a virtual school in North Carolina, Ingerham (2012) observed students for 'on task' and 'off task' behaviours. Findings showed few students fully engaged in the online programme, and Ingerham reported behavioural trends that are typical of face-to-face classroom behaviours, such as off-task behaviour, dependence on teacher direction, being slow to start work and quick to finish. This research suggests the amount of 
time students spend specifically on learning tasks has an effect on their overall achievement levels. It recommends steps are taken to increase opportunities for the online teacher and students to interact to combat off-task behaviours and maximise the benefits of online learning.

Finally, there is evidence which indicates learning that includes face-to-face course delivery as well as online learning may result in improved student experience as well as better learning outcomes compared to employing one approach only (Ingerham, 2012). This may be due to the need for students to feel connected to a real person. Oliver, Osborne, Patel and Kleiman (2009) suggest added mentoring between teacher and student either through synchronous discussion or in-person at the student's school may enhance student understanding of course material, with better learning outcomes. The context of this research has particular relevance to my study, as the ELLs learning English online in my study have both face-to-face course tutoring with their eTutor and online course teaching with their eTeacher.

Affective factors. Affective factors have a direct influence on students' perceptions, attitudes and satisfaction in the online environment, and directly influence student achievement and retention rates (Rice, 2006). There is a limited amount of research on the perceptions of online learners despite this being a critical area of investigation, "as it is, after all, a student's perception that will depict their reality towards online education" (Dobbs, Waid, \& del Carmen, 2009). These authors report some predictors for students' positive perceptions of learning online may be a visual learning style, a willingness to take risks, an internal locus of control, and age.

In addition to positive perceptions of online learning, students consider affective aspects of online teachers as very important. Murphy, Shelley and Baumann (2010) investigated generic competencies for online teachers of tertiary distance language students in the United Kingdom with students reporting a preference for teachers who were "...enthusiastic, approachable, supportive and committed, who created a group atmosphere where students could participate with confidence and who responded positively to diverse learning needs and styles" (p. 131).

Establishing online student to teacher and student to student relationships present many challenges that do not arise in a face-to-face learning environment. Mayes et. al. (2011) suggest reducing perceptions of isolation and establishing a sense of community amongst 
learners through planned course structure and discussion. A lack of social interaction is seen to be a threat to the success of online courses, particularly amongst younger learners in the primary and secondary age groups. Furthermore, this lack of interaction is linked to student attrition rates amongst online learners, particularly in the younger age groups (Rice, 2006). These higher withdrawal rates may be linked to the lower positive perceptions of online learning reported by younger students (Dobbs et al., 2009). Rice (2006) reports rates of student attrition from online courses to be as high as fifty percent. The author further adds “... students who experience consistent, positive relationships with their teachers were less likely to drop out", (Rice, 2006, p. 439).

Findings from Diaz and Entonado (2009) discuss relationships between teachers and students in online and face-to-face environments. These authors found the absence of visual communications (such as a teacher smiling or making a funny face) or even physical contact (such as a pat on the back), can reduce the opportunities for teachers to encourage students and develop positive working relationships,

This lack of opportunity for interactions between teacher and student can lead to students' feelings of depersonalisation (Young, 2004). The fostering of learning environments in which student and group identity or community can be established is therefore very important. Developing an atmosphere where camaraderie, support and warmth are prevailing markers of the online socialisation leads to a sense of community, belonging and trust (Compton, 2009; Tallent-Runnels et al., 2006). The teacher's role in leading this sense of community is very important and is dependent on the relationships that are built between teacher and students as well as within the student group itself.

Lee (2007) suggests course group members have a face-to-face meeting initially if possible before working together in an online community. The author says this will reduce speaking anxiety in a synchronous setting and will promote collaborative interaction. Participants' perceptions of interaction is an important aspect of my study as the students are in the early stages of English language learning and may be anxious about speaking in a language that is not their mother tongue. In addition, the students in my study are at intermediate school, (aged 11-12 years) and may be more self conscious to speak aloud than younger school students at primary school.

Students" online identity can be difficult to establish as "the authenticity of human relationships is always in question in cyberspace, because of the masking and distancing of 
the medium, in a way that is not in question in real life", (Rheingold, as cited in Murugaiah \& Thang, 2010, p. 36). Learner identity is linked to concepts of cultural identity and literacy, affecting learners' self-esteem, which correspondingly affects motivation and ultimately student achievement (Harrington, 2010).

However, the enormity of the task of creating an online community suggested by many authors is downplayed by Edwards, Perry and Janzen (2011). Edwards et. al. propose the notion that exemplary online teachers are able to create an environment in which students have better bonding than in a regular face-to-face class. Moore (as cited in Rice, 2006, p. 438) agrees with this view, stating "distance is not a matter of geography but rather psychology".

Motivation is an important aspect of affect in online learning that Murugaiah and Thang (2010) found in their study of fostering interaction amongst English language learners in Malaysia. These authors suggest there is a tendency for online learners to lose motivation in the face of distance and time differences between themselves, their teachers and their fellow classmates. They suggest interactions that are encouraging and social motivate students who feel isolated (Murugaiah \& Thang, 2010). These authors also suggest maintaining positive affective features is a fundamental role of the teacher and that providing a supportive forum for learning through boosting the learners' self esteem resulted in increased students' levels of motivation.

The literature suggests affective features are an important influence on students' perceptions, affecting their motivation, attitudes, satisfaction and ultimately their achievement levels. An important key to positive perceptions is the relationships that are fostered between students and teachers in the online environment. A further element in developing positive relationships and maximising learning opportunities is interaction, which I will now discuss.

Interaction. The significance of interaction in effective online teaching is strongly emphasized by many researchers (Diaz \& Entonado, 2009; Liu \& Cavanaugh, 2011; Murphy et al., 2010; Oliver et al., 2012; Oliver, Osborne, \& Brady, 2009). As Young (2004) observes, "Simply putting a learner in front of a computer screen...does not necessarily lead to better learning", (p. 135).

Synchronous discussions are seen to be important both in developing positive relationships and also in promoting critical thinking (Maor \& Volet, 2007; Zhang, Gao, Ring, \& Zhang, 
2007). Murugaiah and Thang (2010) reiterate this concept in their action research study of online writing with adults in Malaysia stating “...for online learning to benefit ESL students, it must incorporate social interaction, collaboration and reflection (p.23).

Web-based facilities offer growing oral learning opportunities to ELLs. Increasingly sophisticated tools have enabled the online learning environment to become more learnercentred. Interaction, whether oral (for example through Skype), asynchronous (written in delayed time) or synchronous (written in real time), plays an important part in active learning. This learning is collaborative where meaning is negotiated through student-teacher and student-student participation. Maor and Volet (2007) emphasise the importance of collaborative learning stating "...interactions between peers and between teacher and learners during an online course are critical factors towards successful outcomes and quality of online learning”, (p. 271). However, providing opportunities for interaction within the online learning environment can be challenging for teachers, and there is considerable attention given to this topic in the literature (Baran \& Correia, 2009; Beckett et al., 2010; Blake, 2007; Cunningham, Fägersten, \& Holmsten, 2010; Nandi, Hamilton, \& Harland, 2012).

In a study investigating the domination of online discussions by instructors in a tertiary setting, Baran and Correia (2009) investigated discussion threads in which course members led discussions about their learning. Findings indicated student-led discussions generated new ideas, motivated students to participate and encouraged greater commitment to their learning. The researchers concluded this approach was beneficial to student motivation and improved learning outcomes. The link between discussion and learning is emphasized by Gibbons (2007) as she argues the prominent place of classroom discourse in the learning of a second language. However, the learners in my study are intermediate school and not tertiary, as in Baran and Correia's research. While the principle of learning mediated via interaction remains the same for all ages, the ways in which students interact will be different. For example, while the students in my study do not use threaded discussion, there is considerable emphasis placed on real-time oral interaction with their eTeacher, eTutor and other students.

Students report positive perceptions of oral interaction content in online language courses. Oliver et al. (2009) found in post-course evaluations of online language learning, secondary students requested more interactive experiences and communication. In a different study into the same virtual school, Oliver, Kellogg and Patel (2012) compared perceptions of foreign language students with perceptions of students in other subject areas. The foreign language 
students had significantly lower perceptions of the value of online learning. They suggested that adding more synchronous and asynchronous discussions and having more speaking practice to improve oral proficiency would improve their overall educational experience. It is important to note the learners in the research by Oliver et al. (2012) were learning a foreign language within an English-speaking environment. In contrast, the ELLs in my study are learning English for the purposes of gaining academic success within an English speaking setting, a setting where English is the language of instruction.

Liu and Cavanaugh (2011) and Diaz and Entonado (2009) both comment on the importance of student-teacher interactions as factors positively influencing student achievement in an online environment. Daiz and Entonado's study was with tertiary level students, but primary and secondary school students were the focus of the study by Liu and Cavanaugh. The research by Liu and Cavanaugh examined three variables: the effects of teacher comments, the demographic information of students, and student use of the learning management system. These three factors were considered together for their effects on academic attainment for students studying biology in a virtual school. The results showed these variables affected students' academic achievement in different ways. For example, increased time spent on the learning management system significantly improved students' final scores. While the students in my study are learning English and not science, some parallels may be able to be made in terms of the different variables which affect student perceptions.

In a further study, online discussions among learners prior to writing contributed to significant benefits in learning for tertiary level ELLs in a Malaysian university (Murugaiah $\&$ Thang, 2010). Additional studies investigated the use of anonymity in online discussions as a way to increase participation (Miyazoe \& Anderson, 2011), and evaluated the quality of asynchronous interaction in forums in a fully online course (Nandi et al., 2012). These studies suggested the ways interaction is managed in online courses may affect the benefits for students. For instance, anonymous participation in online discussions and a combination of student-centred and teacher-centred approaches may promote greater student involvement.

The concurrent tasks of learning English and learning curriculum content through English are to a large extent dependent on the oral control students have. Well planned interactivity increases students' opportunities to learn the English language and learn through the English language (Gibbons, 2009). The consensus within the literature is that interactivity that is well planned, supported and structured is most likely to be successful. 
A further consideration affecting students' perceptions of learning language online is cultural issues and I will now consider the impact of these on learners.

Cultural issues. English language learners are culturally, ethnically and linguistically distinct from their L1 peers. Cummins (2001) suggests considerable attention be paid to improving the relationships of power between ELLs and their educators. If culturally diverse students and their families are given more opportunity to become proactively involved in the students' education then they will have a greater chance of bridging the achievement gap with their English L1 peers (Cummins, 2001).

Cultural and linguistic diversity also needs to be taken into consideration within the online English language learning environment, as cultural understandings and perceptions can influence learning. Beckett, Amaro-Jimenez and Beckett (2010) investigated TESL (Teaching English as a Second Language) master's and doctoral students' perceptions and use of online asynchronous discussions (OADs). These students were from different linguistic and cultural backgrounds. The researchers reported there was an overall positive response to OADs. However the researchers also suggested students needed to take a more active role such as taking more ownership of the content of the online postings. They suggested specific training may be needed to transfer ownership of learning from the teacher to the student (Beckett et al., 2010). The authors assert cultural and linguistic barriers are reduced with OADs, as students have time to reflect and compose their posting before submitting it.

Zhu (2012) furthers this theme by comparing culturally diverse students' perceptions of online learning. He investigated the differences between students from a western setting and those from a Confucian-heritage culture. After analysis of the online discussions, Zhu found that while both groups reported positive levels of satisfaction with this style of learning, those students from the Confucian-heritage culture showed reluctance to explore dissonance in discussions. Zhu suggested this may be due to the Chinese students not wanting to overtly disagree with their group members, a stance that would be seen to be inappropriate within their culture (Zhu, 2012). Similar findings were discovered by Thang (2005), when he found university students in Malaysia reluctant to post too much material in OADs because they were afraid their behaviour could be interpreted as disrespectful to their peers, or 'showing off'. 
Online learning appears to benefit some minority student groups. Native American students who were underperforming in face-to-face educational settings improved their academic achievement and reported an increase in independence, confidence and control when studying online (Kaler, 2012). Although this study was at secondary school level and not intermediate as the students were in my study, there may be some useful correlation for my investigation as both studies are focussing on participants' perceptions.

Finally, Liu and Cavanaugh (2011) studied the effects of teachers' comments, students' demographic information and utilization of learning management systems on student achievement. They hypothesized a similar gap would exist in academic performance between high attaining Asian-American and Caucasian-American students and lower attaining Hispanic and African-American students from face-to-face education to online learning. The researchers concluded Caucasian students tended to perform at a higher level than minority groups in an online environment. Furthermore, in his discussion of comparative performance levels between different ethnic groups Kaler (2012) advocated schools teach in ways that recognise and value the different ways various ethnic groups learn.

When teachers know their students' cultural backgrounds and their likely responses within an online learning setting, they are more likely to be prepared for different cultural responses. It would seem a culturally responsive pedagogy is as important in an online environment as in a face-to-face setting. The six students in my study came from six different cultures; two from Confucian-heritage cultures, one Latina, two Pasifika and the final student was Indian. Such a culturally diverse group may have perceptions of their online English language learning that are culturally influenced. I will now discuss the skills and knowledge the online teacher needs in order to be successful.

The role of the online teacher. Teachers' roles in online language teaching require different sets of skills and knowledge than those of a face-to-face language teacher. The progression from successful face-to-face teaching to successful online teaching is not automatic, and cannot be assumed (Young, 2004).

Edwards, Perry and Janzen (2011) assert "To develop quality online teachers, we need to understand what makes online educators not only effective but also exemplary, and to consider changes face-to-face teachers need to make in order to succeed in the online milieu" (p.102). For example, an online language teacher needs to have enhanced interpersonal skills 
and relationships, better organisation and greater empathy with learners in the online learning environment.

Therefore, pedagogical approaches must take into account constructs that are known to enhance online learning (St. Amant, 2007). The role of the teacher is considered to be so important it is one of only four main pedagogical themes White (2006) identifies from the literature. However, as in other areas of online education, there is a lack of pedagogy to guide online teaching practice (Compton, 2009; Hauck \& Stickler, 2006; Oliver et al., 2012). In my study the eTeacher teaches online from a distance and the eTutor tutors the students face-toface. Both roles will have different requirements.

Some researchers offer frameworks of prerequisite conditions for success for online language teachers. In a collaborative research project investigating factors contributing to effective distance language teaching, Murphy, Shelley and Baumann (2010) surveyed 144 adult foreign language students to determine insights into their perceptions of the qualities of effective tutors. The qualities and skills students valued in tutors were positive affective dimensions of engagement, good organisation and a thorough grasp of the course content. The authors advocate affective, organisational and cognitive functions as critical to the effectiveness of distance language tutoring.

Park and Son (2009) investigated English as a foreign language (EFL) teachers' perceptions and use of computer-assisted language learning (CALL) in secondary schools in Korea. They suggested several recommendations for effective computer implementation within an EFL context. These were to have good hardware and technological support; link the curriculum, software and pedagogy; make differentiated learning available; have school-based professional development; make teacher forums available to share teaching experiences and ideas and to enable teachers to approach computer-assisted language teaching with a positive attitude. Although this study is at a secondary school level and not intermediate level where my study is situated, there may be aspects of Park and Son's study that are applicable to my own. The authors' recommendations, in particular, may relate to a New Zealand setting, and will be discussed later in the thesis.

Consideration of three areas to improve perceptions of foreign language students learning online were recommended by Oliver, Kellogg and Patel (2012). These authors advocate attention to teaching and modelling; attention to socialisation and communication; and attention to student learning needs in order to lift students' views of their online language 
courses. These findings have relevance to my study as modelling, socialising and attending to learning needs are important aspects of the findings of my research. In addition, the students in the research by Oliver et. al. are primary, intermediate and secondary school levels, the same level as those in my research. Finally, in her article about preparation of language teachers to teach language online, Compton (2009) suggests the three necessary areas in which teachers need expertise to successfully teach in an online setting are technology, pedagogy and assessment, all key aspects of the online learning in my research. I will now consider these three areas in relation to the literature.

\section{Technology}

Technology is the first of three necessary areas in which Compton (2009) suggests teachers need proficiency to successfully teach in an online setting. Technology plays a prominent role in online education (White, 2006), with the introduction of technology creating many changes in language learning, language assessment and language research (Chapelle, 2007). Increasingly the language teaching profession requires teachers who are not only skilled language teaching practitioners but also able to use technology effectively and to be able to integrate and exploit technology effectively to improve learning opportunities for their students (Mousavi, 2009; Vanderplank, 2010).

Compton (2009) suggests there are three levels of technical competency for teachers. At the novice level, the teacher becomes a proficient user of technology and is familiar with the range of options available. At the next level, the proficient teacher is able to evaluate and choose technologies appropriate to students' learning needs. The third level, that of expert teacher, is where the teacher is able to use and adapt technology innovatively to enhance online language learning. However, the assumption that teachers will use the technologies they know may not be true. Egbert, Paulus and Nakamichi (as cited in Blake, 2009) found language teachers frequently integrated into their teaching only the technologies they used in their personal lives, and not necessarily technologies in which they had professional development.

The importance of seeing online learning in action was emphasised by Compton et al., (2010). In their qualitative study of pre-service teachers' misconceptions about online teaching, these authors suggested pre-service teachers' poor perceptions of virtual schooling would continue unless they observed technology modelled effectively. In my study, the students, eTutor, eTeachers, class teachers and parents had a range of experience and 
competencies in computer hardware and software which may have affected their perceptions concerning online English language learning.

The use of technology can increase students' motivation and aid their learning. In a case study of English Foreign Language university students in Lebanon, Barhous, Bacha and Nabhani (2011) suggested use of technology in language classes would positively affect teachers' attitudes and students' motivation. However Mayes et. al. (2011) assert technology has little educational value in itself. These authors state "The instructional value of any technology is only as good as the quality of its implementation and the skill and comfort levels of its users" (p.161). The educational value of technology depends largely on how it is used. For example, integration of technology into the curriculum is important (Blake, 2009), as is the need for the choice and use of technology to be culturally appropriate (White, 2006). Also, students need adequate technical skills as a prerequisite to successful participation in online courses (Oliver, Osborne, Patel, et al., 2009). Oliver et al. found that students with inadequate software and hardware skills prior to online study were less likely to complete courses successfully. These authors suggested students should be screened for technological skills prior to beginning a course, as well as given technological support for the duration of the course. In my study the students were given both technological and academic support by an eTutor as they did their online work, assistance that possibly increased the likelihood of positive perceptions.

The findings of Oliver et al. (2009) are supported by a case study by Ibarz and Webb (2007). In an investigation into the feasibility of technology driven pedagogy for English language learners in the United Kingdom, the authors conclude "...student perceptions of learning with technology are frequently positive, provided the technology is stable and well supported" (p.221). Moreover, it is the instructor's role to provide technical assistance when needed (Nandi et al., 2012).

However, a caution is sounded in the literature on the topic of the use of technology in online language learning. There is a tendency for teachers to allow the tools to dictate the pedagogy (White, 2006). Rice (2006) stated this succinctly when she asserted "Technology in and of itself may have no special powers to improve learning..." (p. 441). Language learning pedagogy must be seen as the master and the tools as the servant. White (2006) suggested one reason for the tendency for the technical tools to lead language learning pedagogy could be that online technologies have increased and improved more quickly than online pedagogies. 
We should question the pedagogical value of new tools. After all, as Rice (2006) stated in the conclusion of her review of distance education in the K-12 (primary, intermediate and secondary school) context "the effectiveness of distance education appears to have more to do with who is teaching, who is learning, and how that learning is accomplished, and less to do with the medium" (p.440).

Although technology offers many opportunities for learning, and is essential to online learning, the research suggests the use of technology should be accompanied by technological support and a sound pedagogy. I will now consider the topic of pedagogy, as it is the combination of well supported technology and well considered teaching practice that contributes to successful online learning.

\section{ESOL Pedagogy}

No single theory can provide teaching guidance for all ELLs in all circumstances. However, literature suggests several optimum conditions under which ELLs may learn English. I will now discuss some of these.

Communicative language teaching (CLT) is a teaching approach that has considerable prominence in the literature (Ellis, 2005; Nunan, 2004). CLT is a broad language teaching methodology that emphasises interaction for authentic purposes, student-centred learning and task based activities (H. D. Brown, 2007). Within a CLT teaching approach the goal is competent communication and language teaching is not confined to grammatical or linguistic competence. Task based instruction is practised, with students engaging in the functional use of language in order to achieve set tasks. Language is used receptively, for listening tasks and productively, for speaking tasks. The teacher guides, but does not control the learning $(\mathrm{H}$. D. Brown, 2007). This collaborative approach is congruent with sociocultural theory where learning is a shared, communal experience.

Linguistic and academic learning also occurs within an environment where students are assisted to achieve learning that is just beyond their ability to achieve had they not received that help. This assistance, or scaffolding involves a high cognitive challenge for the student, alongside high support to allow successful completion of the task (Gibbons, 2002; Walqui, 2006). Scaffolding involves actions influencing other actions, collaboration and interaction (Walqui, 2006). It entails people working and talking together, in specialised roles of 'teacher' and 'learner', to achieve an outcome that could not have been achieved in isolation. 
A further condition influencing the success of learning English pertains to the affective domain. Affect refers to the emotional aspects of human behaviour; aspects that need to be considered alongside cognitive considerations when discussing second language acquisition. Our affective responses contribute to the success of language learning. Studies on motivation (Schumann, as cited in Brown, 2007) link the motivation of students who are studying a second language to feelings of pleasantness. Schumann stated "positive appraisals of the language learning situation ...enhance language learning and negative appraisals inhibit second language learning" (p.175). In addition, the importance of high motivation, self confidence and low anxiety levels when learning another language are documented in Krashen's seminal affective filter hypothesis (Krashen, 1982). Krashen maintains negative emotions, such as anxiety or self-doubt act as a filter between the L1 speaker and the ELL listener. These negative emotions reduce the amount of language input the listener is able to understand, interfering with the language acquisition process. In contrast, a setting that allows optimal language learning is one that is safe, welcoming and one in which students feel able to take risks and make mistakes as they stretch to use more complex language. If ELLs perceive positive experiences in their English language learning endeavours there will follow greater opportunity for enhanced learning.

Within an online language learning setting good pedagogy requires provision for such communicative practice. For example, in order to progress satisfactorily, language learners need multiple oral practice opportunities within an interactive framework (Gibbons, 2007). In addition, other CLT approaches such as functional use of language for authentic communicative purposes are vitally important.

Pedagogy is one of three necessary areas in which Compton (2009) suggests teachers need proficiency to successfully teach in an online setting. A principled ESOL pedagogy is a necessary prerequisite to technology-driven language learning (Ibarz \& Webb, 2007). Therefore teacher understanding of and provision for the language learning needs of students is essential in an online environment. Christie (2000) suggests "Given the central role of language in teaching and learning, teachers need to develop tools with which to judge the effectiveness of the language patterns they initiate and develop" (p.184).

There is less research investigating this topic than could be expected, given the exponential growth in online teaching practice over the past two decades (Vanderplank, 2010). Furthermore, most research has been undertaken in tertiary settings, with primary and 
secondary education very much underrepresented (Blake, 2011; Felix, 2008). In fact, after a review of research in the past ten years, Vanderplank (2010) paints a picture of “...fragmented and isolated research with relatively few examples of fully integrated and effectively implemented technology or well-designed systematic studies" (p.31). My case study aims to contribute to the existing body of knowledge by investigating participants' perceptions of their experiences of online English language learning. This will be particularly useful as the setting is in an intermediate school, a level of schooling where the least research has been completed.

Principled ESOL pedagogy is a necessary prerequisite to effective teaching in both the faceto-face setting and the online setting. However, the literature suggests there is a lack of research concerning online English language learning pedagogy (Baran \& Correia, 2009; Chapelle, 2007; Felix, 2004; Vorobel \& Kim, 2012). Pedagogy incorporates the concept of assessment, which I will now discuss.

\section{Assessment}

In addition to pedagogy, assessment is a further area in which teachers need proficiency to successfully teach in an online setting (Compton, 2009). Compton offers a hierarchy for online language teaching skills in which she differentiates between novice, proficient and expert teachers, and suggesting assessment skills and knowledge necessary for teachers to reach each level. The progression is based on knowledge of different types of evaluation at the novice teacher level to application of different strategies at the proficient teacher level, and ending with the expert teacher having the capability to integrate different methods of assessment to promote student achievement. This framework could equally apply to teachers in a face-to-face mainstream language class, highlighting that language assessment principles are fundamental to any language teaching.

Therefore, assessment of learners and learning is as important an issue in an online environment as it is when teaching face-to-face (Compton, 2009; Mayes et al., 2011). Teachers need to know if desired learning outcomes have been met so ongoing adjustments to teaching may be made. An understanding of both formative and summative assessment practices and how they influence online learning are needed. Mayes et al. (2011) suggest indicators of effective assessment are prompt formative feedback, openness and security in assessment and effective measures of student understanding. 
Online learning can provide some challenges to assessment (Mayes et al., 2011; TallentRunnels et al., 2006), but these challenges can also give rise to innovation by the use of projects, portfolios, self-assessments, peer assessment, threaded discussion, weekly reflections, chats, timed quizzes and the use of rubrics; some of which cannot be used in a face-to-face teaching format (Gaytan \& McEwen, 2007).

Feedback is another important topic in the online setting. Online learners often expect immediate feedback (Mayes et al., 2011). Synchronous discussion can allow for this, but there is a tendency for online students to expect their online teacher to be available to give student feedback constantly, possibly because it is an online environment. Mayes et. al., (2011) recommend formative feedback is given immediately concerning student participation as well as about course work. Further recommendations include summative assessments being aligned to competency based rubrics to clarify learning objectives, and expectations of participation being clearly outlined to students.

The participants are at the centre of this study and the online English language learning programme is the medium of instruction. Assessment is an important aspect of this particular online English language learning programme as the programme was established only in 2009 and there is interest in whether accelerated English language learning may be attributed to online English language learning within this particular context. However, determining a link between online English language learning and accelerated English language development is outside the scope of this thesis.

In the final part of this literature review, I cover concerns to do with institutional and administrative factors; issues that may be less obvious than topics covered earlier, yet also important aspects to consider. The management and organisation of a programme underpins its daily working and ultimate success. For these reasons this topic is an important one to cover.

\section{Institutional and Administrative Factors}

There is a lack of research on various institutional aspects, in common with the lack of research in other areas of online education. Most of the research that has been done has focussed through the wider lens of distance education, thus incorporating a much broader perspective. 
The role of management and administration in online education is to manage policy, planning, staffing, budgets and resources (Compton, 2009). Traditional face-to-face schooling policies do not transfer automatically to an online environment. A preferable approach is to develop policy frameworks that will sustain online education and enable it to meet the diverse needs of students (Rice, 2006).

However, not all universities offering online courses establish clear policies for support, course development and evaluation to guide decision making (Tallent-Runnels et al., 2006). Rice (2006) claims that policy makers in the United States of America do not understand online learning well, and "only a few states have established policies in place for the development of K-12 online learning programs", (p.429). In addition, proactively establishing institutional policies for online courses is considered to be a benchmark of leadership, with those institutions who do create policies acting as pioneers (Tallent-Runnels et al., 2006).

The need for support from institution administration was highlighted in Park and Son's (2009) study of factors affecting English teachers' perceptions of computer-assisted language learning in secondary schools in Korea. The researchers in this study reported that while Korean teachers of English generally had positive attitudes toward the use of computers in the classroom, the factors influencing successful classroom computer integration were both internal, or teacher related and external or context related.

Oliver, Kellogg, Townsend and Brady (2010) note the lack of research on the needs of online course designers. In their case study of the needs of elementary and middle school teachers developing online courses for a virtual school, the authors recommend supporting designers in the following ways: providing course templates to ensure quality and uniformity; providing professional development on course tools; providing professional development on differentiated learning, and providing feedback from course stakeholders. In short, increased communication between participants is suggested. This study links with my research as I am seeking stakeholders' perceptions of facilitators and barriers to online English language learning.

Course quality is considered to be one of the most concerning aspects of online education for school administrators (Oliver, Osborne, Patel, et al., 2009), suggesting that courses should be aligned to national standards to ensure improved consistency. This presents a problem to those involved in English language teaching in New Zealand, as at the time of writing we have none. 
In this literature review I examined the research concerning online English language learning in the context of English language learning and online learning, and discussed the main themes that emerged. I first discussed terminology, theoretical perspectives, and English language learning, online learning and online English language learning. I then covered perceptions of online English language learning and online learning under the headings of students' perceptions, affective factors, interaction, cultural issues and the role of the online teacher. After that I considered technology, ESOL pedagogy, assessment and finally institutional and administrative factors.

One prevailing theme throughout the literature is the lack of research on online English language learning contexts, particularly at the primary and intermediate school level. There is an urgent need for studies in this area. This lack evident in the body of literature leads me to the following questions I propose for my study.

What are the perceptions of intermediate school stakeholders in an online ESOL programme in New Zealand?

- What do school staff perceive as facilitators and barriers to English language learning in an online ESOL programme?

- What do students and families perceive as facilitators and barriers to English language learning in an online ESOL programme?

These questions need to be answered in order to provide understanding of online English language learning in a New Zealand context. In answering these questions this thesis seeks to offer insights from one school community's experiences of one online English language learning programme thus contributing to the collective body of knowledge. 


\section{Chapter Three. Methodology}

This chapter situates the study within a sociocultural perspective. It describes how the methodology chosen is appropriate to answer the research question within this perspective. It then describes the research setting, participants, data collection and analysis.

\section{Research Paradigm}

This study is situated within a sociocultural perspective. A sociocultural approach to research is one in which an investigation is made within a social environment. It observes and describes how people interact with each other and with their surroundings. Behaviour and phenomena are studied within the natural environment in which they occur. In this research, the participants were those involved in an online English language learning programme; one in which participants interacted within the particular context of their school, and within and about the programme. Therefore a sociocultural research approach is congruent with the research questions proposed in my study.

\section{Qualitative Research}

Qualitative research is "research that relies primarily on the collection of qualitative data" (Johnson \& Christensen, 2008, p. 34). Qualitative data is any non-numerical data, such as words or images, which provide information about the phenomenon being studied. In qualitative research the researcher is the main data collection instrument, collecting data through such means as interviews and observations, and studying behaviour in its natural environment (Johnson \& Christensen, 2008). Qualitative research seeks answers to research questions by 'examining various social settings and the individuals who inhabit those settings' (Berg, 2001, p. 8).

The stakeholders who are the subject of my study operate in the socially constructed environment of a school. This setting is one in which the participants interact and from which they will be able to offer multiple viewpoints of their perceptions of their experiences. For this reason qualitative research was chosen as the most appropriate research approach to answer the questions put forward by this study.

\section{Case Study Design}

This study used a case study design as a way of using various sources of evidence to conduct an empirical investigation of an existing phenomenon within its natural context (Hancock \& Algozzine, 2006). Gaining perceptions from all of those associated with this online English language learning programme has given perspectives of the same occurrence, yet all from slightly different viewpoints. Case study is qualitative research design that gives 
a detailed account of one or more phenomena or individuals to investigate exploratory, descriptive and explanatory research questions (Yin, 1994).

This research reports on the phenomenon of an online English language learning programme carried out in one intermediate school. A case is defined as a bounded system (Johnson \& Christensen, 2008). The case boundaries in my research were the stakeholders of an online English language learning programme within one school. This included the ELLs, their families and the professionals working with them. Another boundary of this research was the time frame in which it took place. Data were gathered within a three week time frame when I visited the school in June 2013. Thus a snapshot view of the case at one point in time is reported (Berg, 2001).

However some stakeholders were not included within the boundaries of the case. These included the Ministry of Education that funded the programme, and the ePrincipals who worked for ELLINZ online (See Chapter Five for further discussion).

As case study investigates a whole unit within a real-life context (Johnson \& Christensen, 2008), and yields in-depth data about personal perspectives (Yin, 1994) I decided that it was the most suitable approach to answer the research questions.

\section{The Setting}

This study took place in Central School, a decile ${ }^{3}$ three intermediate school in a small city of approximately 80,000 in the North Island of New Zealand. Central School has a roll of approximately two hundred and fifty students. Most of the students in the school have English as their home language with 7\% of the students coming from Pasifika homes, and 3\% from other ethnicities.

Central School is set in a suburb close to the centre of a city. Its grounds are spacious, with open spaces for students to play sport. Trees surround this well cared for and well equipped school. Over the three weeks I was in the school I saw many instances of positive interactions between students and an overall caring attitude of staff toward those students in their care. This caring attitude was epitomised by the school principal who spoke with considerable knowledge of his ELL students' countries of origin, home backgrounds, and health. For example the principal told me about one boy's story in detail; an English language learner

\footnotetext{
${ }^{3}$ Deciles are a way in which the New Zealand Ministry of Education allocates funding to schools. A lower decile ranking indicates the school has more students from low socio-economic communities.
} 
who had lost several family members in the 2009 Samoan tsunami and who had since relocated in New Zealand.

\section{The Students' Physical Learning Environment}

In Central School, the eTutor has a full-sized classroom dedicated to the online English language learners. The room is quiet, light, well ventilated and well heated. There are eight desktop computers set up facing inwards, in an octagonal shape, allowing close physical proximity for the students with each other. This physical layout allows students to talk and hear each other and their eTutor easily, yet also work independently.

\section{The Participants}

I recruited the research participants through purposive sampling. I first identified the characteristics of the population of interest and then located individuals within that population and invited them to participate (Johnson \& Christensen, 2008). I identified a suitable school in which to locate my research and then distinguished all of the possible participants; those who were involved in some way in the online English language learning programme.

I identified Central School as a suitable school to place the study for three reasons.

1. The ELLINZ online ePrincipals noted Central School was a school that had successfully implemented online English language learning.

2. There were seven students involved in online English language learning in the year of the study. This was a sufficient number of possible participants, yet allowed for the possibility that some students or families might elect not to participate.

3. Central School was in its second year of implementing online English language learning. Apart from one staff change (the eCoordinator), the school staff had eighteen months experience from which to consolidate and report their perspectives.

The participants in this research were stakeholders in the online English language learning programme in the school. Those who had a direct interest or involvement in the online English language learning programme at Central School were recruited as participants to document the perceptions of online English language learning from a range of viewpoints within the school community.

The following people were invited to participate in the research;

- the school principal, 
- the four class teachers,

- the two eCoordinators (one who was in the role the previous year and the new eCoordinator),

- the eTutor,

- the ICT teacher,

- the two eTeachers (offsite),

- the seven students participating in online English language learning, and

- the parents/caregivers of those students.

The table below explains the responsibilities of the staff identified as stakeholders of the online English language programme at Central School.

Table 1. Roles and responsibilities of school stakeholders

\section{Stakeholder Responsibilities}

Principal Leads the school. Makes funding decisions concerning ELLINZ online.

eTeacher Teaches students online from a physical location that is offsite from the school. Facilitates interaction, organises and presents information, assesses students and provides feedback.

Class teacher Teaches ELLs in their mainstream classes.

eCoordinator Coordinates staff working on the ELLINZ online programme.

eTutor Works alongside ELLs during live online English lessons.

Supervises ESOL sessions between live lessons when students work on pre-set study.

ICT teacher Provides technical/computer support for the eTutor and students within the school.

In addition to the school staff, the students attending the online English language learning programme and their parents/caregivers were invited to participate in the research. Central School had seven students learning English online. Each student was from a different country 
and the students were at foundation or stage one levels of English proficiency on the ELLP. It is likely that this case may be representative of other schools where there are low numbers of ELLs with differing needs in schools without specialist teachers and who adopt online English language learning. Therefore the findings of this case study may be transferable to a certain extent (Berg, 2001).

I identified the deputy principal, the second eTeacher and the previous eCoordinator as three possible additional participants and invited them to take part once data collection had begun. First, I invited the deputy principal to participate. She was acting principal at the time the decision was made for the school to participate in the ELLINZ online programme, as the school principal was on sabbatical leave. I believed she could have some insights that would contribute to the overall findings.

Secondly, I invited the second eTeacher to participate. There were two eTeachers working with the ELLs at Central School, each teaching a different group. The seven ELLINZ online students were in two different teaching groups due the range of English language competencies among the students. Five students were taught by one teacher. These students were functioning at stage one of the ELLP (Ministry of Education, 2008). The two other students were at the foundation stage of the ELLP, and required a different teaching approach. The foundation stage students were taught by the other eTeacher.

The third additional participant was the eCoordinator who had been influential in introducing online English language learning to Central School but had left the school at the end of the previous year. I believed she may have some useful insights into the study also, so I contacted her and she agreed to be interviewed.

\section{Ethical Consents}

I gained permission to proceed with the research from the following people in this order.

1. I was granted ethics approval by the University of Victoria, Wellington (see appendix B).

2. I was given permission from the New Zealand Ministry of Education to proceed with the study. As ELLINZ online was a pilot scheme of the Ministry of Education, it was necessary to obtain permission.

3. I approached the ELLINZ online overseeing principal (not the Central School principal) for permission to proceed. The role of the ELLINZ online overseeing 
principal is administrative, as the ELLINZ online eTeachers are employed through his school payroll.

4. I approached the Central School principal and was granted permission to place the study in his school.

5. Once in Central School, I spoke briefly at a staff meeting, explaining the purpose of the study and inviting identified potential participants to be involved.

6. The school principal sent a short note home to the seven students' families (see appendix C), introducing the study and asking for parents to consent to their child being interviewed, on my behalf. In addition, he asked parents if they would consent to be interviewed themselves.

7. I visited consenting parents in their homes to allow parents to ask me any questions and also to get the consent forms signed.

8. I explained the study to the seven students participating in online English language learning at Central School and invited them to participate in the study.

All of the staff invited to participate gave consent and were subsequently interviewed. Six of the seven students agreed to participate in interviews and three of the possible seven sets of parents agreed to be interviewed. Consenting participants were given information sheets to inform them about the research. They also signed the consent forms (see appendix D).

\section{Data Collection}

Semi-structured interviews were the most appropriate method of inquiry to allow for different perspectives and understandings of the programme (Hancock \& Algozzine, 2006). A semi structured format of interviewing enabled me to be responsive to nuances of meaning as the interviews progressed, and not just follow a rigid questioning structure (Richards, 2003). I sought natural conversations in which the participants felt comfortable to share their feelings, both positive and negative. My intention was to deepen my understanding of the perceptions of the stakeholders, so although the set questions guided my questioning, I wanted to be responsive to the information offered by stakeholders, focussing on the person speaking.

I composed lists of questions to guide my interviews (see appendix E). Although the main research query was the same for all stakeholders, I drafted different sets of questions for the school principal, school staff, online teacher, parents/caregivers and students. I asked the different questions to gain information from those staff holding different roles and 
responsibilities. For example, I asked the school principal about the factors influencing his decision to adopt online English language learning. In addition, I carefully constructed the questions asked of the parents/caregivers and students so they would be easily understood by listeners for whom English was their second language.

All interviews were sound recorded on a digital voice recorder. Most of the interviews with the staff were conducted around the school, depending on the availability of a room that was quiet enough to sound record successfully. They were conducted in offices, the staffroom, empty classrooms and in the case of the previous eCoordinator, in her home. The interviews with the two eTeachers were conducted via Skype. Two sets of parents came into the school to be interviewed, while the remaining interview with parents was conducted in their home. I visited one home after the parents had consented to be interviewed but the mother requested we postpone our interview until both she and her husband could be present as she felt her English was not adequate to express herself. They then visited the school the following day for the interview and her husband interpreted for his wife at times as we spoke.

I originally planned to interview the students in two focus groups, according to the teaching group they belonged to. A focus group is a group interview led by a facilitator in which a topic of interest is discussed (Berg, 2001; Johnson \& Christensen, 2008). Some advantages of using a focus group include being able to gather large amounts of information quickly, providing an interview setting that is comfortable and non-threatening for participants and allowing flexibility to investigate connected but unanticipated topics as they arise in the interview (Berg, 2001). Use of focus groups also fits my world view that language and learning are socially constructed. Four students were in the ELLP stage one group and the remaining two students were in the ELLP foundation group. On the day the stage one group's interview was planned, one student was absent from school, so the remaining three students were interviewed together and the absent student interviewed individually on his return to school. The two students in the foundation group were interviewed as a pair.

I was aware I needed to allow the students considerable 'wait time' so they could formulate and articulate their contributions. All of the interviews with students were conducted in the classroom where they received their online English language learning lessons. I used a visual 'talking guideline' sheet and explained it to the students prior to their interviews (see appendix F). This sheet explained the guidelines of the interview protocol to the students, 
such as polite turntaking, treating group members respectfully and emphasising the need for confidentiality.

Interviews took between six and forty-nine minutes. Typically, the students and parents spoke for the least amount of time and the staff who were involved in the daily running of the programme, the eTeachers and eTutor, spoke for the longest times.

\section{Data Analysis}

All interviews were sound recorded and transcribed by a transcription service. I listened to the recordings several times and compared the recordings to the written transcriptions, making any necessary corrections to the written script. The corrected transcriptions were returned to the adult participants for checking. Participants were asked to make corrections, additions or deletions to the transcript prior to data analysis. No participants made any changes to their written interview script. NVivo 9 software was used to store and organise the research data. NVivo 9 is a data management software programme that stores data from multiple sources and allows the researcher to organise and code data.

I coded the interview transcripts using clear descriptions that described segments of the data (Johnson \& Christensen, 2008). Repeated words or groups of words suggested themes that were then identified and used as codes. For example, words such as valuable, motivating, great, enjoyment and good were all used by participants to express their perceptions of English language learning. The quotes expressing these thoughts were identified and coded under 'positive perceptions'.

Confidentiality was ensured by assigning pseudonyms to the participants and to the school when writing the final thesis. In addition, the location of the school was not divulged to protect its privacy. Data were stored in a password protected computer and digital recordings and written transcripts kept securely.

\section{Trustworthiness}

Mutch (2005) defines trustworthiness in qualitative research as the clear documentation of the research decisions, research design, data-gathering and data-analysis techniques. The trustworthiness of research defends the value or worth of the research, enveloping the criteria of credibility, transferability, dependability and confirmability (Lincoln \& Guba, 1985). These criteria may be established by techniques such as researcher reflexivity, triangulation and member checking. These techniques are recommended by Lincoln and Guba to "guide the field activities and to impose checks to be certain that the 
proposed procedures are in fact being followed" (p.330). I took the following steps to improve the trustworthiness of my study.

Interview transcripts were returned to adult participants for checking and possible correction of the data. This was done to increase the accuracy of the data (Creswell, 2003), and was in keeping with the methodology and qualitative research approach that this study adopted (Richards, 2003). However, none of the participants made any changes to their transcriptions.

I was aware of the need to be reflexive (Johnson \& Christensen, 2008). I actively considered any potential biases that may have influenced my interpretation of findings. I had taught English online at Central School the year before I undertook this research project and I was aware my online teaching experiences could influence my interpretation of findings positively. In order to minimise this possibility I took the following steps.

- I actively reflected on my own personal biases and predispositions I had as the research progressed.

- I kept a personal journal so I could consider and reflect on the decisions made during the research process.

- I sought to use active listening skills, not showing any negative or defensive responses during interviews when negative perceptions were described by interviewees.

- I encouraged the students to tell me about both their positive and negative perceptions. Questions addressed to students such as 'What is hard about your ELLINZ online work?' and 'What can we do to make learning on the computer better for you?' elicited a small but tangible response. I was mindful to affirm all opinions expressed, so the students did not feel they had to please me by stating only positive perceptions.

- I attempted to sidestep any 'desire to please' from my former colleagues by asking direct questions about both the negative and positive factors in their experiences as eTeachers.

However, I also found my previous online teaching experience was an advantage while I was conducting this research. I found I understood the roles, processes and procedures of this programme to a depth that would not have been possible had I come into the research without my online English language teaching experience. This background knowledge helped me to understand the participants' views and issues to a greater degree. 
In this chapter I have described the research approach, and explained the methods used to answer the research questions. I then described the setting in which the study took place and described the procedures of participant selection, consents, data collection and data analysis. Finally I discussed the trustworthiness of the research. 


\section{Chapter Four. Findings}

This chapter will describe the perceptions of the participants. I conducted eighteen semi structured interviews; twelve staff members from Central School or ELLINZ online, three sets of parents, one group of students, one pair of students and one student individually. (Please refer to chapter three for a full list). I expected the participants to naturally divide into the two following groups;

1. the school group, of school staff (principal, deputy principal, eTeachers, eTutor, eCoordinators, ICT teacher and class teachers), and

2. the home group, of families and students.

I composed my research sub questions to reflect that expectation, dividing the participants into a 'home group' and 'school group'. However, three groups of stakeholders naturally emerged from the data. Within each group, participants were connected by the degree of their involvement in the online English language learning programme, the communication that existed both within their groups and between the groups and the extent of their knowledge of the programme. These factors appeared to contribute to the extent they were convinced of the value of online English language learning. These groups are outlined in table two.

\section{Table 2. Groups of stakeholders}

\begin{tabular}{lll}
\multicolumn{1}{c}{ Group 1 } & \multicolumn{1}{c}{ Group 2 } & \multicolumn{1}{c}{ Group 3 } \\
Students, eTutor and & Principal, deputy principal, & Parents and class teachers \\
eTeachers & ICT teacher and & \\
& eCoordinators & \\
\hline
\end{tabular}

The first group was the students, eTutor and eTeachers, who worked together closely and regularly. Of all the participants they were the most closely involved in the online English language learning programme.

The principal, deputy principal, ICT teacher and eCoordinators made up the second group. They knew considerably less than group one about the set up and running of the online English language learning programme.

The third group, parents and class teachers and had the least involvement and knowledge of the online English language learning programme. Research findings are clustered and reported by group under the various themes that developed. The themes are positive 
impressions, withdrawal, timetabling, technology, equitable distribution of resources, meeting students' needs, a commitment to learning, relationships and communication.

\section{Positive Impressions}

Most of the participants responded positively to online English language learning. Group One. Students, eTutor and eTeachers

The students, eTutor and eTeachers all viewed online English language learning positively. eTeacher June commented

I think teaching ESOL online is just really valuable and I think it is working.

A similar comment was made by the other eTeacher, Julia.

I think it [online English language learning] is motivating on the whole and it's a new kind of learning for them [students] and they don't come in and sit in the back of the classroom and go to sleep like they might be doing in some of their other classes so I think that is great.

The two eTeachers saw both the programme itself and the online delivery of the programme as positive, engaging students in their learning. They drew comparisons between teaching in the two settings; the mainstream classroom setting and the online environment. Julia reported her experience as an ESOL teacher supporting subject teachers of ELLs in curriculum subjects in a secondary setting, and seeing some of those students disengaged and unmotivated. Her experience of teaching ELLs online showed the opposite; interested and motivated students.

The students spoke of enjoyment, happiness and fun associated with online English language learning. Students reported feeling happy and good when they achieved good marks.

Enjoyment was reported in particular activities, such as Penina, a year seven girl saying

I like typing because it is fun.

When asked if he had anything further to add at the end of his interview, Michel, a year eight boy said simply

\section{I like ELLINZ.}


It is difficult to capture what the students were referring to here. They may have been reporting enjoyment of the course curriculum content, or the process of using computers to achieve that learning, such as Penina's enjoyment of typing. They may also have been reporting enjoyment of both the content and the process of their learning.

Positive perceptions about online English language learning were also expressed by eTutor Jo, who was the staff member responsible for the daily running of the programme, and the person with the most experience and knowledge of the ELLINZ online programme in Central School. She responded to my question 'How's it all going?' with this statement,

It's been a real adventure. It's a ride and it's been a really good one. I have really enjoyed getting out there and doing the bits and pieces with it and the kids are excited to come over, they are always here before me most days and signing in and ready to go which is an encouragement.

Jo identified students' motivation to work as a key factor positively affecting online English language learning in Central School.

\section{Group Two. Principal, deputy principal, ICT teacher and eCoordinators}

The principal, deputy principal, ICT teacher and eCoordinators also shared positive impressions of online English language learning. Joe, the school principal, commented on students enjoying their work which appeared to be a high priority for him. When he was discussing the decision whether or not Central School would continue online English language learning beyond the first year of trial Joe commented

Watching them working, going in and watching them working and seeing the enjoyment and the progress that they were able to make, it was a clincher for us to say, it's a good programme, let's keep it going.

For Joe, there was a strong link between enjoying the online English language learning programme and successful learning. He explained his point of view in this way,

If you enjoy doing something then you have a far better chance of being successful at it than if you don't enjoy it.

This positive report was echoed by eCoordinator Cathy, the staff member providing immediate oversight and support of the eTutor, who stated 
I always get a very positive feel about the whole programme. When I go in there I know that they are all on task and they are all working well.

Josh, the ICT teacher, had very similar impressions, saying

Whenever I have been in there [the room where online English language learning lessons are held] and they have been working, they have been very motivated, very on task and they are happy to be there, they know what they are doing, it has been really good to see.

These staff members felt the online English language learning experience was an enjoyable process for students, where ELLs are motivated, work well and make progress.

\section{Group Three. Parents and class teachers}

However, the parents and class teachers did not all share these positive impressions and gave mixed reports. Of the three groups of parents interviewed, one father was totally unaware his daughter was attending online English language learning lessons. Another father, Jaswant, father of Arjun a year seven boy, reported knowing little about the English work his son was involved in. However, he was positively inclined toward it, saying

I can't tell you much but I am happy with what he doing because we want [him] to be in extra [English] classes.

The most favourable parent report by far came from Jorge and Maria, parents of a year eight student, Michel. Jorge and Maria attributed several positive effects on their family life to online English language learning. They recounted the difficulties Michel had settling into school initially as a migrant at the beginning of year seven, and how the online English language learning programme had helped him acquire English. He had been unsettled at school initially, which his father attributed to not having adequate English to communicate with the other students. However, as his English language skills improved, so did his happiness at school. Jorge explained the change in Michel in this way

The fact that he is now enjoying the school very much, he wakes up early and gets ready and he is not complaining about coming to school, he gets on his scooter and away he goes. He is enjoying the school and I think it's because now he can communicate properly with the teacher and his school mates, it's because this programme [ELLINZ online] has helped him a lot. 
Three of the four class teachers viewed online English language learning positively. They cited the main factors as increased opportunities for students' learning and reduced responsibility for students' learning falling on the class teachers. Class teacher Jess commented

I think it is great that our school has had the opportunity to be part of it [online English language learning] because the whole reason we are here is for the education of these children and if they can get that success through ELLINZ and give them the next step then let's get into it.

Another class teacher, Didi, had this to say

I definitely like having the programme, I think it just takes a little bit of that stress off and it's good to know that they are getting extra tuition so it is good to have them going out.

These two teachers and Vili, a third class teacher, felt the English language learners in their classes had specific learning needs that were being met, or partially met, by the online English language learning lessons they were attending. However, the teachers did seem unsure about the learning benefits for these students.

\section{Withdrawal}

Group One. Students, eTutor and eTeachers.

The social impact of withdrawal from class on ELLs in order to attend online English language lessons was discussed by some staff members. The eTutor, Jo, felt it was a challenge for the ELLs to come out of class initially, explaining her position on withdrawal from the students' viewpoint.

To be socially accepted is to stay in the classroom with the [other] children. The minute you are withdrawn for whatever reason ... other children look at you and you immediately feel as if you are of a lower level than others.

Jo felt the effects of regular withdrawal from the mainstream class to attend online English language learning would disadvantage ELLs, as the very act of withdrawal for extra tuition inferred they were functioning at a lower academic level than their peers in their mainstream classes. Jo acknowledged the need for the ELLs to feel connected and part of their 
mainstream class and felt mainstream students could influence the ELLs' perceptions of their connectedness within their mainstream class, saying

I suppose the real crunch is whether the other [mainstream] children actually accept what they [the ELLs] are doing is learning or treated as something special or lower level.

Neither the students nor the eTeachers mentioned the students' withdrawal from their mainstream class. The eTeachers would probably be less aware of the process and effects of withdrawal than the eTutor or students, as they teach from a different geographical setting to the school and are not physically present to observe it. It is therefore likely the issue of withdrawal does not surface for eTeachers. The students however are the central players in the process of withdrawal from class. They are the ones who leave their class to go to their online English language learning lesson, then returning to reintegrate at its completion. More than all the other research participants, the students would be the ones who are most directly affected by withdrawal. The interview questions did not directly enquire how students felt leaving their class in the interviews and the topic was not mentioned by any of them.

Group Two. Principal, deputy principal, ICT teacher and eCoordinators.

Withdrawal was not seen as a challenge by those staff members in group two. The ICT teacher, Josh, who also teaches music, described how one student changed from one music class to another in order to attend the online English language learning programme. Josh felt there was no problem with withdrawal from the student's usual class to ensure he did not miss out on either ESOL or music stating

There are kids that have had to change the time that they come to me for music because they have an online class at that time so they just slot in with another class and that has worked well, that child I'm thinking of has been welcomed by the other class, they quite like having a different face in there and it's no problem.

The deputy principal, Jenny, was also positive about the issue of withdrawal, saying I think the teachers genuinely know that the ESOL children are struggling and they're aware that quite a bit of the time they're [the ELLs] sitting in class and actually perhaps not getting as much from what's happening as they should have and 
I think generally they're pleased to see them going out and getting some really focussed target teaching.

This group of participants, with the exception of the ICT teacher, were not directly teaching the ELLs, and may have had more positive views toward withdrawal as a result. They did not carry the responsibility of sending students off to their online lessons, reintegrating them back into class afterwards and trying to keep their assessments and teaching of core subjects up to date.

Group Three. Parents and class teachers. Withdrawal,- 'Another interruption'.

However, the class teachers, those who were responsible for the daily education of these students, had mixed feelings about students from their classes being withdrawn. The disadvantages of withdrawal described by teachers were missing crucial school work, disruption to the class generally, students coming back into class and not knowing what to do and students missing social interaction. Class teacher Didi explained the frustrations she felt from her point of view.

With them [students] going out to ELLINZ of course that adds another interruption because quite often, especially last year, they were out during maths and then they go out again at reading times, so they are out in those crucial times.

Jess also expressed frustration when describing students withdrawing to attend online lessons, saying

It is a little bit frustrating having them go out and come back in at certain times because they do miss the programme and then they come back, they don't know what they are meant to be doing.

In addition, Shontelle felt that regular absences from the class in order to attend online English language learning lessons disrupted the school day and socially disadvantaged her student, Adi, a year seven girl. Shontelle explained Adi missed out on essential class work such as mathematics and school wide assessments, making it very difficult for her to catch up. She commented

We get told they [the students] enjoy it [online English language learning] and that is great but is it actually benefitting, is it worth it, is it worth them losing the in-class time for them to go over and do that or is it just fun and easy? 
Shontelle was not convinced of the implied benefits of online English language learning when balanced with the detrimental effects she perceived of Adi missing time out from her class. Shontelle had serious concerns about Adi's opportunities to make meaningful relationships with other classmates, saying

She is missing all that interaction. I am concerned about those friendships formed because there is always something about being taken out of a classroom, always. I don't know an easy way around it.

Despite these reservations, some advantages to withdrawal were expressed by class teachers. Didi suggested camaraderie and support among the ELLs from different mainstream classes could be one advantage. She expressed it this way

Well it's good that all those students [ELLs] get out and get to spend time together so that they are not quite so isolated. I think that probably is a good thing, to know that there are others [other ELLs] out there.

\section{Timetabling}

Group One. Students, eTutor and eTeachers. Timetabling

Withdrawal of students for specialised teaching such as online English language learning also has implications for timetabling. The more programmes a school offers the more complex the timetable becomes.

Jo, the eTutor recalled her experiences saying

There has been [challenges] with the admin side of it, the timetabling. As the children go on, it works within set timetables then all of a sudden the timetable changes in the classroom and the child actually wants to go to that. The timetable thing is big, just trying to fit everybody in.

Group Two. Principal, DP, ICT teacher and eCoordinators. Timetabling

One of the difficulties encountered was that timetables do not remain static. A timetable is organised to suit all of those involved, but then when one item on the timetable changed, other changes needed to be made to accommodate that change. Pat, the eCoordinator in the year the online English language learning was initially set up recalled the difficulties saying 
We had to do quite a bit of juggling with some of the technology classes to fit it in and then at one stage they set up another class and some of our kids went into that and that mucked everything up again.

The Deputy Principal, Jenny commented

From a timetabling perspective we do have the odd hiccup because intermediate schools are so busy and there's always other things happening. We've had a bit of an issue this term when we've missed quite a few of the lessons, the children have been torn between going to ESOL and wanting to go off and do more exciting things, of course, but we've had to say your ESOL comes first because we can't change that time.

Fitting everything into the school day was seen to be a challenge by all of the staff interviewed.

Parents and class teachers. Timetabling

Class teachers spoke of their students missing essential class work in class and of their difficulties keeping track of their ELLs' class work and assessments. Didi had this to say

Last year they [ELLs] did [miss out on core learning in class] because ELLINZ was always in my maths time slot and this year is the same. They do miss out on a bit of maths. It's even hard just timetabling to cover everything as it is anyway at the moment.

When I asked Vili about any changes he could suggest to improve the delivery of online English language learning at Central School he proposed looking at the timetable issue saying It would be a timetable change as I am trying to get it [the timetable] to work in more with my own class room programme because at the moment she [Vili's student, Penina] is out once or twice a day so it becomes a bit muddled.

However, the class teachers appeared to be resigned to the fact that there were more demands on the ELLs' time than hours available in the school day. Shontelle commented

I don't like her [student Adi] missing out on the maths or the spelling, the basic stuff, but something has got to give so really we [class teachers] just fit in.

None of the parents or students commented on timetabling. 


\section{Technology}

Group One. Students, eTutor and eTeachers. Technology

An effective online English language learning programme is to a certain extent dependent on the knowledge and use of technology by those who are involved. A range of challenges were reported by participants. Some of the difficulties encountered were the result of staff having to learn new information and skills, and some were actual problems with the technology itself. As eTutor, Jo was the staff member in Central School most involved with the programme on a daily basis, and therefore had the most learning to do. Jo described her challenges orienting herself to the ELLINZ online website in this way

Probably really just managing that computer, managing to know where to go to find things and finding them quickly without holding anything up.

Other technology challenges described by Jo were Skype reception dropping off when she attempted to use picture as well as sound, or when more than one school was connected at a time, time delays when using adobe connect, the difficulties of students learning to use the technology correctly, and computers that were slow to respond. Jo appeared to be resolved to these issues and took responsibility to solve problems for herself as much as possible, saying

We have one computer that just goes so slow it doesn't matter how many times you look at it, it is just a slow computer and it's just an age thing and that relates to the funding and all the other things. But the computers match the system and we are able to do our work and we are able to achieve it so it is not a huge barrier it's just a little learning thing.

Mostly Jo was satisfied with the technology, saying

I don't think there have been that many [technical challenges] at all.

June, one of the eTeachers appeared to experience more difficulty with the technology. She cited difficulties with VoiceThread (a Web-based interactive application sharing tool), Skype freezing during live lessons and slow running and poor sound quality of Adobe Connect. She described these problems as frustrating, and said

The biggest challenge is the technology, when the technology doesn 't cooperate it can make it quite difficult, it can be quite frustrating. 
June explained that flexibility was needed to manage the technological breakdowns that occurred, stating

You have to have a plan $B$ and sometimes a plan $C$, because things will go down and everyone needs to be prepared for that.

The other eTeacher, Julia, who had been teaching English online for only four months at the time of the interview found the technology was working smoothly, saying

I have been pleasantly surprised that there haven't been as many IT hiccups as there often are in face-to-face classrooms.

Although the students did not report frustrations with technology themselves, staff members did so on their behalf. From Jo's point of view, access to computers remained the single main challenge to the ELLs, saying

Probably that is the biggest hurdle for the children is the actual not having the equipment outside of the school.

Jo described how one of her students went to the public library and accessed her online English language learning programme there. Another student told me he had a computer at home but it was broken. An additional student reported he had no reliable internet connection at his home. As one of the strengths of online learning is being able to log on to your work from any internet connection, such as home computers, students who do not have this option are not able to continue their English language work at home or share their learning with their parents.

Group Two. Principal, deputy principal, ICT teacher and eCoordinators. Technology

Two staff members who were very actively involved in the set up of online English language learning at Central School were Josh, ICT teacher and Pat, the eCoordinator at the time. Josh spoke of the tight time frame of the initial set up, stating

It [the initial set up of computers] wasn't a huge amount [of extra work] and it all had to happen quite quickly so there was a bit of scrabbling around to try and get enough computers over there [to the designated classroom] and we had to get things together and use old teacher laptops and things just to get the numbers [of 
computers] up and to get webcams and things like that organised. But it wasn't massively onerous.

Pat spoke of an intense initial set up time, trailing to a manageable ongoing maintenance of hardware and software as everyone became more knowledgeable and skilled as their experience increased. Pat explained

Initially the technology was a headache and took a huge amount of my time because I was the first port of call for Jo [eTutor] when things didn't work with the computers.

After the initial set up, staff needed to learn how to use and maintain the software and hardware so it worked as it was designed. When difficulties were encountered there was a clear line of communication from the eTutor to the eCoordinator. If the eCoordinator could not solve the problem it was referred to the ICT teacher, who in turn passed it on to the ICT support company contracted by the school, if the problem could not be solved. Josh explained

We have a support contract with [ICT support company] anyway so we were able to tap into that for anything that was beyond me, which was quite a lot and I would just $\log$ a job for them to say can you check this, that and the other.

Group Three. Parents and class teachers. Technology

Little mention was made of technology challenges by parents or class teachers apart from one incident cited by Didi when she could not access a student's work that was emailed to her

Last year Jo tried to email me something but I couldn't open it up.

This difficulty was not resolved.

\section{Equitable Distribution of Resources}

Group One. Students, eTutor and eTeachers

When discussing drawbacks to online English language learning one eTeacher, June, felt the cost of providing it was detrimental commenting

It is a very expensive programme.

The cost of operating this online English language learning programme to the school included hardware and software costs and paying part of the eTutor's salary.

Group Two. Principal, deputy principal, ICT teacher and eCoordinators 
The perception that online English language learning was expensive was shared by several other staff members. The person responsible for balancing the budget for learning needs within Central School was eCoordinator Cathy, who was also the school's special needs coordinator. The English language learners were just one group within her care. Cathy spoke at length about the difficulties of balancing the available budget to best meet the needs of all the students, saying

One of the big things obviously is funding because at the moment the ELLINZ is funded out of my SEG Grant ${ }^{4}$ so to come out of the SEG Grant obviously has a huge impact on my special needs area so to have some sort of funding, specifically towards employing a teacher to run this programme would make a huge difference.

Cathy further explained her point of view in this way

That doesn't compute when you have got a hundred kids that need help and you have one teacher aide who is working with seven pupils. Financially it is a huge thing, the board [Board of Trustees] has agreed to do it and agreed to follow it on but when you know that you have one person tied up with only seven pupils then it doesn't actually really compute.

However, Joe, the school principal and the one who had the final decision about funding in the school was quite convinced about the positive value of the financial outlay of the eTutor's salary saying

When we reviewed it [the online English language learning programme] at the end of the year [the first year of operation] and we knew that we had to be paying for Jo to be the eTutor, we didn't hesitate to say we want to keep going with it and we're prepared to pay for it.

Group Three. Parents and class teachers

The provision of almost one teacher aide's [Jo] hours to the programme seemed to be an imbalance of resourcing to class teacher Shontelle as well as to the eCoordinator Cathy. Shontelle commented

Is it [online English language learning] beneficial, because we lose a whole teacher aide to this? That's massive when we have such high needs in our classes, that's

\footnotetext{
${ }^{4}$ The Special Education Grant (SEG) is a financial grant from the New Zealand Ministry of Education to fund special needs in schools.
} 
another downfall, a whole teacher aide, a good teacher aide, one that should be in the classroom.

Shontelle was not convinced the learning benefits of online English language learning outweighed the financial sacrifice needed to run the programme.

\section{Meeting Students' Needs}

Group One. Students, eTutor and eTeachers

The students were very sure that online English language learning helped them to learn English, citing three main areas of learning. These were curriculum content (for example reproduction), English language forms (what nouns and adjectives are, new words, writing, spelling) and learning new computer functions and skills as they did their online English language learning (for example accessing Google Drive, making their own presentations on PowerPoint and how to do a safe search on Google images so they do not breach copyright).

When questioned why he said he liked ELLINZ online, Arjun, replied

We learn new stuff.

I then asked him how online English language learning helps him learn English. He elaborated

Helps me with my writing and spelling.

Michel reported similar experiences when questioned about how online English language learning helped him

It helps me a lot to learn English right now, it learns me how to speak and how to learn the vocabulary.

Although Nuon and Emo, the two foundation level English language learners were not able to give long explanations they still expressed a very clear message. When asked "Does it (online English language learning) help you to learn English?" both boys exclaimed with emphasis in unison

Yes!

The two eTeachers and the eTutor, the participants who had the most knowledge of both English language learners' needs and the specific learning that was taking place in the 
ELLINZ online programme, expressed clear opinions that online English language learning did meet their students' learning needs. Reasons given included excellent student engagement, students' enjoyment of the curriculum content, student's enjoyment of computers and the various interfaces and programmes, instant feedback (such as when doing vocabulary activities), the interactive nature of the programme, the differentiation of the programme to specifically target individual ability levels, the underpinning of ELLINZ online with a reading and vocabulary programme, the growth in students' confidence, and collegiality within groups who are learning together.

eTutor Jo observed improved oral skills amongst her learners, saying

They do actually start to speak clearer.

Students' improved confidence to speak was also noted by Jo

One of the students will listen to what is happening in the lesson and then all of a sudden ask a question. That is an improvement whereas she would have just sat there [previously] and said nothing, so to have the confidence to ask a question because she doesn't understand how something works is an improvement.

Possibly one factor contributing to the improvement in oral skills Jo observed is the multiple opportunities students have to interact. Jo saw the oral interaction practice that happened in live lessons as a positive precursor to improved skills.

The oral opportunities were not just between eTeacher and students either. Jo commented on a collegial tone within the group that gave the opportunity to enhance group work and its accompanying oral practice, saying

They don't really compete against each other. They work together which is really interesting. The confident ones do actually work together with the others that are not familiar [with the work], and so it does work quite well.

June, one of the two eTeachers also commented on the cooperative learning style evident in her online English classes.

I like that there are small classes and they have that time with the eTutors and that they are peer helping, supporting and cooperating, that someone might be an expert in one area and can go around and help others. 
Working together, helping, supporting and cooperating were words used to describe the way the ELLs worked with their eTeacher, eTutor and each other. This way of interacting and working would give occasion for the talking necessary to improve oral skills and aid the understanding of curriculum content.

Julia, one of the eTeachers, felt the scaffolded and differentiated curriculum, covering the four skill areas of reading, writing, listening and speaking were important factors in meeting the ELLs' learning needs. She commented

In terms of the strengths I think it is a very well thought out programme, whoever has had input in writing it, it is incredibly structured and step by step and differentiated which is great as a teacher to come into that.

And later in the interview Julia added

I think the fact that it [the ELLINZ online programme] tries to cover all four skill areas [is good].

Julia's understanding of the learning needs of the ELLs with whom she worked was for a carefully crafted curriculum that was scaffolded and differentiated to meet the different English proficiency levels amongst those students who attended her online English lessons. She also felt a balance of the four skill areas was necessary, and felt this online English language learning programme provided the balance.

There was no doubt in Jo's mind about the learning that was occurring during online English language lessons. She based her opinion on cumulative skill and knowledge gains she observed in the students, supported by pre and post assessments that students did for each of their learning modules. Jo stated

But I think predominantly they enjoy coming out now because they are actually learning something and because their knowledge is growing. It's an excitement to come over here because there is something new to do and they are actually remembering what they have done before. That is the real nice feeling at the end, to know that they have come a long way from the beginning and to see their results after they have done their post and pre-tests and to see what they actually do learn.

Eteacher June compared online English language learning to face-to-face English language teaching in a mainstream classroom, commenting 
I do think they [the students] are learning and I am comparing it to teaching ESOL in a classroom that they are probably learning more online.

Learning new computing skills as they learn English was seen as an advantage by the eTeachers and eTutor. They felt increased computing skills, knowledge and confidence would benefit the ELLs in their future learning and work. Use of computers in online learning was seen to improve motivation and hold the interest of students. eTeacher June commented

I think that young people are quite interested in computers and interfacing with the technology.

The value of increased computing skills for future employment opportunities was also commented on by June, who stated

They are mastering [computer] skills that they will be able to apply and use in the future.

The students, eTeachers and eTutor all agreed online English language learning did meet the learning needs of the students.

Group Two. Principal, deputy principal, ICT teacher and eCoordinators

Pat, the eCoordinator from the previous year, and the person responsible for initiating the introduction of online English language learning to Central School considered the online English language learning programme as

A very well rounded programme that gave kids a lot more specific oral goals and specific content language, with the activities that backed up what they had to do.

She also felt it met the learning needs of the participating students.

\section{Group Three. Parents and class teachers}

Three of the class teachers cited the opportunity to get 'quality teaching', 'an opportunity to learn' and it being generally 'helpful' to have students attend online English language learning lessons. Vili summed it up by saying

For me when she [his student Penina] goes out I am seeing that as an advantage to me because she is getting extra help that I can't give her within the class. I know she 
is getting taught things that she needs to have. I will never say no to help, if there are other people that can do it better, a better job than I can, then I am all for it.

Vili felt the input students received from online English language learning met a need he was unable to fill in the mainstream classroom. Three of the four class teachers agreed that the ELLs at Central School were likely to have their learning needs met by online English language learning classes. However they appeared to hold this belief without any evidence of students' increased English functioning. No class teachers talked of measurable gains in any area of English functioning of their students.

When I questioned class teacher Shontelle, the teacher least favourably disposed toward online English language learning, whether she had noticed any benefits to her student Adi as a result of attending online English language learning, she made this reply

Not yet.

The interviews took place in June, 2013. At this stage Adi had been attending online English language lessons for approximately three months [ELLINZ online lessons start at the beginning of March each year and there was a two week holiday in April]. Possibly Shontelle had not noticed any improvement in Adi's English skills as Adi was reluctant to talk in class, making it difficult to measure improvement. Possibly it could be due to insufficient or incomplete assessments in class as a result of her absences to attend ELLINZ online [something Shontelle had commented on], or maybe Adi had not in fact made any progress at that stage.

Of the three groups of parents interviewed two said they did not have enough information to comment on whether learning English online was meeting their children's English language learning needs. Joji commented

To know about what this programme is about, I will be more happy to know more and where it leads and where it goes and how it ends, how they get the results and the credits and all this. I like to know about the whole programme and I will be happy about that rather than just always surprised. She's online but where will it take her after the programme? 
Jafar, the other father, was aware his son Arjun was attending online English language lessons but did not have any further information. He requested the web address from me saying

I am thinking I will go and check it myself.

In contrast, Michel's parents, Jorge and Maria, outlined specifically both academic and social advantages their son received learning English online. They linked Michel's improved happiness at school with his improved English and credited online English language learning for this learning. Jorge explained

Yes because he couldn't communicate and if you have a child that is not speaking, a child that is not getting together with other children, he kind of is strange you know so he was solitary and all those things. But now that he mingles with children and he speaks and does things, he has been accepted I suppose with the group. He has some friends.

And later in the interview Jorge said

He is enjoying the school and I think it's because now he can communicate properly with the teacher and his school mates, it's because this programme [ELLINZ online] has helped him a lot.

Jorge and Maria felt there was a strong correlation between Michel learning English online and progressing in English proficiency. They also felt there was evidence of improved social functioning as well as improved academic performance. This contrasts with some of the class teachers' concerns that withdrawal from class, as is needed to attend online classes, would reduce the students' social functioning.

\section{A Commitment to Learning}

Group One. Students, eTutor and eTeachers

The eTeachers and eTutor consistently exceeded reasonable expectations of time input in their efforts to ensure the success of online English language learning in Central School. For example, the time demands of the job were significantly more than the hours for which eTeacher June was employed. At the time of the research she was employed for .6 of a fulltime teaching position, yet estimated she worked over 40 hours weekly. The other eTeacher, Julia also reported working many more hours than she was employed for, saying 
It's a 12 hour job supposedly. I think it must be a 40 hour job for me and I think I am quite fast really. It is the whole setting everything up for elearning is quite time consuming.

These hours reported by the two eTeachers included teaching in other schools, as well as Central School.

Jo, the eTutor also reported putting considerably more time into her work than she was employed for. Jo said

In the initial stages[of working as an eTutor] they used to laugh at me at home, ... I would sit at home and spend quite a bit of time just going around the [ELLINZ online] site and just reading and familiarising myself. I wanted to be able to show the children easily and I couldn't do that if I didn't know, so it has been a huge learning curve for me to be able to do that and to teach the other children how to do it.

Jo wanted to be able to solve problems for her students quickly and easily from the beginning of the programme. The amount of new learning she needed to engage in to be able to do this successfully was more than the hours that had been allocated to do the job by Central School, but Jo was quite happy to do extra work in her own time. Later in the interview she continued

I shouldn't say it but sometimes I just do the admin at home. It is easier sometimes.

For Jo, the priority was to be prepared for the following day's work, and she was happy to work extra hours to achieve that. She shared her deep sense of purpose in the following statement.

I am here for the kids, I enjoy seeing them learn and I like to see them actually achieve and watching them work out that they can do something. If that means I have to put in a little bit extra it is not the end of the world. It's not going to break any bones or anything. You just do it.

Jo and the eTeachers displayed a profound commitment to the learning of their students; a commitment that enabled them to work longer than the hours for which they were employed in order to achieve the goal of students' accelerated English language development.

Group Two. Principal, deputy principal, ICT teacher and eCoordinators 
School deputy principal, Jenny, made this comment when asked about factors that contributed toward the successful implementation of online English language learning at Central School.

I suppose it's like everything, it's the personnel, isn't it, it's the teacher or the teacher aide within the school, committed to making it happen who makes the children feel safe and ensures it ticks along well with a positive attitude.

This commitment to the students and their learning was displayed strongly by many of the staff involved in different aspects of online English language learning. The overall attitude was encapsulated by Josh, the ICT teacher describing his response when he was asked for help to set up the ICT supports necessary for the programme.

So I said "Yes I will do what I can to make it happen".

There was no comment from the class teachers.

\section{Relationships}

Group One. Students, eTutor and eTeachers

Another quality that participants perceived as contributing toward successful implementation of online English language learning in Central School was the ability to make and sustain positive working relationships between those involved. eTeacher Julia commented on the relationship between eTeachers and eTutors

Their [eTutors'] role is just so crucial and so therefore you need to spend time I think actually building that relationship between yourself and the eTutors otherwise it could all go to custard I think.

Julia linked positive relationships, communication and the overall effectiveness of the programme closely. Positive relationships between students and eTeacher were also recognised as important. eTutor Jo commented

They [the students] interact with the eTeacher really well.

The relationship between student and eTutor is a crucial one, as the eTutor is the staff member who spends considerable time with the ELLs. Not only does she support students during the live lessons with their eTeacher, but she supervises the completion of unfinished 
work between live lessons. Jo, the eTutor showed sensitivity to students' learning needs and positive working relationships when she described how she speaks to her students

I will say 'I am new at this and I don't know how to do it either, so we are going to learn together'. It just breaks down that barrier and all of a sudden you are working with them and they don't feel as though you are the teacher.

\section{Group Two. Principal, deputy principal, ICT teacher and eCoordinators}

Although he was not as closely involved in the daily running of the online English language learning programme, school principal Joe also saw positive relationships between those involved as one significant factor in the programme's success. He stated

What I was always impressed with was the flow between [eTeacher] and the boys, and [eTeacher] and [eTutor], and [eTutor] and the boys, and [eTutor] and [eTeacher]. I was really impressed with that relationship that [eTeacher] was able to strike up with each of the individuals and with [eTutor] herself and I think you worked really well together to make it successful.

This three way relationship between students, the eTutor and the eTeacher was acknowledged to be vital as they are the three parties involved in the twice weekly live lessons, the essence of the programme. Joe recognised the positive relationships were three way and reciprocal, and that it was these positive relationships that contributed toward the success of the programme.

\section{Group Three. Parents and class teachers}

Among the parents and class teachers there was no mention of positive relationships between the participants in the online English language learning programme. This may be because parents and class teachers were considerably more distanced from the daily running of the programme than the others.

\section{Communication}

The current prevailing ethos in education and other disciplines emphasizes the importance of professionals working cooperatively in a cohesive manner, as opposed to working independently in isolation or 'silos' (Lawlis, 2012). One factor contributing to successful cohesion is effective communication between the various people or groups of people who are involved in a particular school or programme (Breakspear, 2010). Effective 
communication among all participants is a prerequisite to the success of any programme a school may implement.

Group One. Students, eTutor and eTeachers

The first group, students, eTutor and eTeachers were the ones who knew most about online English language learning. They had the most frequent and closest communication with each other as they worked together. The communication between the students, eTeachers and herself was commented on by the eTutor, Jo

We have a really good relationship with all of our teachers [eTeachers] and it is almost like the person is sitting right next to you and that is great.

Regular communication between her and the eTeachers was also reported by Jo

I do check my emails regularly at home so that I know that if either [of the eTeachers] have sent something to me, then I know that I have got to pick that up.

Other forms of communication for Jo included an online forum for eTutors within the ELLINZ online website for her to join and interact with other eTutors, and personal visits from the ELLINZ online ePrincipals. Jo said

I have been lucky that I had visits last year from the different principals [ePrincipals] and that, just checking up how we are going, sitting in on the lessons and giving us feedback that way.

Group Two. Principal, deputy principal, ICT teacher and eCoordinators

The school principal, Joe, observed frequent and close communication between the main participants, saying

I was really impressed with that relationship that [the eTeacher] was able to strike up with each of the individuals [students] and with [eTutor] herself.

However, Joe acknowledged the communication was only working between those who were directly involved, saying

I don't think that many children other than those involved in the programme were aware that it [online English language learning] even took place. 
Frequent reports of school staff and parents being uninformed about ELLINZ online emerged as the interviews progressed. Despite this there were some exceptions. Cathy, the eCoordinator recounted attending an initial one day course at the start of the school year specifically to inform eTutors and eCoordinators, saying

But the course was good, I can now put faces to names and I now know generally what the programme is all about and what is expected from it and what is expected as far as commitment and timetabling and all that sort of stuff. So that was really important for me to get my head around it all.

\section{Group Three. Parents and class teachers}

None of the four class teachers interviewed felt they knew much at all about the online English language learning programme their students were attending, and commented to that effect.

I have been over there [the classroom where the online English language learning is held] while they [ELLs] have been in there but I actually haven't sat down and had a good look or seen what they have done or learnt about the programme (Didi)

With regard to ELLINZ as a class room teacher, we do not really know what it involves within the school as we have not been informed (Jess)

I am surprised that we have never been really taught about what ELLINZ does and what they do, what is the outline of learning. There must be some criteria. Never been told that (Shontelle)

At the moment the only challenge I have is learning more about what ELLINZ is. Because I don't know what is happening over there I can't marry up what is happening over there and what is happening in the class (Vili)

All of the class teachers wanted to know more. They felt knowing more about ELLINZ online would help them to understand their students' learning needs more and work more effectively, incorporating some of the students' online work into the classroom. The class teachers wanted to know about assessment, what levels their ELLs were functioning at, what they did in online English language learning and how they could integrate the English language learning their students were doing into their class activities. All four teachers made comments which underlined this fact. 
I think if we knew what they actually did for a start would be good, in ELLINZ, we need to have a session so we can actually see what is going on or do a few sessions with them to actually see (Didi)

A staff meeting I feel would be very very beneficial for all staff (Jess)

If the teachers had an outline of what they were doing it could be really beneficial for us (Shontelle)

I guess that would be my biggest challenge would be finding out what ELLINZ is and how it's improving our ESOL kids (Vili)

The class teachers felt their lack of knowledge about online English language learning prevented them from incorporating the learning their ELLs were doing in online lessons into the classroom. Their comments indicated they wanted to teach alongside the eTeachers and not operate independently in their own 'silo'. Some class teachers made suggestions about this. Didi proposed

Maybe if they [the ELLs] then had something that they could log on in the class and stuff they could then work on, or if we could see some of their completed work.

Jess also expressed an interest in working cooperatively.

I would really like to know about it [online English language learning] and what they are doing because maybe I could tap into some things I do not know.

Later in the interview Jess said

I would love to know what we [class teachers] could do back in the class room to support that [English language learning].

Shontelle also expressed a keen interest in integrating the English language learning her student, Adi, was doing at online English language lessons into her classroom, saying [If teachers knew more] then we could make those connections with our students, I could make sure with Adi that I am talking to her about whatever they are doing over there [in the online English language learning programme].

Vili expressed similar feelings to his colleagues. He felt a better understanding of online English language learning would result in better cooperation, saying 
At least the class room teachers then have something to feed on and gauge how much they can help their ESOL kids.

The teachers did not know about online English language learning and they wanted to know about it so they could better understand and meet their ELLs' learning needs.

One incident involving successful communication came from class teacher Vili. He recounted an opportunity he had to observe students working earlier in the year.

\section{I have watched one lesson where they were talking to someone in Dunedin or Christchurch and kids were fully engaged and eager to tell the person on the computer what was happening.}

Vili had not planned to observe that day; he was walking through the classroom by chance and thought he would stay and watch for a while. However, that chance observation was informative and valuable to him.

Two fathers of two different students and both parents of a third student participated in interviews. One father was unaware his child was attending an online English language learning programme at school; another father knew his son attended but knew nothing more. The third set of parents, Jorge and Maria, were aware their son was attending but knew very little also.

Joji, father of Adi, who did not know she was learning English online, was surprised at my request for an interview. He had this to say

No I didn't know anything at all about Adi's learning English online at school because they didn't inform me about her attending this programme.

Joji was happy for his daughter to attend online English language learning but would have liked to have been informed, saying

I like to thank the school that they do that [send Adi to online English language lessons] but if I could be informed first that would be good.

Education was a high priority for Joji and his wife. They immigrated to New Zealand specifically to increase their children's educational opportunities. Joji wanted to know specific information about the work his daughter was doing at school, saying 
At least give me some information about what's involved [in the online English language learning programme].

Jorge and Maria had a similar experience to Joji. When I asked Jorge what he knew about the online English language learning his son, Michel, was doing at school he replied

Not that much but the only thing we know is that this way of Michel getting English through the computer at school.

Jorge explained further

At the moment I don't have all the information about the programme, what Michel is doing, but it is not the school's fault, it is my fault. We participate as much as we can with the school but sometimes it is not that easy.

He explained the family had been busy settling into a new life in New Zealand, and he had not yet taken the time to investigate the work his son was doing at school.

The third and final parent interviewed was Jafar, father of Arjun. When I asked him if Arjun told him about the online English language learning he was doing at school he replied

No he doesn't. He is busy with his games or TV when he comes back [from school] and doesn't talk much about it [online English language learning].

However, although they did not know very much, all of the parents interviewed were keen to learn more about online English language learning. For example, Jafar expressed a strong desire to learn more about the online English language learning his son was doing saying saying

Even I want to learn you know.

\section{Summary of Findings}

The participants of an online English language learning programme in an intermediate school were interviewed to establish their perceptions of contributing factors that either facilitated or were obstacles in the learning process. My initial expectation was for the eighteen participants to naturally divide into two groups of school staff (principal, deputy principal, eTeachers, eTutor, eCoordinator, ICT teacher and class teachers) and families (students and parents). As the data analysis proceeded, it became evident the participants did not naturally form these two groups. Instead three groups emerged. 
The three groups were defined by the degree to which they were actively engaged in the online English language learning programme, the extent they communicated with others both inside and outside of their group, the amount of knowledge they had about the purposes and processes of the ELLINZ online programme, and the degree to which they were convinced of its value (see table three below).

Table 3. Summary of findings

\begin{tabular}{|c|c|c|}
\hline Group 1 & Group 2 & Group 3 \\
\hline $\begin{array}{l}\text { Students, eTutor and } \\
\text { eTeachers }\end{array}$ & $\begin{array}{l}\text { Principal, DP, ICT teacher } \\
\text { and eCoordinators }\end{array}$ & Parents and class teachers \\
\hline $\begin{array}{l}\text { Extensive active engagement } \\
\text { in daily programme }\end{array}$ & $\begin{array}{l}\text { Some active engagement in } \\
\text { daily programme }\end{array}$ & $\begin{array}{l}\text { Little active engagement in } \\
\text { daily programme }\end{array}$ \\
\hline $\begin{array}{l}\text { Frequent and effective intra } \\
\text { group communication about } \\
\text { English language learning } \\
\text { and the ELLINZ online } \\
\text { programme }\end{array}$ & $\begin{array}{l}\text { Some intra group } \\
\text { communication, mainly at } \\
\text { administrative level. }\end{array}$ & $\begin{array}{l}\text { No intra group } \\
\text { communication }\end{array}$ \\
\hline $\begin{array}{l}\text { Little inter group } \\
\text { communication about }\end{array}$ & $\begin{array}{l}\text { Little inter group } \\
\text { communication about }\end{array}$ & $\begin{array}{l}\text { Little inter group } \\
\text { communication about }\end{array}$ \\
\hline $\begin{array}{l}\text { English language learning } \\
\text { and the ELLINZ online } \\
\text { programme }\end{array}$ & $\begin{array}{l}\text { English language learning } \\
\text { and the ELLINZ online } \\
\text { programme }\end{array}$ & $\begin{array}{l}\text { English language learning } \\
\text { and the ELLINZ online } \\
\text { programme }\end{array}$ \\
\hline $\begin{array}{l}\text { Extensive knowledge about } \\
\text { the purposes and processes of } \\
\text { the ELLINZ online } \\
\text { programme }\end{array}$ & $\begin{array}{l}\text { Some knowledge about the } \\
\text { purposes and processes of the } \\
\text { ELLINZ online programme }\end{array}$ & $\begin{array}{l}\text { Little knowledge about the } \\
\text { purposes and processes of the } \\
\text { ELLINZ online programme }\end{array}$ \\
\hline $\begin{array}{l}\text { Convinced of value of the } \\
\text { ELLINZ online programme }\end{array}$ & $\begin{array}{l}\text { Accept value of the ELLINZ } \\
\text { online programme }\end{array}$ & $\begin{array}{l}\text { Tentative acceptance of value } \\
\text { of the ELLINZ online } \\
\text { programme }\end{array}$ \\
\hline
\end{tabular}

Each group had distinct perceptions of online English language learning based on three factors; the degree to which they were actively engaged in the daily programme, the extent they communicated with others both within and outside of their group about the ELLs' 
English learning and the online English language learning programme, and the amount of knowledge they possessed of ESOL pedagogy, the online programme or both. These three factors appeared to directly influence the opportunity participants had to contribute to the programme, and ultimately affected their acceptance of its value. The emergence of these three different groups with their very different experiences, knowledge bases and beliefs has significant implications which will be discussed in the following chapter. 


\section{Chapter Five. Discussion}

In this chapter I will discuss how the findings reveal deeper issues about the nature of online language learning. First I will discuss the stakeholders. Then I will discuss a learning community. After that I will consider oral interaction and curriculum in the context of meeting the English language learning needs of ELLs. Facilitators and barriers to learning will then be examined in the context of whether online English language learning can meet ELLs learning needs. Following this I will discuss the degree of active engagement of participants, communication and the amount of knowledge held.

\section{Stakeholders}

All of the people who took part in this research were stakeholders who had a vested interest in the progress of the English language learning of the students. All stakeholders stood to gain in some way by the progress of the ELLs. The eTeachers and eTutor would gain recognition for the accelerated learning of their students. The decision makers (school principal, DP, and eCoordinator) similarly would gain acknowledgment if the online English language learning programme they chose to adopt was confirmed to be successful. Class teachers would gain as they would be able to integrate ELLs more successfully into the mainstream classroom as students' English language levels increased. The parents' gain would be to have children achieving closer to their L1 peers at school and the students themselves would gain access to, and achieve across the curriculum. Consequently, all of those who participated in this study were able to offer insights into online language learning that reflected their own experience of this phenomenon. The common interests and goals of the people who took part in this research identified them as a community, which I will now discuss.

\section{A Learning Community}

The research participants may be described as a community, linked by their shared practice and common interest in the English language progress of the ELLs. In his discussion of case studies Berg (2001) describes a community as "some geographically delineated unit within a larger society" (p.331). Using this definition, the participants in my study were a defined group within the larger group of the school. The eTeachers were included in this defined group. Although geographically distanced, they were included in the community by the internet. A community usually encompasses similar cultural or subcultural composition, diffuse interactions and connections between the members, and a sense of communal identity (Berg, 2001). 
Each community member involved in the online English language learning programme had a different role to fulfil in reaching the goal of raising English language achievement for the students. Some participants had a very central role, while others had a role that was more peripheral. For example, the students had a central role, and were at the heart of the community. Their learning needs led the practice of the online English language learning. They were present in every lesson. The role of the class teachers however was more distant. They sent their ELLs to another part of the school for their online English language learning lessons, which were taught by the eTeachers. Class teachers did not have the same active involvement in the daily online English language learning programme as the students. That is not to say the class teachers' role in the community was less important however, it was merely different.

\section{Meeting the English Language Learning Needs of ELLs}

This study is placed within a sociocultural perspective. Sociocultural learning reflects an understanding that language learning takes place within a social and collaborative environment, rather than one that is isolated and competitive (Celentin, 2007). Within this perspective, learners' knowledge is co-constructed with others in an active, communal and intentional approach. The sociocultural paradigm suggests learning occurs within the context of the everyday lives and cultures of the learners as they are scaffolded, or assisted into extending their cognitive and linguistic skills by those who are more expert (Lee, 2007).

One key aspect of my study was whether participants felt online English language learning was meeting the needs of the students. However, in order for the class teachers and other participants to assess the merits of the online English language learning for their students they needed two areas of knowledge;

1. an understanding of the language and curriculum learning needs of their English language learners, and

2. an understanding of how the online English language learning programme worked.

Group one was made up of students, eTutor and eTeachers. The eTeachers, and to a lesser degree the eTutor, demonstrated a thorough understanding of the students' language and curriculum learning needs. In addition, the eTeachers, eTutor and students all had a comprehensive understanding of how the online English language programme worked. 
However, neither of the two knowledge bases listed above appeared to be held by groups two (principal, DP, ICT teacher and eCoordinators) or three (parents and class teachers). The class teachers and parents commented on how little they knew about the online English language learning programme. So despite reporting positive impressions, it is uncertain whether these impressions were formed on any substantial evidence.

However, the eTutor and eTeachers did hold sufficient knowledge and understanding of both the needs of ELLs and the programme to express an informed opinion. While the students did not hold formal knowledge of their English language learning needs, they did have a robust grasp of the programme itself. Most of the students showed proficient computer skills in navigating the ELLINZ online website and operating the various programmes within it. I observed one student, a very new speaker of English at the foundation stage on the ELLP successfully navigate between three different computer windows as he completed his writing task proficiently. This student had successfully learned how to utilise the learning supports that were offered. I will now discuss oral interaction and curriculum in the context of meeting the needs of ELLs.

Oral interaction. The importance of oracy for effective ESOL teaching is well established in the literature. Proficiency in oral language is essential to academic competence for ELLs (de Jong \& Harper, 2005; Genesee, Lindholm-Leary, Saunders, \& Christian, 2005; Gibbons, 2002). Within an online setting however, it is how online tools are used that determines their educational value to students (Blake, 2007). When meaningful interactions are promoted, the opportunity for student engagement and subsequent learning are maximised. Ingerham (2012) and Liu and Cavanaugh (2011) suggest that for online learning to have maximum benefit to students, interactivity must be a strong feature of any learning programme. These interactions include three main types; students interacting with students, students interacting with instructors and students interacting with curriculum content (Ingerham, 2012). All three types of interaction were reported by research participants in my study.

The online English language learning programme operating in Central School featured regular opportunities for students to engage in talk about their learning. A regular part of the live lessons included students participating in speaking tasks, where they would practice target grammatical structures and vocabulary as they discussed the curriculum content covered in lessons. The school principal and the class teacher who had the opportunity to 
observe an online English language learning lesson both commented on students interacting orally with the eTutor and eTeacher about their learning. In addition, there was evidence these speaking opportunities were benefitting the students. The eTutor reported advances in her students' oral skills, saying they were speaking more clearly, speaking more often, speaking more confidently, and asking more questions. Engaging with curriculum content and each other was evident as students worked cooperatively and collegially on tasks. This reciprocal work involved discussion about curriculum content which may have enhanced students' ability to develop the academic language necessary to succeed at school (Gibbons, 2007).

An effective curriculum. Curriculum design is a further consideration in the discussion of meeting the learning needs of ELLs. This involves practical and theoretical considerations to assist the process of choosing course content in order to match the English language learning needs of the students with the resources available. Careful application of available resources and the learning needs of the students alongside good teaching principles allows for the best possible match of curriculum and students' learning needs (Nation \& Macalister, 2010).

In my case study the two eTeachers shared positive perceptions of the soundness of the online curriculum. They felt the programme was well founded, as it systematically covered the four skill areas of reading, writing, listening and speaking. The eTeachers also liked the way the programme was scaffolded and differentiated for students. These positive perceptions link with SLA literature on this subject. Brown (1995), suggests that a systematic approach to language curriculum design requires the inclusion of needs analysis, learning objectives, appropriate language testing, materials development and language teaching. The online curriculum included learning objectives of raising achievement in reading, writing, listening and speaking.

Two of the six students in this study were functioning at foundation level of the ELLP and four at stage one. Within each stage (for example stage one), there can be a range of ability levels with students' English language functioning at the lower, middle or upper levels of each individual stage. Therefore the eTeachers differentiated the learning materials to provide a curriculum at the appropriate level for each student. This was a very positive response to meeting the individual learning needs of students. In addition, the eTeachers knew the levels 
their individual students were functioning at, based on the appropriate language testing Brown (1995) mentions.

Another prerequisite for optimal English language learning in both online and face-to-face English language learning is planned interactions (Oliver, Osborne, Patel, et al., 2009). These were certainly evident in this programme. The evidence of Oliver, Osborne, Patel, et al's study suggests that despite the challenges to reliable sound quality such as Skype connections dropping off and poor sound quality of speakers on computers, the frequent oral interactions between student-student, student-eTeacher and student-eTutor probably contributed toward the learning of curriculum content and increased understanding and use of vocabulary that was mentioned by the students.

\section{Can Online English Language Learning Meet ELLs' Learning Needs?}

There appear to be advantages to online education. It is cost effective, allows more equitable access to learning, and is not dependent on time and distance (Tallent-Runnels et al., 2006). However, the level of effectiveness of online teaching has been a cause of concern for both professionals (Antón, 2011), and families (Antón, 2011; Blake, 2011). The leadership team at Central School were able to take advantage of some of the benefits of online education by electing to participate in the online English language learning programme. For example, participation in the programme allowed students access to a trained ESOL teacher, something that was not available within the school.

However, judging the efficacy of online learning as opposed to face-to-face learning poses particular challenges. How is the judgment to be made? Do we decide on the basis of student achievement or student perception? Blake (2011) suggests it is difficult to make comparisons between online and face-to-face language learning due to significant variation in format, use of technological tools and pedagogies. Rice (2006) agrees with this viewpoint, suggesting a lack of consistent methodology complicates the comparison of online learning and face-toface learning. The participants in my study predominantly judged the online English language learning programme on affective factors.

This online English language learning programme reflects sociocultural values in that participants reported a close relationship between learning and the social setting in which it occurred. The programme and participants co-created a social environment where engagement, participation and interaction are stressed, making it a setting in which students can use and learn language (Beckett et al., 2010; Blake, 2007, 2011; Oliver et al., 2012). 
Although it was sometimes a challenge for educators to harness the technical capabilities online English language learning offers, stakeholders commented on the active participation of the ELLs. Engagement that is active or dynamic is commensurate with an ideal language learning environment (Oliver et al., 2012). I will now discuss the perceived facilitators and barriers to learning that were reported by the participants.

Facilitators to learning. Stakeholders commented specifically on positive perceptions, commitment to students' learning of English and positive relationships in their discussion of facilitators to learning. I will now examine each of these in turn.

Positive perceptions. The positive response to online English language learning reported from most of the stakeholders was consistent with a positive response to computer based language learning in the literature. Positive perceptions are regularly reported by students and teachers working with technology to enhance English language learning (Felix, 2004, 2008; Ibarz \& Webb, 2007).

A safe and positive learning environment was perceived by the students. The students at Central School reported very favourable perceptions toward learning English online. Students spoke of positive feelings and enjoyment associated with learning English. This correlated with studies set in other school environments where students also reported positive perceptions of online English language learning (Felix, 2004). Very positive emotions were evident as the students at Central School described their perceptions. Reasons students cited for these positive perceptions were being able to achieve good marks and participate in online activities.

The two eTeachers saw the programme as worthwhile as it motivated and included students, and allowed them to participate in the learning process. These views are significant as teachers' perceptions of the use of technology in teaching are a crucial factor affecting the degree of success to which ICT is used within the classroom (Park \& Son, 2009). The two eTeachers' personal interest in computers and elearning, as well as the fact they elected to teach English in an online environment could have been factors contributing toward their positive perceptions of the value of what they were doing.

Comments from most of the research participants about online English language learning were predominantly concerning affective features rather than academic gains for students. It is important to consider both affective and academic factors however, as there were links 
between the two evident in the literature reviewed. For example, attitude and motivation can influence learning outcomes of language learners (Ushida, 2005). The positive attitudes of the students in my study toward their learning may have contributed toward their increased motivation. In turn, those who are motivated have more likelihood of success (Ushida, 2005).

Although affective factors were signalled by the participants as an important emphasis in the findings, there was a notable lack of attention on the students' academic growth and success. Only the eTeachers, eTutor, one of the eCoordinators and one set of parents commented on student achievement. No other comments were made by any of the other participants. This may have been due to the lack of information they received on the students' progress, or it may not have been a high priority for them.

In particular the class teachers were not aware of the English progress the students learning English online were making. Yoon (2008) suggests a link between class teachers' perceptions of their roles as teachers of classes containing some ELLs and the teaching approaches they adopt. In Yoon's research the class teachers' approaches were affected by their beliefs of whether the responsibility for teaching English to the ELLs in their classes belonged to them or to specialised ESOL teachers. In addition, the teachers' beliefs also affected the ELLs' subsequent participation in the class and their identity as learners. In the case of Central School, the class teachers seemed to see the responsibility of English teaching belonging to the eTutor and eTeachers and not to them. One reason why academic gains were not mentioned by interviewees could be that there was no specific question referring to this in the research questions. However, as the questions were semi structured, with freedom for participants to deviate from the questions as they wished, the staff could have commented if they wanted.

The positive attitudes and high levels of motivation reported by the ELLs at Central School were also commented on by their parents and the staff. Michel's father, Jorge, was adamant his son's involvement in learning English online, increased happiness at school and improved English skills were intrinsically linked. School staff also made similar links between the online English language learning experience, motivation of the students and students' engagement in their work. These findings correlate with the experiences of other English language students, where researchers in a tertiary setting suggest one vital role for English language teachers is motivating their students (Bahous et al., 2011). These authors suggest an approach that caters for students' diverse needs as one major factor toward increasing their 
motivation. Although these findings were based on research at a tertiary level, it is likely that the eTeachers in my study contributed to the reported high levels of motivation by catering for the individual learning needs of the students. It is also likely the high levels of motivation reported by students contributed to their overall satisfaction with their learning experience, and ultimately linked to their improved levels of learning.

An additional reason to be mindful of ELLs' motivation is that actual or perceived educational failure may result in low self-expectations (Ibarz \& Webb, 2007). The six student participants were all allocated ESOL funding from the Ministry of Education, who see identification and support for English language learners as a key focus (Ministry of Education, 2004). In order to qualify for ESOL funding, students needed to score at a designated level below their L1 peers of the same age in listening, speaking, reading and writing assessments. However, teachers are cautioned not to view the achievement gap between ELLs and their same-age cohorts as inappropriate development, or to view them as "educationally disadvantaged" or "underachieving", as most ELLs are simply following a trajectory of normal development for second language acquisition (Ministry of Education, 2005). Valencia (1997) describes viewing ELLs as "educationally disadvantaged" as a deficit thinking paradigm. Within a deficit thinking paradigm the students' underachievement is thought to arise from their cognitive or motivational lacks, or deficits that are attributed to the students' families. By following this hypothesis, teachers and schools are exonerated from the responsibility to teach the ELLs in their schools sufficiently to enable the students' full access to the curriculum.

It is likely the ELLs at Central School had experienced some degree of academic struggle to keep up with their English L1 speaking peers in their mainstream classes. The class teachers were aware of this struggle, and this could be one of the main reasons three of the four teachers liked their ELLs attending online English language learning lessons. For example, Jess, the class teacher of Arjun commented about his lack of understanding of instructions in her classes despite his effective use of social language. She anticipated his English comprehension would develop as a result of him learning English online.

The positive perceptions of stakeholders toward the online English language learning programme enhanced opportunities for active engagement in the programme. This case study indicates that the more positively stakeholders felt toward the programme the more inclined they were to be actively engaged. 
Commitment to students' learning of English. A further significant factor that demonstrated participants' active engagement in the daily programme was in their commitment to the students' learning. I will now discuss those aspects that arose, namely time and participants' perceptions of their roles.

My research indicates that for those involved in teaching and tutoring the ELLs in this online English language learning programme, staff were prepared to go over and above the call of duty to ensure they were always ready to teach their students. Several of the participants worked longer than the hours for which they were employed. The eTeachers and eTutor felt it was necessary to devote considerable time to ensure the successful implementation of technology for learning in the online teaching environment. In this particular online English language learning programme staff needed to be able to use and teach many software programmes as well as numerous features of the ELLINZ online website in order to deliver the programme to the students. The eTeachers and eTutor reported working many more hours than those for which they were employed in order to ensure lessons were prepared and students' different proficiency levels were catered for. Administrative tasks also took considerable time. The eTeachers perceived it took more time to complete lesson plans, prepare teaching materials and do required administration in an online teaching setting than in one that is face-to-face. Both eTeachers on the programme had considerable experience teaching ESOL in secondary school settings, and used this experience as a point of comparison. Time constraints can have ramifications; they are reported to be one factor leading to failed use of technology in computer assisted language learning (CALL) in American schools (Park \& Son, 2009).

High levels of commitment are amongst teacher qualities appreciated by students of distance language learning courses (Murphy et al., 2010). In Central School a high level of commitment was evident amongst the eTeachers and eTutor. The support given to students, shown in part by the extra time staff were regularly committing to ensure the programme's success, contributed to the students' satisfaction and success of the programme overall.

However, apart from the ICT teacher and the eCoordinator who were involved in the initial set up of the online English language learning programme, the rest of the school staff (principal, DP, class teachers) and the parents did not have the same opportunity to demonstrate commitment to the programme as the eTutor and eTeachers. Possibly the reasons were two fold; firstly their responsibilities were spread more thinly than those of the 
eTutor and eTeachers. English language development was just one part of their child's education in which the parents, ideally, were familiar. There are many more subject areas that parents could gain knowledge about, such as mathematics or technology. Secondly, the parents of the ELLs in Central School are English language learners themselves, which may add additional challenges when communicating with school staff. In addition, parents have time commitments to jobs and their other family members (Lewis, 2001). Consequently there is a greater challenge to be actively engaged in the online English language learning programme for parents than for the eTeachers and eTutor who dedicate many hours to it each week.

A contributing factor limiting the active engagement of parents in the programme could be a cultural one, concerning parents' perceptions of their own roles and the roles of teachers (Coady, Cruz-Davis, \& Flores, 2008). The students at Central School came from Fiji, Samoa, Mexico, India, Cambodia and Burma; countries which usually adopt a style of teaching that is more strongly teacher-led than is practiced in New Zealand. The parents in my case study may have felt their children's education was the responsibility of the school and that it was not appropriate for them to be involved.

Research by Yoon (2008) suggests class teachers may not support the learning of ELLs in their classes due to a lack of understanding of how their roles and teaching approaches can best support ELLs' learning needs. This was well supported by my findings. The way the class teachers at Central School viewed themselves appeared to influence their involvement in the online English language learning of the ELLs in their classes. It seemed the class teachers did not see themselves as an integral part of a team supporting the English language learning of their ELLs. Their perceived identity appeared to be that of 'curriculum teacher' and not 'curriculum and English language teacher'. It appeared they did not take advantage of the opportunities to place the students in a position of 'contributor' in the class by asking them to demonstrate their achievements of their online learning. The teaching of English was left to the eTutor and eTeachers with little or no active engagement from the class teachers.

Meeting the needs of the ELLs was therefore more of a challenge for some stakeholders than others. This finding is congruent with the literature to date: even very proficient class teachers report reduced confidence when teaching specialised groups such as ELLs (Karabenick \& Clemens Noda, 2004). 
Positive relationships. My study strongly endorses the finding that relationships between students and those teaching them are vitally important as affective factors enhancing English language development. The students, eTutor and eTeachers reported very warm relationships.

The ability for ESOL teachers to establish rapport with their students is an important aspect of teaching and one that contributes to students' learning (Wette, 2009). In Wette's case study of ESOL teachers with adult learners, the ability to create rapport signified teachers' knowledge and experience. The study also showed the value of positive relationships as an important precursor to effective learning. Other studies have shown similar findings. Teachers' establishment of positive empathetic relationships with their students increases the effectiveness of both the teaching and learning process (Roger, as cited in H. D. Brown, 2007). In addition, the understanding and empathy the eTutor and eTeachers demonstrated with the different cultures of their students is seen as an indicator of effective cross-cultural teaching (Hawk, Cowley, Hill, \& Sutherland, 2002).

The students reported high motivation, self confidence and low anxiety in their English language learning. These positive affective responses may allow the optimal language learning Krashen (1982) suggests; one that is safe, welcoming and one in which students feel secure. The positive experiences the ELLs at Central School report in their English language learning endeavours should allow greater opportunity for enhanced learning.

A further factor that facilitated participants' meeting the learning needs of ELLs was the existence of a positive working relationship amongst some of the stakeholders. Online language learners' perceptions of their learning experience are important as it is more difficult to discern their requirements and circumstances than in a face-to-face classroom (White, 2006). In a recent study Murphy, Shelley and Baumann (2010) showed students placed importance on specific qualities of teachers in distance language learning courses, namely high affective features of enthusiasm, approachability, support and commitment.

For the students, eTeachers and eTutor there was an established atmosphere of enthusiasm and support, qualities valued by students learning online (Murphy et al., 2010). The provision of an eTutor onsite emerged as a significant factor influencing positive relationships. The eTutor also provided tutoring and support both during live lessons and in the sessions between live lessons. The literature suggests that the provision of an adult tutor was an important factor in course completion, amount of work done and the quality of participation 
of students in online learning (Rice, 2006). Positive relationships were very evident among the ELLs, the eTeachers and the eTutor; factors which may have contributed toward the ELLs' enthusiasm to attend the programme. Perhaps more significantly, the positive relationships that were evident between eTeachers, eTutor and students appeared to circumvent students' feelings of depersonalisation suggested by Young (2004) as a possible consequence of learning online.

Relationships among students were also reported in the literature as significant in ensuring increased participation and positive learning outcomes for learners (Rice, 2006). In a study examining the viability of English language tutoring to adult migrants via a CD-ROM-based programme, the opportunity for students to socialise with each other (thus practicing language skills) was given as one of the reasons for the success of the model (Ibarz \& Webb, 2007). This study was with adult learners and the students at Central School are intermediate aged, but the findings are similar. It is likely the paired speaking tasks regularly set in their online learning not only contributed to the students' English proficiency but also established the obviously warm and friendly relations among the students.

However, the close positive relationships enjoyed by the students, eTutor and eTeachers, were not evident amongst the other stakeholders who were interviewed. Restrictions such as fewer opportunities to interact, as in the case of ELLs and the principal (despite him taking a personal interest in these students) or ELLs and the eCoordinator, meant the development of close relationships was less likely to occur. Similarly, the relationship and roles of class teacher with ELLs, and eTutor with ELLs is different. Class teachers have a group of 25-30 students to teach and usually strive to keep a greater emotional distance between themselves and students. By contrast, an eTutor or even an eTeacher teaching from a physical distance is working with a small group of ELLs, and has the time and opportunity to establish close, friendly working relationships. I will now consider barriers to learning in the context of meeting students' needs.

Barriers to learning. Other factors emerged from the data as barriers to learning English online. Stakeholders commented specifically on withdrawal from class, timetable issues and technological issues in their discussion of barriers to learning. I will now discuss each of these in turn.

Withdrawal from class. The impact of educational policies in Western countries has encouraged a move toward mainstreaming ELLs (Gibbons, 2009), with students being 
withdrawn regularly for a short time from their mainstream class for specialised ESOL instruction (Calderon et al., 2011). ELLs are seen to have their learning needs best met by inclusion within a class of L1 peers as they learn the English language and curriculum content concurrently. Placement in the mainstream may work well for ELLs, so long as their teacher understands and accommodates their English language learning needs. However specialised ESOL intervention in the form of withdrawal from class for part of the day may be the most advantageous way to accommodate very new speakers of English (Gibbons, 2009). Although Central School has an established practice of withdrawal of students in order to meet specific learning needs, some of the class teachers felt too much time out of class would have a negative impact on the learning and socialisation of the ELLs they taught.

There were conflicting responses in this study to the issue of withdrawal from class teaching. Withdrawal from the mainstream class in order to attend online English language learning lessons was perceived to be a 'problem' directly in proportion to the effect it had on stakeholders. A fully mainstreamed option, where students are in the mainstream class fulltime may not be the best option however, as most mainstream programmes of study do not take the language and literacy needs of ELLs into account (Gibbons, 2009).

For the eTeachers and eTutor withdrawal was not mentioned, as they had very little involvement in the process or implications of the students being taken out of class. There was little opportunity for contact between the eTeachers and class teachers, so it was unlikely for the topic to be discussed. For the principal, DP, ICT teacher and coordinator, withdrawal was acknowledged but not seen as a problem. However, for the class teachers who were the most affected by the withdrawal process, the practice posed considerable challenges. Their concerns were two fold; firstly the students missing class work and secondly, anticipated social difficulties for the students as a result of their frequent absences from their mainstream class.

Firstly class teachers spoke specifically of students missing core curriculum work such as mathematics and reading. They also mentioned students missing school wide assessments, resulting in a further challenge for class teachers of having insufficient information to place students in ability level groups for particular subjects. However, even if the ELLs did the school wide assessments their results may not have been valid, given the students' English language levels (Ministry of Education, 2005). 
A second perceived disadvantage of withdrawal for ELLs that one class teacher voiced was students' social disadvantage. She taught a girl she described as "reserved" and felt the frequent class absences of her student were a major challenge. Conversely a different class teacher did not consider withdrawal as a social inhibitor at all. However, he described the student in his particular class as outgoing. It is possible a more outgoing student could cope with any social challenges regular withdrawal from class may present more successfully than a less outgoing student. The topic of withdrawal is discussed in a secondary school setting by Bedford and Kitchen (2006) when they examined ESOL students' choices of secondary school subjects (including ESOL as a subject choice). These researchers found many students expressed regret at their inability to enter mainstream subjects of their choice. My case study is inconclusive on this point; it is difficult to say whether the younger students in my study had similar feelings about wanting to remain in their mainstream class in preference to being withdrawn to attend online English language learning classes.

One significant contributor to increased academic achievement of ELLs is teachers using instructional language at a level understandable to the learner (Echevarria \& Vogt, 2010). This entails the teacher giving oral instructions or providing reading material at an English language level that can be comprehended. Some class teachers in my study expressed concern that their ELLs were missing important content work in their mainstream class when they were withdrawn to attend online lessons. However this would only be a realistic concern if the ELLs comprehended the teaching input they received in class, something class teacher Jess was convinced her student Arjun was not able to do (see chapter four). Furthermore, the six student participants were functioning at two different English ability levels; four at stage one and two at foundation level of the ELLP. If Arjun (who was at stage one) was judged by his teacher to not be able to comprehend the instruction he was receiving in class, it is likely even less mainstream class instruction would have been understood by the two foundation level ELLs.

Timetable issues. The practice of withdrawal from class to attend extra tuition has implications for timetabling also. Issues to do with the timetable were one area in which the complexities of an intermediate school were particularly challenging. In this case study most of the school staff commented on the challenges of fitting all of the planned learning activities for students into the school day. Extracurricular and remedial lessons were routinely timetabled for many Central School students resulting in regular withdrawal of students from their mainstream class. Students attended classes specifically designed for learning extension, 
such as online English language learning. These online lessons needed to fit in with the eTeacher (off site) as well as the school. Teachers, teacher aides and teaching spaces needed to be accommodated within the timetable to ensure all of the planned events could take place.

O'Regan (2012) asserts that effective timetabling requires consideration of the needs of students, staff and the learning institution. O'Regan's study within Australian tertiary settings suggests factors to be considered for effective timetabling are policy and process, technology, people (including their cultural context) and communication. In my case study, the timetable changed regularly. Although most of the staff commented on the challenge of working out the timetable issues they felt that with communication and negotiation these challenges were surmountable.

Technological issues. Technical difficulties were named as a further barrier to online English language learning in my study. Ongoing technological training and support is necessary for those delivering the teaching and support to online learners (Park \& Son, 2009), and for those who are learning (Liu \& Cavanaugh, 2011). This support is important as technical difficulties experienced in online English language learning are linked with a reduction in students' learning, motivation and online interactions (Felix, 2008; Murugaiah \& Thang, 2010). Conversely, stable technology is associated with positive student perceptions of computer assisted language learning (Felix, 2008).

However, given the software, hardware and internet connections involved in online learning, stable technology is an ambitious aspiration, as problems may be due to any one of many variables. For those involved in the online English language learning at Central School, technological experiences were mixed. The eTeachers and eTutor reported excellent, timely support from the ePrincipals, whose responsibility was to offer this support. It is likely that students' reported high motivation could be partly due to the timely technical support they received. Staff reported their computing skills increased rapidly as they learned 'on the job'; meaningful learning that had immediate application. Despite the support received, frustrations experienced by these staff members and students included issues to do with hardware, software and untrustworthy internet connections. My research supports the literature that suggests that positive perceptions and motivation of staff and students are enhanced by ongoing conscientious technical support (Felix, 2008).

Another area of concern was that of students learning English online yet not having internet provision or even a computer at home. This is one characteristic of a learner's environment 
that is likely to predict success in an online setting (Liu \& Cavanaugh, 2011). Out of the six ELLs interviewed, two had internet provision at home, three did not and one was unsure whether or not his home had internet provision. As students can access their online English language course work from any internet linked computer, it seemed a formidable barrier to learning if the students did not have the opportunity to show their work to their families, or to continue their ESOL work from home. Liu and Cavanaugh (2011) suggest offering assistance to students to link up with the internet at home could enhance their opportunities for learning in their investigation of factors influencing student academic achievement in an online setting. This may have been helpful to the students at Central School also.

In summary, withdrawal from class, timetable issues and technological issues were perceived by participants to be the main barriers to online English language learning meeting the needs of ELLs.

\section{Degree of Active Engagement}

The degree of active engagement refers to the degree to which participants were actively involved in the daily programme within the confines of their individual roles. In my research, each participant had a different role in the daily process of the online English language learning programme. The degree to which participants are actively engaged in the daily programme is important for several reasons. Active engagement allows participants increased opportunities to communicate with others, learn more about the English language learning needs of ELLs and contribute to that process. For example, Cummins (2001) suggests minority community participation in the school programme as one characteristic that may add to the status of that group and ultimately be a contributing factor toward the minority students' academic success. In other words, encouraging the active engagement of parents in the online English language learning process of their child would enable them to work alongside educators and contribute meaningfully to their child's learning.

Participants' engagement in the programme was demonstrated by the time, effort and energy they reported giving toward the successful implementation of the programme within their individual area of responsibility. However, individual roles and responsibilities differed.

The eTutor had a pivotal role of providing tutoring during live online lessons as well as tutoring sessions between the live lessons. On the other hand, the school principal's role was more peripheral; that of providing physical resources and overall support of the online 
English language learning programme within Central School, a role that required considerably less time on a daily basis, but equally important.

However, even allowing for the different levels of involvement required by the different roles, some participants had levels of active engagement that appeared disproportionate to those roles. For instance there was very little reported or observed interaction between class teacher and the online programme in any way. Three of the four class teachers had not had the opportunity to observe their students doing online English work in live lessons and were not aware of the curriculum content or manner in which their ELLs were learning. Consequently class teachers' opportunities to be actively engaged by viewing students' work, discussing students' work or incorporating the content learning of the programme into their classroom were limited.

\section{Extent of Communication}

According to Wenger (2000), the success of an organisation is dependent on participants having a sufficiently developed collective understanding of the project to enable them to understand it and contribute to it. For collective understanding of participants on a project such as this online English language learning programme, communication is an essential feature. The opportunity to participate in the online English language learning programme in this study was directly affected by the extent to which research participants communicated, actively sharing information for the purpose of more effective English language teaching and learning.

Communication of the groups involved in online English language learning at Central School came under two headings; intragroup communication and intergroup communication. Intra group communication refers to the communication within each of the three groups, and describes the frequency and effectiveness of the communication between members of the same group. This varied widely from very effective intra group communication in group one (students, eTutor and eTeachers) to very little intra group communication in group three (parents and class teachers). Intergroup communication refers to communication between the three different groups. All three groups showed evidence of little intergroup communication. That is to say, none of the members of a group communicated with members of other groups very much about English language learning or the online programme. Effective intragroup and intergroup communication is an important factor toward successful implementation of the programme. As Wenger (2000) suggests, when different participants converse and share 
ideas, challenges and successes they can learn from each other and improve practice. Participants' perceptions of communication affected their views of what constituted facilitators and barriers to online English language learning, and they formed an important finding in my study.

Communication between the different participants involved in the ELLs' education in my study was seen to be an important aspect to raising educational standards. Increased communication between home and school is one way schools can more effectively address the educational needs of students who are learning English (Calderon et al., 2011). These authors suggest the cultural, linguistic and social differences ELLs are likely to experience in their adopted country can issue challenges far beyond those faced by L1 students. They call for open communication to facilitate positive relationships between home and school (Calderon et al., 2011). When parents of linguistic and ethnic minority students (ie ELLs) are involved in their children's education as partners, parents develop an increased sense of efficacy that in turn communicates itself to their children, resulting in increased academic consequences (Cummins, 2001). Communication enables involvement. This study supports these hypotheses in both cultural and communicative assertions. Therefore it appears to be a vital component for the success of this online English language learning programme to have open communication between the different parties involved. However, there were some challenges to effective communication, which I will now discuss.

Challenges to effective communication. The complexities of a busy intermediate school and an online learning institution are environments which present many barriers to effective communication. Factors such as professionals and families speaking different home languages and the eTeachers teaching from different geographical places to Central School add further challenges. Because this English language learning programme is taught via the internet and the eTeachers may be teaching from any geographical place in New Zealand the chance for face-to-face interaction is limited to opportunistic visits between eTeachers and school or planned occasional visits between ePrincipals and participating schools. Thus communications between staff working from another geographical location and the school or home are usually limited to the telephone, Skype, email or a physical letter. In addition to these constraints, the students did not communicate with their parents about their online English language learning. Jafar recounted how little his son Arjun told him about any of the work he was doing at school. Joji was unaware his daughter Adi was even attending online English language lessons and while Jorge and Maria knew their son Michel was learning 
English online they admitted he didn't tell them much about it. Time pressures also contributed to the lack of communication amongst participants. The eTeachers reported difficulty fitting lesson preparation, teaching and administrative work into the hours for which they were employed. Extra activities such as contacting class teachers or parents may have added extra time pressure to an already full workload. Extending the hours of employment of the eTeachers may possibly allow more opportunity for increased communication. The class teachers also might need to have extra time allocated to enable these communications. Different groups had different perceptions of communication within the online English language learning programme, which I will now discuss.

Participants' perceptions of communication. Perceptions of the levels of communication participants experienced varied between the different groups. Group one experienced communication that was frequent, efficient and satisfying. The various methods used to communicate between eTutor and students with the eTeachers and others in the online community (such as Skype, email, the ELLINZ online web site, a designated special interest forum for eTutors on the ELLINZ online website and face-to-face visits) appeared to meet their needs. However groups two and three did not perceive the same levels of satisfaction with the levels of communication. Each of the four class teachers felt they received little communication about the programme and expressed a desire to be better informed. They wanted to have some form of communication, such as a staff meeting, to learn about the purpose and aims of the programme.

Perceptions of inadequate communication reported in this study are consistent with other research documented in the literature. In a study of collaboration between an aquarium and an elementary school, communication difficulties between staff members were cited as a major challenge to the success of its implementation (Kisiel, 2010). The author suggests active engagement of stakeholders is unlikely if concerns and suggestions are not able to be shared. In the case of Central School, this also was found to be true. There appeared to be very little exchange of information between those who knew about online English language learning and those who did not. This foundational level of communication is necessary before the more specific communication about changing practice could take place.

Assessment was one fundamental area in which the lack of communication was evident. Teachers expressed a perceived lack of communication about assessment. They were not aware of the English levels the ELLs from their classes were attaining or of the progress they 
were making. Instruction that is built on frequent appropriate assessment is an important guiding principle for ESOL teachers (Echevarria \& Vogt, 2010). These authors suggest assessment based instruction will increase ELLs' engagement and meaningful participation in the classroom. In my study the ELLs were certainly being rigorously and frequently assessed and the eTutor and eTeachers knew exactly how each student was progressing. However class teachers did not perceive they received adequate communication about the online English language learning programme, what their students were learning or how they were learning it. Each of the four class teachers expressed a desire to have more information about their students' levels of achievement. Without that information the class teachers felt they could not focus their teaching at the appropriate content or English language level for the ELLs they taught in their classes. Shontelle and Vili expressed a desire to incorporate the activities and learning from the online English language learning programme into their classes; an aim that would probably advantage the ELLs' learning.

These class teachers' aspirations are congruent with research that links the need for teachers to concurrently teach curriculum content and language forms to learners of English (Gibbons, 2009). It has been established that ELLs learn most effectively when they have explicit language learning aims alongside core content learning (Echevarria \& Vogt, 2010). If the class teachers had assessment data for the ELLs in their classes, they may have been able to better meet the learning needs of their students.

For parents, the degree to which they received communication about the online English language learning programme influenced the degree to which they were able to participate in their children's education. According to Cummins' (2001) seminal framework addressing the achievement gaps of linguistic minority students, one important factor influencing empowerment and ultimate academic success of these students is the extent to which the minority community (in this case the parents) is incorporated into the educational practices of the school. Parents reported they did not receive communication about the programme. They did not know about it and could not become involved, thus reducing the opportunities they had to participate. This is not to say no communication attempts were made, rather that parents did not perceive they received adequate information.

However, when given the opportunity, the parents demonstrated a high interest in communicating about the online English language learning programme. During the data collecting phase of my research two families made special visits to the school to talk to me 
and one family invited me into their home. These parents wanted to know what their children were doing at school and took the opportunity to question me as I conducted the interviews. The parents seemed to warmly receive and appreciate the face-to-face communication with me, corresponding with research that reports parents of ESOL students may prefer the direct communication of a personal visit by school staff over the indirect communication of notes and emails (Coady et al., 2008). These parents appeared to be seeking vital information about their children's learning, one important aspect of providing quality education to ELLs (Calderon et al., 2011). This case study clearly supports the need to exploit the levels of interest shown by parents of ELLs.

Whose responsibility? A further consideration about communication is to decide where the responsibility to communicate with parents lies. There are two possibilities; the Ministry of Education sponsored provider of the programme or the school. Somehow the responsibility appeared to have fallen between the cracks with neither party taking active responsibility for this. The obvious connection between school and home is the students themselves, but it seems they did not tell their parents very much at all.

The issue of communication is vital for all stakeholders as the extent to which stakeholders perceive they have effective communication directly affects their opportunities for active participation in the programme. The extent and effectiveness of communication is widely fluctuating within this online English language learning programme. Within group one (eTeacher, students and eTutor) there is frequent and excellent communication. With the other two groups however, my study suggests that communication is perceived to be inadequate.

Communication had a direct influence on the degree to which participants had knowledge of, or understood the purposes and processes of the online English language learning programme. The more participants communicated about the programme, the more they understood it. Therefore the issue of understanding or knowledge was an important one to my study. I will now consider the different amounts of knowledge held about the programme by the various stakeholders, and the implications that arise.

\section{Knowledge Held}

The amount of knowledge held is the term I will use to describe the extent to which stakeholders understood the purposes and processes of the online English language learning programme. This knowledge directly affected the degree to which stakeholders were able to 
take part in the programme. For example, specialist skills in teaching the language of the curriculum as well as raising English language skills is essential for teachers of ELLs if they are to meet their students' learning needs appropriately (Harper \& de Jong, 2004; Walqui, 2006). Not all of the stakeholders required the same level of knowledge of the online English language learning programme. However, they all did need to have a sufficient knowledge level to enable them to participate fully within their individual role in the programme. For instance it would be helpful if parents knew how to access the website so they could talk with their child about the programme. Different roles require different kinds of knowledge, and it is important no stakeholder has reduced opportunities to participate because of a lack in this area. Had the class teachers had more knowledge of second language acquisition they may have viewed the programme differently (Gleeson, 2012). The opportunity for stakeholders to participate in the online English language learning programme is dependent, in part, on the knowledge they hold. The discussion of which knowledge of the programme was held by the various participants proved to be an important parameter in establishing perceptions in this study.

In addition to different understandings about the programme, participants had different kinds of knowledge in other areas. The class teachers knew the curriculum. Parents knew their children best. eTeachers had specialist knowledge about ESOL pedagogy and the ELLINZ online programme, and the ICT teacher had specialist knowledge of computing. However, the extent to which there was communal utilisation of knowledge influenced the extent to which participants were able to actively engage and participate in the programme. Thus the lack of communication between some of the participants reduced their participation and ability to contribute.

The link between perceptions and knowledge. The online English language learning programme was perceived to be a more valuable and helpful educational tool the more stakeholders knew and understood it. Conversely, those who did not know or understand it did not regard it as highly. This finding aligns with the findings of Park and Son (2009) in their study of English as a foreign language (EFL) teachers using CALL in Korea. These researchers found that while the use of CALL increased students' opportunities for engagement and motivation, adverse factors affecting the successful implementation of CALL within the EFL classroom included a lack of sound pedagogy and practical skills amongst teachers. Those EFL teachers who were least familiar and had least knowledge of the theory and practice of CALL were those most likely to have difficulties implementing it 
successfully in their classrooms. The results of my study align closely to these findings. Although Park and Son's research relates to adults learning English as a foreign language and not children learning English within an English speaking milieu as in my research, the EFL teachers shared similar experiences to those involved in this online English language learning programme. The knowledge and skill levels of participants in my research were associated with the degree to which they perceived the learning was implemented successfully.

\section{Summary of Discussion}

The extent to which participants view online English language learning positively depends on the degree to which participants understand the purpose of the online English language learning programme and their individual role within it. Equally important is the opportunity participants have to contribute within the confines of their role. Therefore the three factors of participants' active engagement in the daily programme, the extent of communication among participants and the amount of knowledge held are significant contributors to the increased positive perceptions of the programme. These factors build on each other with the end result being optimal conditions for participation. The more actively a participant is involved in the daily programme the more opportunities they have for communication about English language learning, the individual students and the programme. In addition, the more this specific communication takes place the more equipped a participant is to be able to contribute to the ongoing process of English language learning.

Opportunities for involvement were not available equally to all of the groups. While group one (students, eTutor and eTeacher) had full opportunity to be involved in the programme, groups two (principal, DP, ICT teacher and eCoordinators) and three (parents and class teachers) did not. Further, the lack of opportunity for these two groups appeared to lead to a reduced acceptance of the value of the programme. I suggest the apparent lack of acceptance of the value of the online English language learning programme by groups two and three is because they do not know enough about it, are not included in the communication loop and therefore are not involved sufficiently in order to participate fully and be convinced of its value.

In the following chapter, I will make some recommendations for practice that may increase opportunities for participation for these two groups. 


\section{Chapter Six. Conclusions}

In this chapter I summarise my study, discuss its limitations and consider transferability. I will then discuss implications of this study and make some recommendations.

\section{Summary of Research}

This qualitative study investigated perceptions of participants of an online English language learning programme within one school community. A single case study design was chosen as the most suitable method to answer the exploratory research questions (Yin, 1994). Of specific interest in the study were those factors considered by participants to be facilitators or barriers to the process of ELLs learning English online.

The introduction of the ELLINZ online programme into selected New Zealand schools in 2010 presented an opportunity to investigate how participants perceived online English language learning at an intermediate school level within a New Zealand setting. This programme also presented an opportunity to add to the literature by revealing participants' perceptions of those factors that facilitated or were barriers to the learning process. Additionally, because this particular online programme uses in-school tutoring alongside online teaching it has aspects of a blended approach, thus increasing the study's potential to contribute to the body of knowledge in this area of education.

Much of the existing research into online learning, online language learning and online English language learning has been directed at tertiary and adult levels. There is a lack of research concerning online learning at the primary and intermediate school levels (Blake, 2011; Liu \& Cavanaugh, 2011) and online language learning at those same levels (Felix, 2004; Oliver et al., 2012) (in New Zealand schools these are students in years 7-13). In addition there is a particular lack of research of year 7-13 ELL students learning online within the New Zealand setting. These learners are both learning English as an additional language and learning curriculum content in a classroom through the medium of English.

Analysis of the data and comparisons with current literature showed some interesting findings. Participants had positive perceptions of online English language learning overall, linking with positive perceptions reported in the literature (Felix, 2001, 2008). In addition to positive perceptions, research participants emerged as three distinct groups, identified by their commonly held views. These groups were defined by the degree to which they were 
actively engaged in the online English language learning programme, the extent they communicated with others both inside and outside of their group and the amount of knowledge they had about the purposes and processes of the ELLINZ online programme. These three views appeared to directly affect the degree to which they were convinced of the value of online English language learning.

Group one (students, eTutor and eTeachers) was extensively engaged in the daily programme. Group members had frequent intra group communication and extensive knowledge of the purposes and processes of English language learning and the ELLINZ online programme. They were convinced of the value of the ELLINZ online programme. Group two (principal, DP, ICT teacher and eCoordinators) had some active engagement in the daily programme, some intra group communication and some knowledge of the purposes and processes of English language learning and the ELLINZ online programme. They had a correspondingly reduced acceptance of the value of the ELLINZ online programme. Group three (parents and class teachers) had the least active engagement in the daily programme, no intra group communication and little knowledge of the purposes and processes of the ELLINZ online programme. Their acceptance of the value of the programme was the least of the three groups.

The more participants were actively engaged in the daily programme, communicated effectively about it and understood its purposes and processes the more they were convinced of its value. I suggest it will be useful to consider ways of increasing the opportunities for active engagement, communication and knowledge bases of all participants, as this may increase opportunities for participation and lead to more successful implementation of online English language learning in this setting.

\section{Limitations}

This research project was borne out of my personal interest in and familiarity with the online English language learning process. This has to be acknowledged as a possible limitation of the study. I engaged in critical self reflection about my potential biases in order to address this potential problem (Johnson \& Christensen, 2008). During the research process, I was aware of my empathy toward the two eTeachers, as I had similar experiences to them the previous year when I was teaching English online in the same position. I was conscious of the temptation to add my own experiences to theirs and 'over report' their 
perceptions, thus skewing the data. While the experience of teaching English online certainly enabled me to understand the eTeachers' points of view, and others' points of view to a lesser degree, I was aware that my responsibility was to report the perceptions of a school community of which I was no longer a part.

Another possible limitation was the temptation to report primarily positive findings. A positive report would provide qualitative data to administrators and policy-makers which could potentially influence decisions about the continuation of the programme. This in turn could result in a positive outcome for the future employment of my former eTeacher colleagues.

An additional limitation may have been the language barrier between the students and their parents and me. Difficulty expressing themselves in English may have been a factor for three of the sets of parents not wanting to be interviewed. A lack of English proficiency may also have affected the depth of communication in the interviews with the remaining parents who did consent. The students may have expressed themselves more fully had I been able to provide interpreters during my interviews with them. However as an experienced ESOL teacher, I used communication strategies such as pausing, clarifying, repetition and giving "wait time" to ensure that the parents and children had time and opportunities to express themselves.

\section{Transferability}

A further limitation of this study is its small number of participants. This study represents perceptions from participants from one school community, and one set of stakeholders. Although my study yielded increased understanding of the stakeholders of this particular online English learning programme in Central School, it does not necessarily demonstrate findings that would be consistent with online English language learning courses in other schools or at other educational levels. The perceptions of these stakeholders are not able to be generalised to other stakeholders in different settings (Berg, 2001; Richards, 2003), and therefore have limited application to learners and settings outside Central School. However, its value may be as an initial investigation of this new field of pedagogy in New Zealand.

\section{Implications}

The differing levels of participation in the programme displayed by the different groups may well have an impact on the overall outcomes of this, or any other online English 
language learning programme. The task of providing an inclusive educational service to particular student groups is a challenge that goes beyond that of an online English language learning programme for ELLs. For example, the Ministry of Education's Intensive Wraparound Service (IWS) (Ministry of Education, 2012) was initiated to coordinate supports for students with highly complex learning and behavioural needs and their families and whanau. As the name suggests, the IWS aims to coordinate efforts from family, teachers and other specialists to better meet the needs of students. This initiative has far reaching consequences for the efficacy and perceptions of programmes such as the online English language learning programme in my study. This trend toward a more cohesive and comprehensive response to students with complex learning and behavioural needs has been evident both in New Zealand and overseas for the past two decades (Mitchell, 2012).

Although in my study the students' learning needs are to acquire English in order to access the curriculum, the benefit of moving from fragmented intervention services to those that are coordinated and integrated seems opportune. When all of the participants are aware of their own and others' optimal roles and potential value in supporting the English language learning of ELLs, they will be able to intentionally contribute to that final goal with knowledge and confidence. Further, with increased knowledge about good ESOL pedagogy and this specific online programme, the collective response will be able to become more integrated and coordinated.

In order for a more coordinated and integrated approach to happen two major concept shifts are required by the participants. The first one is in the belief system that undergirds the concept and the second in increasing the opportunities to participate for those who are less closely aligned to the programme's purposes and processes.

How the parents, class teachers and other supporting staff at Central School see themselves and their roles may influence their contribution toward the students' learning of English. Self beliefs, or perceived identity about their respective roles may positively or negatively influence their desire to participate. In addition, there needs to be a belief in the value of online English language learning; a belief that appeared to increase the more the research participants learned about it. Once a participant who is not centrally involved in the process believes they can make a difference and is convinced of the merit of online English language learning then they have a firm rationale to motivate their involvement. As they learn more 
specific ways of supporting students all participants can contribute to the overall goal of increased English proficiency. This concept is summarised under the headings below.

\section{Perspectives to Enhance Programme Effectiveness}

Two perspectives that may enhance the effectiveness of the programme have arisen from the research. First, it would be helpful for all participants to reflect on their individual roles and the contributions they may make to the English language learning of the students. Specifically, it would be helpful for participants to have:

- an understanding of the purposes and processes of online English language learning, and

- an understanding of the value of their own individual role within the online English language learning programme. Increased appreciation of the value of individual roles could help participants assume the identity of a significant contributor to the overall achievement of students.

The second perspective that may enhance programme effectiveness relates to the opportunity to participate. This is important for the following reasons.

- Increased communication between all participants about students' learning and progress would allow for more comprehensive understanding.

- Increased education about online English language learning would possibly lead to greater participation.

Some possible practical suggestions to achieve ways of increasing participants' beliefs and opportunities for involvement will now be outlined.

- Possibly a staff meeting could be held at the start of each school year to share the purposes and processes of the online English language learning programme with the school staff.

- Possibly a parents' meeting could be held at the start of each school year to share the purposes and processes of the online English language learning programme with parents.

- Different ways of disseminating information could be investigated. For example, school newsletters (in English and the main languages of participating students), the school website, the ELLINZ online website and parent-teacher evenings could be utilised. 
- Parents might be invited to school to observe a live online English language learning lesson.

- Teachers might ask the ELLs in their classes to demonstrate their online English work in the classroom to themselves or to one or two friends. ELLs could be encouraged to explain what they are learning and how they are learning it.

- Parents may perhaps be encouraged to ask their children to show their English work at home to the family.

- School-wide professional development could up skill staff on how to meet the needs of ELLs.

- A Skype meeting may possibly be scheduled midyear between the eTeachers and class teachers to discuss the progress of participating ELLs. Time would need to be allocated to enable this to happen.

- Increased communication between the participating school and ELLINZ online staff might foster relationships, trouble shoot and promote mutual understanding.

These recommendations range from reasonably complex to simple. A complex recommendation might be school-wide professional development. A simple recommendation might be the class teachers asking ELLs to show their online work in the mainstream classroom. This would not be time consuming yet would elevate both the status of the work being done and the student's own status to their mainstream peers. However, any extra work on top of professionals' existing workloads would need to be supported by teacher release time, translation services or extra hours of employment for the eTeachers.

\section{Conclusion}

As a general conclusion to this research, online English language learning is perceived favourably by involved stakeholders as meeting the needs of the ELLs for whom it was designed. Not all of the participants are involved in the process however. I have made some recommendations to increase the participation of all participants in order to improve the learning and attainment of the ELLs.

Learning English together with learning to navigate a new culture and educational system is a substantial undertaking for the English language learners in our schools and a coordinated and integrated response is needed to best support them. I hope that this research will contribute to 'the archaeology of the future' of our knowledge and practice of online teaching with ELLs in New Zealand (Richards, 2003, p. 21). 
I leave the last word to Michel, one of the participants who stands to benefit most from online English language learning

It helps me a lot to learn English right now. 


\section{References}

Antón, M. (2011). A review of recent research (2000-2008) on applied linguistics and language teaching with specific reference to L2 Spanish. Language Teaching, 44(1), 78-112. doi: $10.1017 / \mathrm{s} 0261444810000340$

Bahous, R., Bacha, N. N., \& Nabhani, M. (2011). Motivating students in the EFL classroom: A case study of perspectives. English Language Teaching, 4(3), 33-43.

Baran, E., \& Correia, A. (2009). Student-led facilitation strategies in online discussions. Distance Education, 30(3), 339-361.

Beckett, G. H., Amaro-Jiménez, C., \& Beckett, K. S. (2010). Students' use of asynchronous discussions for academic discourse socialization. Distance Education, 31(3), 315-335. doi: 10.1080/01587919.2010.513956

Bedford, J., \& Kitchen, M. (2006). Secondary schools as gatekeepers: The role of ESOL students in placement decisions. TESOLANZ Journal, 14.

Berg, B. L. (2001). Qualitative research methods for the social sciences (4th ed.). MA: Pearson.

Blake, R. J. (2007). New trends in using technology in the language curriculum. Annual Review of Applied Linguistics, 27, 76-97. doi: 10.1017/s0267190508070049

Blake, R. J. (2009). The use of technology for second language distance learning. The Modern Language Journal, 93(Focus Issue).

Blake, R. J. (2011). Current trends in online language learning. Annual Review of Applied Linguistics, 31, 19-35. doi: 10.1017/s026719051100002x

Breakspear, S. (2010). Cultivating a culture of innovation. Australian Educational Leader, $32(2)$.

Brown, H. D. (2007). Principles of language learning and teaching (5th ed.). New York: Pearson Longman.

Brown, J. (1995). The elements of language curriculum: A systematic approach to program development. Boston, MA: Heinle \& Heinle.

Calderon, M., Sanchez, M., \& Slavin, R. (2011). Effective instruction for English learners. The Future of Children, 21, 103+.

Casey, D. M. (2008). A journey to legitimacy: The historical development of distance education through technology. TechTrends, 52(2), 45-51.

Celentin, P. (2007). Online Education: Analysis of interaction and knowledge building patterns among foreign language teachers. Journal of Distance Education, 21(3), 3958.

Chapelle, C. A. (2007). Technology and second language acquisition. Annual Review of Applied Linguistics, 27, 98-114. doi: 10.1017/s0267190508070050

Christie, F. (2000). The language of classroom interaction and learning. In L. Unsworth (Ed.), Research communities: Functional linguistic perspectives. London: Cassell.

Coady, M., Cruz-Davis, J., \& Flores, C. (2008). Personalmente: Home-school communication practices with (im)migrant families in North Florida. Bilingual Research Journal, 31.

Collins Cobuild Advanced Learner's Dictionary. (2003). (4th ed.). Glasgow: HarperCollins.

Compton, L. (2009). Preparing language teachers to teach language online: A look at skills, roles, and responsibilities. Computer Assisted Language Learning, 22(1).

Compton, L., Davis, N., \& Correia, A. (2010). Pre-service teachers' preconceptions, misconceptions, and concerns about virtual schooling. Distance Education, 31(1), 3754. 
Creswell, J. W. (2003). Research design: Quantitative and mixed methods approaches (2nd ed.). California: Sage Publications.

Cummins, J. (2001). HER Classic. Empowering minority students: A framework for intervention. Harvard Educational Review, 71(4).

Cunningham, U., Fägersten, K. B., \& Holmsten, E. (2010). "Can you hear me, Hanoi?" Compensatory mechanisms employed in synchronous net-based English language learning. International Review of Research in Open and Distance Learning, 11(1), 161-177.

de Jong, E. J., \& Harper, C. A. (2005). Preparing mainstream teachers for English-language learners: Is being a good teacher good enough? Teacher Education Quarterly, 32(2), 101-124.

Diaz, L., \& Entonado, F. (2009). Are the functions of teachers in e-learning and face-to-face learning environments really different? Educational Technology \& Society, 12(4).

Dobbs, R. R., Waid, C. A., \& del Carmen, A. (2009). Students' perceptions of online courses: The effect of online course experience. Quarterly Review of Distance Education, $10(1), 9-26,89,91$.

Echevarria, J., \& Vogt, M. (2010). Using the SIOP Model to improve literacy for English learners. New England Reading Association Journal, 46(1).

Edwards, M., Perry, B., \& Janzen, K. (2011). The making of an exemplary online educator. Distance Education, 32(1).

Ellis, N. (2005). At the interface: Dynamic interactions of explicit and implicit language knowledge. Studies in Second Language Acquisition, 27.

Felix, U. (2001). The web's potential for language learning: The student's perspective. ReCALL : The Journal of EUROCALL, 13(1).

Felix, U. (2004). A multivariate analysis of secondary students' experience of web-based language acquisition. ReCALL : The Journal of EUROCALL, 16(1), 237-249.

Felix, U. (2008). The unreasonable effectiveness of CALL: What have we learned in two decades of research? ReCALL : The Journal of EUROCALL, 20(2), 141-161. doi: $10.1017 / \mathrm{s} 0958344008000323$

Fletcher, J., Parkhill, F., \& Harris, C. (2011). Supporting young adolescent students from minority cultural groups who are underachieving in learning. Support for Learning, 26(3), 122-126.

Gaytan, J., \& McEwen, B. C. (2007). Effective online instructional and assessment strategies. The American Journal of Distance Education, 21(3).

Genesee, F., Lindholm-Leary, K., Saunders, W., \& Christian, D. (2005). English language learners in U.S. schools: An overview of research findings. Journal of Education for Students Placed at Risk (JESPAR), 10(4).

Gibbons, P. (2002). Scaffolding Language, Scaffolding Learning. Teaching second language learners in the mainstream classroom. Portsmouth NH: Heinemann.

Gibbons, P. (2007). Mediating academic language learning through classroom discourse. In J. Cummins \& C. Davison (Eds.), International handbook of English language teaching (pp. 701-718). USA: Springer.

Gibbons, P. (2009). English learners, academic literacy and thinking: Learning in the challenge zone. Portsmouth, NH: Heinemann.

Gleeson, M. (2012). "Jack of all trades": The ambiguous role of the ESOL teacher in secondary schools. Tean Journal, 4(2).

Hancock, D. R., \& Algozzine, B. (2006). Doing case study research: A practical guide for beginning researchers. New York: Teachers College Press.

Harper, C. A., \& de Jong, E. J. (2004). Misconceptions about teaching English-language learners. Journal of Adolescent and Adult Literacy, 48(2). 
Harrington, A., M. (2010). Problematizing the hybrid classroom for ESL/EFL students. The Electronic Journal for English as a Second Language, 14(3).

Hauck, M., \& Stickler, U. (2006). What does it take to teach online? CALICO Journal, 23(3), 463-475.

Hawk, K., Cowley, E., Hill, J., \& Sutherland, S. (2002). The importance of the teacher/student relationship for Maori and Pasifika students. Set: Research Information for Teachers, 3.

Ibarz, T., \& Webb, S. (2007). Listening to learners to investigate the viability of technologydriven ESOL pedagogy. Innovation in Language Learning and Teaching, 1(2), 208226.

Ingerham, L. (2012). Interactivity in the online learning environment: A study of users of the North Carolina virtual public school. Quarterly Review of Distance Education, 13(2), 65-75.

Johnson, B., \& Christensen, L. (2008). Educational research: Quantitative, qualitative and mixed approaches (3rd ed.). USA: Sage Publications.

Kaler, C. B. (2012). A model of successful adaptation to online learning for college-bound Native American high school students. Multicultural Education \& Technology Journal, 6(2), 60-76.

Karabenick, S., \& Clemens Noda, P. (2004). Professional development implications of teachers' beliefs and attitudes toward English language learners. Bilingual Research Journal, 28(1).

Keegan, D. (1990). Foundations of distance education (2nd ed.). London: Routledge.

Kisiel, J. (2010). Exploring a school-acquarium collaboration: An intersection of Communities of Practice. Science Education, 94(1), 95-121. doi: 10.1002/sce.20350

Krashen, S. (1982). Principles and practice in second language acquisition. Oxford: Pergamon Press.

Lawlis, T. (2012). Interprofessional education: Higher education health professional attitudes, barriers and enablers. (PhD), University of Canberra. (199204)

Lee, L. (2007). Fostering second language oral communication through constructivist interaction in desktop videoconferencing. Foreign Language Annals, 40(4), 635-649.

Lewis, M. (2001). Communication and authority in ESOL: Teachers, parents and official voices. Australian Language Matters, 9(2).

Lincoln, Y., \& Guba, E. (1985). Naturalistic inquiry. Newbury Park, CA: Sage Publications.

Liu, F., \& Cavanaugh, C. (2011). Success in online high school biology: Factors influencing student academic performance. Quarterly Review of Distance Education, 12(1), 37$54,71-72$.

Lyall, S. (2008). Dialogic teaching: Discussing the theoretical contexts and reviewing evidence from classroom practice. Language and Education, 22(3), 222-240.

Maor, D., \& Volet, V. (2007). Interactivity in professional online learning: A review of research based studies. Australasian Journal of Educational Technology, 23(3).

Mayes, R., Luebeck, J., Ku, H., Akarasriworn, C., \& Korkmaz, Ö. (2011). Themes and strategies for transformative online instruction: A Review of literature and practice. Quarterly Review of Distance Education, 12(3), 151-166,221-222.

Ministry of Education. (2004). ESOL Funding Assessment Guidelines. Wellington: Learning Media.

Ministry of Education. (2005). ESOL Progress Assessment Guidelines. Wellington: Learning Media.

Ministry of Education. (2007). The New Zealand Curriculum for English medium teaching and learning in years 1-13. Wellington: Learning Media. 
Ministry of Education. (2008). The English Language Learning Progressions. Wellington: Learning Media.

Ministry of Education. (2010). The Literacy Learning Progressions. Wellington: Learning Media.

Ministry of Education. (2012). Intensive Wraparound Service: Ministry of Education.

Mitchell, D. (2012). Joined-up: A comprehensive ecological model for working with children with complex needs and their families/whanau. Wellington: Ministry of Education.

Miyazoe, T., \& Anderson, T. (2011). Anonymity in blended learning: Who would you like to be? Journal of Educational Technology \& Society, 14(2), 175-n/a.

Mousavi, S. A. (2009). Multimedia as a test method facet in oral proficiency tests. International Journal of Pedagogies \& Learning, 5(1), 37-48.

Murphy, L., Shelley, M., \& Baumann, U. (2010). Qualities of effective tutors in distance language teaching: Student perceptions. Innovation in Language Learning and Teaching, 4(2), 119-136.

Murugaiah, P., \& Thang, S. (2010). Development of interactive and reflective learning among Malaysian online distant learners: An ESL instructor's experience. International Review of Research in Open and Distance Learning, 11(3).

Mutch, C. (2005). Doing educational research: A practitioner's guide to getting started. Wellington: NZCER Press.

Nandi, D., Hamilton, M., \& Harland, J. (2012). Evaluating the quality of interaction in asynchronous discussion forums in fully online courses. Distance Education, 33(1), 530.

Nation, P., \& Macalister, J. (2010). Language curriculum design. New York \& London: Routledge.

Nunan, D. (2004). Task-based language teaching. Cambridge, UK: Cambridge University Press.

O'Regan, C. (2012). Timetabling. Journal of Higher Education Policy and Management, 34(3), 273-284.

Oliver, K., Kellogg, S., \& Patel, R. (2012). An investigation into reported differences between online foreign language instruction and other subject areas in a virtual school. CALICO Journal, 29(2), 269-n/a.

Oliver, K., Kellogg, S., Townsend, L., \& Brady, K. (2010). Needs of elementary and middle school teachers developing online courses for a virtual school. Distance Education, 31(1), 55-75. doi: 10.1016/s03601315(02)00077-5

Oliver, K., Osborne, J., \& Brady, K. (2009). What are secondary students' expectations for teachers in virtual school environments? Distance Education, 30(1), 23-45.

Oliver, K., Osborne, J., Patel, R., \& Kleiman, G. (2009). Issues surrounding the deployment of a new statewide virtual public school. Quarterly Review of Distance Education, 10(1), 37-49,90-91.

Park, C., \& Son, J. (2009). Implementing computer-assisted language learning in the EFL classroom: Teachers' perceptions and perspectives. International Journal of Pedagogies \& Learning, 5(2), 80-101.

Rice, K. L. (2006). A comprehensive look at distance education in the K-12 context. Journal of Research on Technology in Education, 38(4), 425-448.

Richards, K. (2003). Qualitative inquiry in TESOL. Hampshire: Palgrave McMillan.

St. Amant, K. (2007). Online education in an age of globalization: Foundational perspectives and practices for technical communication instructors and trainers. Technical Communication Quarterly, 16(1), 13-30. 
Tallent-Runnels, M. K., Thomas, J. A., Lan, W. Y., Cooper, S., Ahern, T., Shaw, S., \& Liu, X. (2006). Teaching courses online: A review of the research. Review of Educational Research, 76(1), 93-125.

Thang, S., M. (2005). Investigating Malaysian distance learners' perceptions of their English proficiency courses. Open Learning: The Journal of Open, Distance and e-Learning, 20(3), 243-256.

Ushida, E. (2005). The role of students' attitudes and motivation in second language learning in online language courses. CALICO Journal, 23(1).

Valencia, R. (1997). The evolution of deficit thinking: Educational thought and practice. London: Falmer Press.

Vanderplank, R. (2010). Deja vu? A decade of research on language laboratories, television and video in language learning. Language Teaching, 43(1), 1-37. doi: $10.1017 / \mathrm{s} 0261444809990267$

Vorobel, O., \& Kim, D. (2012). Language teaching at a distance: An overview of research. CALICO Journal, 29(3), 548-n/a.

Vygotsky, L. (1962). Thought and language. Cambridge: MA: MIT Press.

Walqui, A. (2006). Scaffolding instruction for English language learners: A conceptual framework. International Journal of Bilingual Education and Bilingualism, 9(2).

Wenger, E. (2000). Communities of practice and social learning systems. Organization, 7(2), 225-246.

Wette, R. (2009). Making the instructional curriculum as an interactive, contextualized process: Case studies of seven ESOL teachers. Language Teaching Research, 13(4), 337-365.

White, C. (2003). Independent language learning in distance education: Current issues. Paper presented at the Independent learning conference.

White, C. (2006). Distance learning of foreign languages. Language Teaching, 39(4), 247264.

Wong-Fillmore, L., \& Snow, C. (2000). What teachers need to know about language. http://people.ucsc.edu/ ktellez/wong-fill-snow.html

Yin, R., K. (1994). Case study, research design and methods. California: Sage Publications.

Yoon, B. (2008). Uninvited guests: The influence of teachers' roles and pedagogies on the positioning of English language learners in the regular classroom. American Educational Research Journal, 45(2), 495-522.

Young, S. S. C. (2004). In search of online pedagogical models: Investigating a paradigm change in teaching through the School for All community. Journal of Computer Assisted Learning, 20(2), 133-150. doi: 10.1111/j.1365-2729.2004.00073.x

Zhang, T., Gao, T., Ring, G., \& Zhang, W. (2007). Using online discussion forums to assist a traditional English class. International Journal on ELearning, 6(4), 623-643.

Zhu, C. (2012). Student satisfaction, performance, and knowledge construction in online collaborative learning. Journal of Educational Technology \& Society, 15(1), 127-n/a. 


\section{Appendices}

\section{A. Ethics approval \\ 8 March 2013 \\ Annette Tate \\ MEd student \\ Victoria University of Wellington Facu ty of Education \\ C/- School of Educational Psychology and Pedagogy \\ Donald Street \\ Wellington \\ Dear Annette \\ RE: Ethics application SEPP/2012/79 RM 19587}

I am pleased to advise you that your ethics application 'What are the perceptions of participants in an online English language learning progremme?', with the required changes, has been approved by the Victoria University of Wellington Faculty of Education Ethics Committee. Please note that the approval for your research to commence is from the date of this letter.

Best wishes for your research.

Yours Sincerely

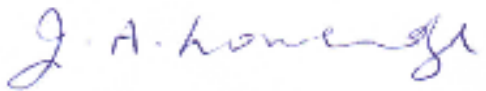

Dr Judith Loveridge

Co-Convener

Victoria Universily of Wellington Faculty of Education Ethics Comınittee 


\section{B. Information sheets and consent forms}

What are the perceptions of stakeholders of an online ESOL programme?: The case of one Intermediate school in New Zealand.

- What do school staff perceive as facilitators and barriers to English language learning in an online ESOL programme?

- What do students and families perceive as facilitators and barriers to English language learning in an online ESOL programme?

Index

Page 2 Information sheet for the school principal/deputy principal

Page 4 Consent form for the school principal/deputy principal

Page 6 Information sheet for the eTutor

Page 8 Consent form for the eTutor

Page 10 Information sheet for the class teachers

Page 12 Consent form for the class teachers

Page 14 Information sheet for the eCoordinator

Page 16 Consent form for the eCoordinator

Page 18 Information sheet for the school ICT teacher

Page 20 Consent form for the school ICT teacher

Page 22 Information sheet for the eTeacher (offsite)

Page 24 Consent form for the eTeacher (offsite)

Page 26 Information sheet for the parents/caregivers

Page 28 Consent form for the parents/caregivers (their own participation)

Page 30 Consent form for the parents/caregivers (their child's participation)

Page 32 Information sheet for the students

Page 34 Consent form for the students 


\section{Victoria \\ Ti: Whare Wananga - te Trpoko o te Ika a Mäut

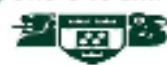

What are the perceptions of stakeholders of an online ESOL programme?: The case of one Intermediate school in New Zealand.

- What do school staff perceive as facilitators and barriers to English language learning in an online ESOL programme?

- What do students and families perceive as facilitators and barriers to English language learning in an online ESOL programme?

1/ Information sheet for school principal/deputy principal

Researcher: Annette Tate: School of Psychology and Pedagogy, Victoria University of Wellington.

Dear principal/deputy principal,

I am undertaking research for my Masters degree in Education at Victoria University of Wellington. I would like to invite you and the staff, students and families associated with the ELLINZ (English Language Learning in New Zealand) online programme in your school to participate in a case study because yours is a school that has adopted the ELIINZ online programme to meet the needs of your English language learners.

This research would involve me visiting your school for one three week period. During this time I would like to interview those directly or indirectly involved in the ELLINZ online programme. These interviews would take approximately 30-45 minutes. I anticipate interviews will be held during the month of June, either during school hours or after school; at a time that suits the participants. Interviews will probably be held at the school, although I may visit the students' homes to interview the parents/caregivers, if that is their preference. I would like to interview you, as principal and deputy principal, the eTutor, the class teachers, the eCoordinator and the school ICT teacher. I would also like to do a group interview with the students from the ELLINZ online programme, a short individual interview with the students and interview their parents/caregivers. These interviews will be semi-structured with some questions and prompts, but also will follow the lead of the interviewee/s. I have attached a schedule of questions. Interviews will be recorded and transcribed for later analysis. Transcriptions of the interviews will be returned to the adult participants to check that their perceptions have been interpreted accurately and fairly reported. Participants will be given the opportunity to change or remove any information at this stage, also. Participants will also be given a summary of findings if they wish. 
The information gathered will form the basis of my research. The data will be kept securely in a locked file or password protected electronic file. The school and individual staff will not be identified in the research or in subsequent reports or presentations resulting from this research. The name, location or any identifying features of the school will not be revealed. The thesis will be submitted for marking to the School of Psychology and Pedagogy and deposited in the University library, and findings may be used at conferences or in academic articles.

The Victoria University of Wellington Faculty of Education Human Ethics Committee requires that permission be granted by participants before any research is undertaken. Participation is voluntary and participants may withdraw from the research without question at any stage up until the time data analysis is completed (September 2013).

It is hoped this research will yield insights to the programme as a whole and help shape future directions to better cater for our English language learners in an online environment.

This research has been assessed and approved by Victoria University Faculty of Education Ethics Committee.

If you have any questions or would like to receive more information about this research please contact my supervisors or me.

Annette Tate (Student)

tateanne $a$ myvuw.ac.nz

Phone 034543565

Dr Carolyn Tait (Primary supervisor)

Carolyn.taitavuw.ac.nz

Senior Lecturer, School of Educational Psychology and Pedagogy Phone 044639563

Dr Margaret Gleeson (Secondary supervisor) Margaret.gleeson@vuw.ac.nz

Senior Lecturer, School of Educational Psychology and Pedagogy

Phone 044639590

If you have any concerns about the conduct of this research please contact the Chair of the Human Ethics Committee, Allison Kirkman Allisonkirkman@vuw.ac.nz

Regards

Annette Tate 


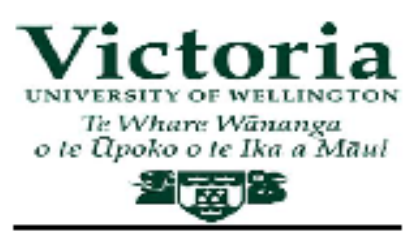

What are the perceptions of stakeholders of an online ESOL programme?: The case of one Intermediate school in New Zealand.

- What do school staff perceive as facilitators and barriers to English language learning in an online ESOL programme?

- What do students and families perceive as facilitators and barriers to English language learning in an online ESOL programme?

\section{Consent form (principal/deputy principal)}

Name:

Please tick the boxes to signal your agreement

I give permission for Annette Tate to invite participants for this research.

I understand participation in this research is voluntary.

I agree to be interviewed.

I agree to have the interview sound recorded.

I have been given information about this research and I have had an opportunity to have my questions answered.

I understand the name or location of the school will not be identified.

I understand that I will not be identified by name.

I understand that the information from this research will be stored in a secure site.

I understand that I may withdraw from this project at any stage up until when data analysis is completed (September 2013).

I understand that the findings may be reported in a journal article and/or at a conference but the school's identity and my identity will be confidential. 
I give informed consent for Annette Tate to use the information I provide for her study.

I would like to receive a summary of the findings of this study via email/surface mail/public meeting (Please circle preferred option)

I would like to receive a summary of the findings of this study via email. My email address is

$\square$ I would like to receive a summary of the findings of this study via surface mail. My address is

Signed 


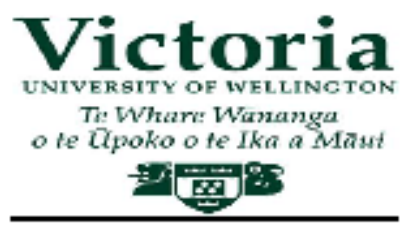

What are the perceptions of stakeholders of an online ESOL programme?: The case of one Intermediate school in New Zealand.

- What do school staff perceive as facilitators and barriers to English language learning in an online ESOL programme?

- What do students and families perceive as facilitators and barriers to English language learning in an online ESOL programme?

2/ Information sheet for the eTutor

Researcher: Annette Tate: School of Psychology and Pedagogy, Victoria University of Wellington.

Dear eTutor,

I am undertaking research for my Masters in Education at Victoria University of Wellington. I would like to do a case study on your school because yours is a school that has adopted the ELLINZ (English Language Learning in New Zealand) online programme to meet the needs of your English language learners. The ELLINZ online overseeing principal and the principal of your school have given permission for your school to participate in this research.

This research would involve me visiting your school for one three week period. During this time I would like to invite you to participate in an interview. The interview would take approximately 30-45 minutes. I anticipate interviews will be held during the month of June, either during school hours or after school; at a time that suits you. Interviews will probably be held at the school, although I may visit the students' homes to interview the parents/caregivers, if that is their preference. I will ask your assistance, along with the mainstream teachers to invite the parents/caregivers along to school for a meeting to explain the study. I will also interview the principal, class teachers, eCoordinator and school ICT teacher. In addition I would like to do a group interview with the students, a short individual interview with the students and interview their parents/caregivers. These interviews will be semi structured with some questions and prompts, but also will follow the lead of the interviewee/s. I attach a schedule of questions to be asked. Interviews will be recorded and transcribed. Transcriptions of the interviews will be returned to you to check that your perceptions have been interpreted accurately and fairly reported. You will be given the opportunity to change or remove any information at this stage, also. 
The information gathered by interviews and observations will form the basis of my research and will be kept confidential. The data will be kept securely in a locked file or password protected electronic file. You and your school will not be identified in the research or in subsequent reports or presentations resulting from this research. You will be given a pseudonym. The name, location or any identifying features of the school will not be revealed. The thesis will be submitted for marking to the School of Psychology and Pedagogy and deposited in the University library, and findings may be used at conferences or in academic articles.

The Victoria University of Wellington Faculty of Education Human Ethics Committee requires that permission be granted by participants before any research is undertaken. Participation is voluntary and participants may withdraw from the research without question at any stage up until the time data analysis is completed (September 2013).

It is hoped this research will yield insights to the programme as a whole and help shape future directions to better cater for our English language learners in an online environment.

This research has been assessed and approved by Victoria University Faculty of Education Ethics Committee.

If you have any questions or would like to receive more information about this research please contact my supervisors or me.

Annette Tate (Student) tateanne: 0 myvuw ac.nz

Phone 034543565

Dr Carolyn Tait (Primary supervisor)

Carolyn.tait@uww.ac.nz

Senior Lecturer, School of Educational Psychology and Pedagogy Phone 044639563

Dr Margaret Gleeson (Secondary supervisor) Margaret.gleeson@uxuw.ac.nz

Senior Lecturer, School of Educational Psychology and Pedagogy Phone 044639590

If you have any concerns about the conduct of this research please contact the Chair of the Human Ethics Committee, Allison Kirkman Allison kirkman@vuw.ac.nz

Regards

Annette Tate 


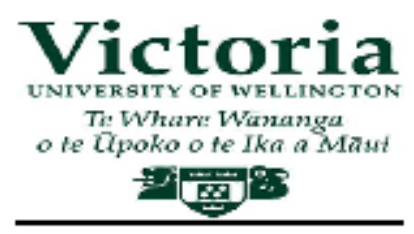

What are the perceptions of stakeholders of an online ESOL programme?: The case of one Intermediate school in New Zealand.

- What do school staff perceive as facilitators and barriers to English language learning in an online ESOL programme?

- What do students and families perceive as facilitators and barriers to English language learning in an online ESOL programme?

\section{Consent form (eTutor)}

Name:

Please tick the boxes to signal your agreement

I understand participation in this research is voluntary.

I agree to be interviewed.

I agree to have the interview sound recorded.

I have been given information about this research and I have had an opportunity to have my questions answered.

I understand the identity or location of the school will not be identified.

I understand that I will not be identified by name.

I understand that the information from this research will be stored in a secure way.

I understand that I may withdraw from this project at any stage up until when data analysis is completed (September 2013).

I understand that the findings may be reported in a journal article and/or at a conference but the school's identity and my identity will be confidential.

I give informed consent for Annette Tate to use the information I provide to inform her 
study.

I would like to receive a summary of the findings of this study via email/surface mail/public meeting (Please circle preferred option)

I would like to receive a summary of the findings of this study via email. My email address is

I would like to receive a summary of the findings of this study via surface mail. My address is

Signed 


\section{Victoria \\ Ti: Whare Wananga o te apoko o te Ika a Mast 분풍}

What are the perceptions of stakeholders of an online ESOL programme?: The case of one Intermediate school in New Zealand.

- What do school staff perceive as facilitators and barriers to English language leaming in an online ESOL programme?

- What do students and families perceive as facilitators and barriers to English language learning in an online ESOL programme?

3/ Information sheet for the class teachers

Researcher. Annette Tate: School of Psychology and Pedagogy, Victoria University of Wellington.

Dear class teachers,

I am undertaking research for my Masters in Education at Victoria University of Wellington. I would like to do a case study on your school because yours is a school that has adopted the ELLINZ (English Language Learning in New Zealand) online programme to meet the needs of your English language learners. The ELLINZ online overseeing principal and the principal of your school have given permission for your school to participate in this research.

This research would involve me visiting your school for one three week period. During this time I would like to invite you to participate in an interview. I am interested in your perceptions of teaching and learning English as a second language in an online environment from the perspective of a mainstream teacher who teaches students who attend this programme. The interview would take approximately $30-45$ minutes. I anticipate interviews will be held during the month of June, either during school hours or after school; at a time that suits the participants. Interviews will probably be held at the school, although I may visit the students' homes to interview the parents/caregivers, if that is their preference. I will ask your assistance, along with the eTutor, to invite the parents/caregivers along to school for a meeting to explain the study. I will also interview the principal, eTutor, eCoordinator and school ICT teacher. In addition I would like to do a group interview with the students, a short individual interview with the students and interview their parents/caregivers. These interviews will be semi structured with some questions and prompts, but also will follow the lead of the interviewee/s. I attach a schedule of questions to be asked. Interviews will be recorded and transcribed for later analysis. Transcriptions of the interviews will be returned 
to you to check that your perceptions have been interpreted accurately and fairly reported. You will be given the opportunity to change or remove any information at this stage, also.

The information gathered will form the basis of my research and will be kept confidential. The data will be kept securely in a locked file or password protected electronic file. The school and individual staff will not be identified in the research or in subsequent reports or presentations resulting from this research. The name, location or any identifying features of the school will not be revealed. You will be given a pseudonym. The thesis will be submitted for marking to the School of Psychology and Pedagogy and deposited in the University library, and findings may be used at conferences or in academic articles.

The Victoria University of Wellington Faculty of Education Human Ethics Committee requires that permission be granted by participants before any research is undertaken. Participation is voluntary and participants may withdraw from the research without question at any stage up until the time data analysis is completed (September 2013).

It is hoped this research will yield insights to the programme as a whole and help shape future directions to better cater for our English language learners in an online environment.

This research has been assessed and approved by Victoria University Faculty of Education Ethics Committee.

If you have any questions or would like to receive more information about this research please contact my supervisors or me.

Annette Tate (Student) tateanne@amyvuw.ac.nz

Phone 034543565

Dr Carolyn Tait (Primary supervisor)

Carolyn.tait@vuw.ac.nz

Senior Lecturer, School of Educational Psychology and Pedagogy Phone 044639563

Dr Margaret Gleeson (Secondary supervisor) Margaret.gleeson@uw.ac.nz

Senior Lecturer, School of Educational Psychology and Pedagogy Phone 044639590

If you have any concerns about the conduct of this research please contact the Chair of the Human Ethics Committee, Allison Kirkman Allison kirkman@ @vuw.ac.nz

Regards

Annette Tate 


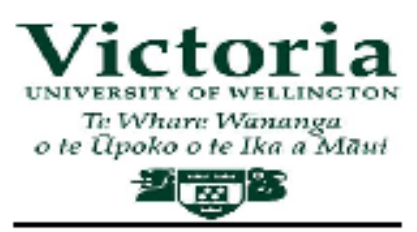

What are the perceptions of stakeholders of an online ESOL programme?: The case of one Intermediate school in New Zealand.

- What do school staff perceive as facilitators and barriers to English language learning in an online ESOL programme?

- What do students and families perceive as facilitators and barriers to English language learning in an online ESOL programme?

\section{$\underline{\text { Consent form (class teachers) }}$}

Name:

Please tick the box to signal your agreement

I understand participation in this research is voluntary.

I agree to be interviewed.

I agree to have the interview sound recorded.

I have been given information about this research and I have had an opportunity to have my questions answered.

I understand the identity or location of the school will not be identified.

I understand that I will not be identified by name.

I understand that the information from this research will be stored in a secure site.

I understand that I may withdraw from this project at any stage up until when data analysis is completed (September 2013).

I understand that the findings may be reported in a journal article and/or at a conference but the school's identity and my identity will be confidential.

I give informed consent for Annette Tate to use the information I provide to inform her 
study.

I would like to receive a summary of the findings of this study via email/surface mail/public meeting (Please circle preferred option)

I would like to receive a summary of the findings of this study via email. My email address is

I would like to receive a summary of the findings of this study via surface mail. My address is

Signed 


\section{Victoria \\ Ti: Whare Wananga o te apoko o te Ika a Mast ॠ西早}

What are the perceptions of stakeholders of an online ESOL programme?: The case of one Intermediate school in New Zealand.

- What do school staff perceive as facilitators and barriers to English language learning in an online ESOL programme?

- What do students and families perceive as facilitators and barriers to English language learning in an online ESOL programme?

4/ Information sheet for the eCoordinator

Researcher: Annette Tate: School of Psychology and Pedagogy, Victoria University of Wellington.

Dear eCoordinator,

I am undertaking research for my Masters in Education at Victoria University of Wellington. I would like to do a case study on your school because yours is a school that has adopted the ELIINZ (English Language Learning in New Zealand) online programme to meet the needs of your English language learners. The ELLINZ online overseeing principal and the principal of your school have given permission for your school to participate in this research.

This research would involve me visiting your school for one three week period. During this time I would like to invite you to participate in an interview. I am interested in your perceptions of teaching and learning English as a second language in an online environment from the perspective of a teacher who is in the eCoordinator's role. The interview would take approximately 30-45 minutes. I anticipate interviews will be held during the month of June, either during school hours or after school; at a time that suits the participants. Interviews will probably be held at the school, although I may visit the students' homes to interview the parents/caregivers, if that is their preference. I will also interview the principal, class teacher, eTutor and school ICT teacher. In addition I would like to do a group interview with the students, a short individual interview with the students and interview their parents/caregivers. These interviews will be semi structured with some questions and prompts, but also will follow the lead of the interviewee/s. I attach a schedule of questions to be asked. Interviews will be recorded and transcribed. 
Transcriptions of the interviews will be returned to you to check that your perceptions have been interpreted accurately and fairly reported. You will be given the opportunity to change or remove any information at this stage, also. The information gathered will form the basis of my research and will be kept confidential. The data will be kept securely in a locked file or password protected electronic file. You and your school will not be identified in the research or in subsequent reports or presentations resulting from this research. The name, location or any identifying features of the school will not be revealed. The thesis will be submitted for marking to the School of Psychology and Pedagogy and deposited in the University library, and findings may be used at conferences or in academic articles.

The Victoria University of Wellington Faculty of Education Human Ethics Committee requires that permission be granted by participants before any research is undertaken. Participation is voluntary and participants may withdraw from the research without question at any stage up until the time data analysis is completed (September 2013).

It is hoped this research will yield insights to the programme as a whole and help shape future directions to better cater for our English language learners in an online environment.

This research has been assessed and approved by Victoria University Faculty of Education Ethics Committee.

If you have any questions or would like to receive more information about this research please contact my supervisors or me.

Annette Tate (Student)

tateanne $a$ myvuw.ac.nz

Phone 034543565

Dr Carolyn Tait (Primary supervisor)

Carolyn.tait@yuw.ac.nz

Senior Lecturer, School of Educational Psychology and Pedagogy Phone 044639563

Dr Margaret Gleeson (Secondary supervisor) Margaret.gleeson@vuw.ac.nz

Senior Lecturer, School of Educational Psychology and Pedagogy Phone 044639590

If you have any concerns about the conduct of this research please contact the Chair of the Human Ethics Committee, Allison Kirkman Allison kirkman @ vuw.ac.nz

Regards

Annette Tate 


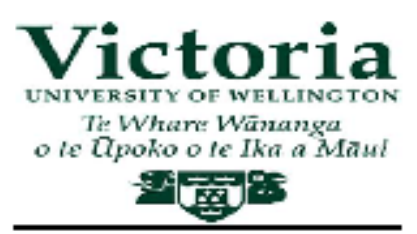

What are the perceptions of stakeholders of an online ESOL programme?: The case of one Intermediate school in New Zealand.

- What do school staff perceive as facilitators and barriers to English language learning in an online ESOL programme?

- What do students and families perceive as facilitators and barriers to English language learning in an online ESOL programme?

\section{Consent form (eCoordinator)}

\section{Name:}

Please tick the box to signal your agreement

I understand participation in this research is voluntary.

I agree to be interviewed.

I agree to have the interview sound recorded.

I have been given information about this research and I have had an opportunity to have my questions answered.

I understand the identity or location of the school will not be identified.

I understand that I will not be identified by name.

I understand that the information from this research will be stored in a secure way.

I understand that I may withdraw from this project at any stage up until when data analysis is completed (September 2013).

I understand that the findings may be reported in a journal article and/or at a conference 
but the school's and my identity will be confidential.

I give informed consent for Annette Tate to use the information I provide to inform her study.

I would like to receive a summary of the findings of this study via email/surface mail/public meeting (Please circle preferred option)

$\square$ I would like to receive a summary of the findings of this study via email. My email address is

$\square$ I would like to receive a summary of the findings of this study via surface mail. My address is

Signed 


\section{Victoria \\ Ti: Whare Wananga o te apoko o te Ika a Mast

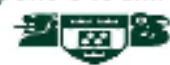

What are the perceptions of stakeholders of an online ESOL programme?: The case of one Intermediate school in New Zealand.

- What do school staff perceive as facilitators and barriers to English language leaming in an online ESOL programme?

- What do students and families perceive as facilitators and barriers to English language learning in an online ESOL programme?

5/ Information sheet for the school ICT teacher

Researcher: Annette Tate: School of Psychology and Pedagogy, Victoria University of Wellington.

Dear school ICT teacher,

I am undertaking research for my Masters in Education at Victoria University of Wellington. I would like to do a case study on your school because yours is a school that has adopted the ELLINZ (English Language Learning in New Zealand) online programme to meet the needs of your English language learners. The ELLINZ online overseeing principal and the principal of your school have given permission for your school to participate in this research.

This research would involve me visiting your school for one three week period. During this time I would like to invite you to participate in an interview. I am interested in your perceptions of teaching and learning English as a second language in an online environment from the perspective of the ICT teacher. The interview would take approximately $30-45$ minutes. I anticipate interviews will be held during the month of June, either during school hours or after school; at a time that suits the participants. Interviews will probably be held at the school, although I may visit the students' homes to interview the parents/caregivers, if that is their preference. I will also interview the principal, class teachers, eTutor and eCoordinator. In addition I would like to do a group interview with the students, a short individual interview with the students and interview their parents/caregivers. These interviews will be semi structured with some questions and prompts, but also will follow the lead of the interviewee/s. I have attached a schedule of questions to be asked. Interviews will be recorded and transcribed.

Transcriptions of the interviews will be returned to you to check that your perceptions have been interpreted accurately and fairly reported. You will be given the opportunity to change 
or remove any information at this stage, also. The information gathered will form the basis of my research and will be kept confidential. The data will be kept securely in a locked file or password protected electronic file. You and your school will not be identified in the research or in subsequent reports or presentations resulting from this research. You will be given a pseudonym. The name, location or any identifying features of the school will not be revealed. The thesis will be submitted for marking to the School of Psychology and Pedagogy and deposited in the University library, and findings may be used at conferences or in academic articles.

The Victoria University of Wellington Faculty of Education Human Ethics Committee requires that permission be granted by participants before any research is undertaken. Participation is voluntary and participants may withdraw from the research without question at any stage up until the time data analysis is completed (September 2013).

It is hoped this research will yield insights to the programme as a whole and help shape future directions to better cater for our English language learners in an online environment.

This research has been assessed and approved by Victoria University Faculty of Education Ethics Committee.

If you have any questions or would like to receive more information about this research please contact my supervisors or me.

Annette Tate (Student)

tateanne@omyuw.ac.nz

Phone 034543565

Dr Carolyn Tait (Primary supervisor)

Carolyn.tait@vuw.ac.nz

Senior Lecturer, School of Educational Psychology and Pedagogy Phone 044639563

Dr Margaret Gleeson (Secondary supervisor) Margaret.gleeson@uwu.ac.nz

Senior Lecturer, School of Educational Psychology and Pedagogy Phone 044639590

If you have any concerns about the conduct of this research please contact the Chair of the Human Ethics Committee, Allison Kirkman Allison kirkman@vuw.ac.nz

Regards

Annette Tate 


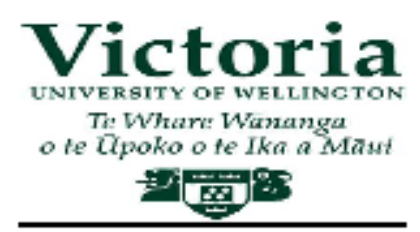

What are the perceptions of stakeholders of an online ESOL programme?: The case of one Intermediate school in New Zealand.

- What do school staff perceive as facilitators and barriers to English language learning in an online ESOL programme?

- What do students and families perceive as facilitators and barriers to English language learning in an online ESOL programme?

\section{Consent form (school ICT teacher)}

\section{Name:}

Please tick the box to signal your agreement

7 I understand participation in this research is voluntary.

I agree to be interviewed.

I agree to have the interview sound recorded.

I have been given information about this research and I have had an opportunity to have my questions answered.

I understand the identity or location of the school will not be identified.

I understand that I will not be identified by name.

I understand that the information from this research will be stored in a secure way.

I understand that I may withdraw from this project at any stage up until when data analysis is completed (September 2013).

$\square$ I understand that the findings may be reported in a journal article and/or at a conference but the school's and my identity will be confidential.

I give informed consent for Annette Tate to use the information I provide to inform her study. 
I would like to receive a summary of the findings of this study via email/surface mail/public meeting (Please circle preferred option)

I would like to receive a summary of the findings of this study via email. My email address is

I would like to receive a summary of the findings of this study via surface mail. My address is

Signed 


\section{Victoria \\ Ti: Whare Wananga - te Tipoko o te Ika a Mánt 풀}

What are the perceptions of stakeholders of an online ESOL programme?: The case of one Intermediate school in New Zealand.

- What do school staff perceive as facilitators and barriers to English language leaming in an online ESOL programme?

- What do students and families perceive as facilitators and barriers to English language learning in an online ESOL programme?

6/ Information sheet for eTeacher (offsite)

Researcher. Annette Tate: School of Psychology and Pedagogy, Victoria University of Wellington.

Dear eTeacher,

I am undertaking research for my Masters in Education at Victoria University of Wellington. I would like to invite you to participate in a case study of one of the schools in which you teach online. The ELIINZ online overseeing principal and the principal of your school have given permission for Central school (pseudonym) to participate in this research.

I would like to interview those directly and indirectly involved in the ELLINZ online programme. I would like to invite you to participate in an interview, as the eTeacher, either via skype or in person. I also plan to interview the principal, the eTutor, class teachers, eCoordinator and school ICT teacher. In addition I plan to do a group interview with the students, a short individual interview with the students and interview their parents/caregivers. These interviews will be semi structured with some questions and prompts, but also will follow the lead of the interviewee/s. I anticipate interviews will take approximately $30-45$ minutes and I attach a schedule of questions to be asked. I anticipate interviews will be held during the month of June, either during school hours or after school; at a time that suits the participants. Interviews will probably be held at the school, although I may visit the students' homes to interview the parents/caregivers, if that is their preference. Interviews will be recorded and transcribed for later analysis. Transcriptions of the interviews will be returned to you to check that your perceptions have been interpreted accurately and fairly reported. You will be given the opportunity to change or remove any information at this stage, also. The information gathered will form the basis of my research and will be kept confidential. The data will be kept securely in a locked file or password protected electronic file. The school and individual staff will not be identified in the research or in subsequent reports or 
presentations resulting from this research. The name, location or any identifying features of the school will not be revealed. The thesis will be submitted for marking to the School of Psychology and Pedagogy and deposited in the University library, and findings may be used at conferences or in academic articles.

The Victoria University of Wellington Faculty of Education Human Ethics Committee requires that permission be granted by participants before any research is undertaken. Participation is voluntary and participants may withdraw from the research without question at any stage up until the time data analysis is completed (September 2013).

It is hoped this research will yield insights to the programme as a whole and help shape future directions to better cater for our English language learners in an online environment.

This research has been assessed and approved by Victoria University Faculty of Education Ethics Committee

If you have any questions or would like to receive more information about this research please contact my supervisors or me.

Annette Tate (Student)

tateanne $a$ myvuw.ac.nz

Phone 034543565

Dr Carolyn Tait (Primary supervisor)

Carolyn.tait@vuw.ac.nz

Senior Lecturer, School of Educational Psychology and Pedagogy Phone 044639563

Dr Margaret Gleeson (Secondary supervisor) $\quad$ Margaret.gleeson@avuw.ac.nz

Senior Lecturer, School of Educational Psychology and Pedagogy Phone 044639590

If you have any concerns about the conduct of this research please contact the Chair of the Human Ethics Committee, Allison Kirkman Allison kirkman $@$ vuw.ac.nz

Regards

Annette Tate 


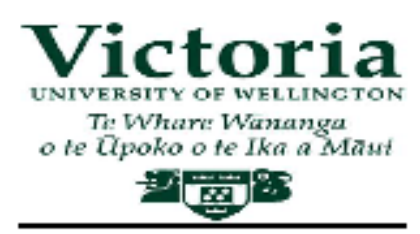

What are the perceptions of stakeholders of an online ESOL programme?: The case of one Intermediate school in New Zealand.

- What do school staff perceive as facilitators and barriers to English language learning in an online ESOL programme?

- What do students and families perceive as facilitators and barriers to English language learning in an online ESOL programme?

\section{$\underline{\text { Consent form (eTeacher offsite) }}$}

Name:

Please tick the box to signal your agreement

7 I understand participation in this research is voluntary.

I agree to be interviewed.

I agree to have the interview sound recorded.

I have been given information about this research and I have had an opportunity to have my questions answered.

I understand the identity or location of the school will not be identified.

I understand that I will not be identified by name.

I understand that the information from this research will be stored in a secure way.

I understand that I may withdraw from this project at any stage up until when data analysis is completed (September 2013).

$\square$ I understand that the findings may be reported in a journal article and/or at a conference but the school's and my identity will be confidential.

I give informed consent for Annette Tate to use the information I provide to inform her study. 
I would like to receive a summary of the findings of this study via email/surface mail/public meeting (Please circle preferred option).

I would like to receive a summary of the findings of this study via email. My email address is

I would like to receive a summary of the findings of this study via surface mail. My address is

Signed 


\section{Victoria \\ Ti: Whare Wamanga \\ - te Qpoko o te Ika a Mäut

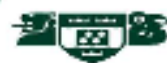

What are the perceptions of stakeholders of an online ESOL programme?: The case of one Intermediate school in New Zealand.

- What do school staff perceive as facilitators and barriers to English language learning in an online ESOL programme?

- What do students and families perceive as facilitators and barriers to English language learning in an online ESOL programme?

7/ Information sheet for parents/caregivers

What do parents/caregivers think?

Dear parents/caregivers,

My name is Annette Tate and I am a Master of Education student at Victoria University of Wellington.

Your child, is studying ESOL online at school. That means he or she is learning English using the intemet and computers.

I am interested in learning what school staff, parents and their children think about this way of learning English. I would like to invite your child to be a part of this study. If you agree this means that I will interview your child as part of a group. I want to talk to your child by himself or herself for a short time of about 15 minutes too. These interviews will be sound recorded.

I would also like to invite you to talk to me (either one or both parents or caregivers) about what you think. The information you give may help teachers improve the way we work with students who are learning English. The interview would last for 30-45 minutes and you could choose the time and whether you want to talk to me at your home or at the school. I plan to do the interviews in June. I will record the interview so I can remember what you say.

It is your choice whether you and your child want to be part of this study. It is OK if you choose not to talk to me. If you do choose to talk to me, your ideas and your child's ideas will be confidential. You will be given another name when I write my research. That means no one except my supervisors (teachers) and myself will know what you have said. Everything you say will be kept in a secure place such as a locked drawer or a password protected computer file. You may like to invite an interpreter along to our talk to help us understand 
each other. You may change your mind about being interviewed and having your information reported at any time up to when I finish analysing my information (September 2013).

Whether you or your child participates in this study or not will not affect how well they do at school or their involvement in the programme.

The ELLINZ online overseeing principal and the principal of your school have given permission for your school to participate in this research

This research has been assessed and approved by Victoria University Faculty of Education Ethics Committee.

If you have any questions or would like to receive more information about this research please contact my supervisors or me.

Annette Tate (Student) tateanne@myvuw.ac.nz

Phone 034543565

Dr Carolyn Tait (Number 1 supervisor) Carolvn.tait@avuw.ac.nz

Senior Lecturer, School of Educational Psychology and Pedagogy

Phone 044639563

Dr Margaret Gleeson (Number 2 supervisor) Margaret.gleeson@avuw.ac.nz

Senior Lecturer, School of Educational Psychology and Pedagogy

Phone 044639590

If you have any concerns about this research please contact the Chair of the Human Ethics Committee, Allison Kirkman Allison kirkman@vuw.ac.nz

Regards

Annette Tate 


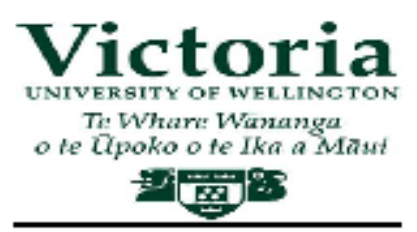

What are the perceptions of stakeholders of an online ESOL programme?: The case of one Intermediate school in New Zealand.

- What do school staff perceive as facilitators and barriers to English language learning in an online ESOL programme?

- What do students and families perceive as facilitators and barriers to English language learning in an online ESOL programme?

\section{Consent form (Parents/caregivers for their own participation)}

Name of parent/caregiver: Name of student:

Please tick each box to show you understand and agree

I understand participation in this research is voluntary.

I agree to be interviewed.

I agree to have the interview sound recorded.

I have been given information about this study and I have had an opportunity to ask questions about it.

I understand the identity or location of the school will not be identified.

I understand that my child and I will not be identified by name.

I understand that the information from this study will be stored in a secure place.

I understand that I may change my mind about talking about online English language learning at any stage up until when the information is studied (September 2013).

I understand that the information gained from this study may be reported in a journal article and/or at a conference but the school's and my child's identity will be confidential. I give informed consent for Annette Tate to use the information I provide to help her study. 
I would like to receive a summary of the findings of this study via email/surface mail/public meeting (Please circle preferred way)

I would like to receive a summary of the findings of this study via email. My email address is

I would like to receive a summary of the findings of this study via surface mail. My address is

(Signed) 


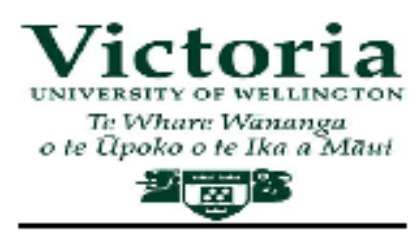

What are the perceptions of stakeholders of an online ESOL programme?: The case of one Intermediate school in New Zealand.

- What do school staff perceive as facilitators and barriers to English language learning in an online ESOL programme?

- What do students and families perceive as facilitators and barriers to English language learning in an online ESOL programme?

\section{Consent form (Parents/caregivers for their child's participation)}

Name of parent/caregiver. Name of student:

Please tick each box to show you understand and agree

I understand participation in this research is voluntary.

I agree to allow my child to be interviewed.

I agree to allow my child's interview to be sound recorded.

I have been given information about this study and I have had an opportunity to ask questions about it.

I understand the identity or location of the school will not be identified.

I understand that my child and I will not be identified by name.

I understand that the information from this study will be stored in a secure place.

I understand that I may change my mind about talking about online English language leaming at any stage up until when the information is studied (September 2013).

I understand that the information gained from this study may be reported in a journal article and/or at a conference but the school's and my child's identity will be confidential.

I give informed consent for Annette Tate to use the information my child provides to help her study. 
I would like to receive a summary of the findings of this study via email/surface mail/public meeting (Please circle preferred way)

I would like to receive a summary of the findings of this study via email. My email address is

I would like to receive a summary of the findings of this study via surface mail. My address is

(Signed) 


\section{Victoria \\ Ti: Whare Wananga \\ o te apoko o te Ika a Mast \\ 뉴뭉}

What are the perceptions of stakeholders of an online ESOL programme?: The case of one Intermediate school in New Zealand.

- What do school staff perceive as facilitators and barriers to English language learning in an online ESOL programme?

- What do students and families perceive as facilitators and barriers to English language learning in an online ESOL programme?

\section{8/ Information sheet for students}

What do students think?

My name is Annette Tate and I am a student at Victoria University of Wellington.

You are studying ESOL online at school in your ELLINZ online lessons. I want to know what you think about ELLINZ online and learning English online using computers. I would like to invite you to talk to me about what you think.

What you think may help teachers improve the way we work with other students who are learning English. I want to have a group interview (talk) with all of the ELLINZ online students together in June this year. We will talk in school time or during a lunch time in one of the classrooms. The talk would last for about 30 minutes. I also want to talk with you by yourself for about 15 minutes. I will record the interviews so I can remember what everyone says.

It is your choice whether you want to talk to me or not. It is OK if you do not want to talk to me. Your ideas and opinions will be confidential. That means no one except my supervisors (teachers) and myself will know what you have said. You may change your mind about being involved at any time during the study up until when I have studied what everybody says. If you change your mind, please just tell your teacher or me. Whether you choose to talk to me or not will not affect how well you do at school.

Your school has said I am allowed to do this study.

These are the names of my supervisors, or my teachers from the university. If you want to you can email them or email me and ask questions. You can ask me questions when I come to school, too. 
Annette Tate (Student)

Phone 034543565

Dr Carolyn Tait (Number 1 supervisor)

Phone 044639563

Dr Margaret Gleeson (Number 2 supervisor)

Phone 044639590 tateanne@myvuw.ac.nz

\section{Carolyn.tait@usuw.ac.nz}

Margaret.gleeson@vuw.ac.nz

language learning please sign the permission slip/paper and give it to your eTutor or Annette 


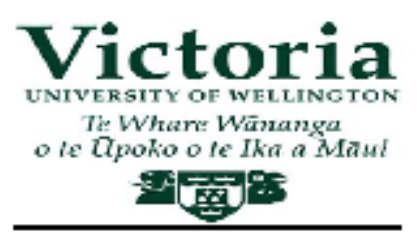

What are the perceptions of stakeholders of an online ESOL programme?: The case of one Intermediate school in New Zealand.

- What do school staff perceive as facilitators and barriers to English language learning in an online ESOL programme?

- What do students and families perceive as facilitators and barriers to English language learning in an online ESOL programme?

\section{$\underline{\text { Consent form (Students) }}$}

Name:

Please tick each box to show you understand and agree.

I know I can choose if I want to talk about online English language learning or not.

I am okay about talking with Annette Tate about online English language learning.

I am okay about talking with the other ELIINZ online students about online English language learning.

I am okay about Annette recording what I say.

If I change my mind about talking to Annette, I can tell my eTutor or Annette.

I have discussed this with my parents.

(signed) 


\section{Explanation of the ELLP}

The English Language Learning Progressions (ELLP) are a set of booklets published by the New Zealand Ministry of Education. They enable a teacher to track ELLs' development on matrices for listening, speaking, reading and writing from Years 1-13. The matrices within the ELLP outline the typical developmental stages an English language learner is likely to go through, and suggest next learning steps. The ELLP also contains information to assist teachers to select content, vocabulary and tasks suitable to ELLs' English language learning needs. 


\section{Interview questions}

What are the perceptions of stakeholders of an online ESOL programme?: The case of one intermediate school in New Zealand.

- What do school staff perceive as facilitators and barriers to English language learning in an online ESOL programme?

- What do students and families perceive as facilitators and barriers to English language learning in an online ESOL programme?

\section{Interview questions}

\section{Questions for school principal}

- Can you outline how you/your school got involved with ELLINZ online?

- What influenced your decision?

- Did you consult with other staff members about deciding to use ELLINZ online?

- How has it worked out?

- What has worked well for you/the school/the students? Why do you think this is?

- What has been challenging for you/the school/the students? Why do you think this is?

- Would you like to suggest any changes? What? Why?

- Any more comments?

\section{Questions for school staff}

- Can you outline how you/your school got involved with ELLINZ online?

- What role have you played in this?

- How has it worked out?

- What has worked well for you/the school/the students? Why do you think this is?

- What has been challenging for you/the school/the students? Why do you think this is?

- Would you like to suggest any changes? What? Why?

- Any more comments?

\section{Questions for ELLINZ online staff (eTeacher)}

- How is ESOL eTeaching going at this school?

- Is esol eTeaching meeting the learning needs of these students? Why? Why not?

- What is going well? Why do you think this is?

- What is challenging? Why do you think this is?

- Would you like to suggest any changes? What? Why?

- Any more comments?

\section{Questions for students}

- Tell me about your ELLINZ online work. 
- Does it help you learn English? How?

- What do you like about it? Why?

- What don't you like about it? Why?

- What is easy?

- What is hard?

- Tell me about a lesson you had.

- What else do you want to say?

\section{Questions for parents/caregivers}

- What can you tell me about the ELLINZ online programme your child is doing at school?

- What do you think about it?

- What is working well for your child?

- What is not going so well for your child?

- What would you like the school/ELLINZ online to do to support your child more?

- Any more comments?

\section{General probes}

- Can you tell me more about that?

- Can you give me an example of that?

- Any more comments? 
E. Note to parents

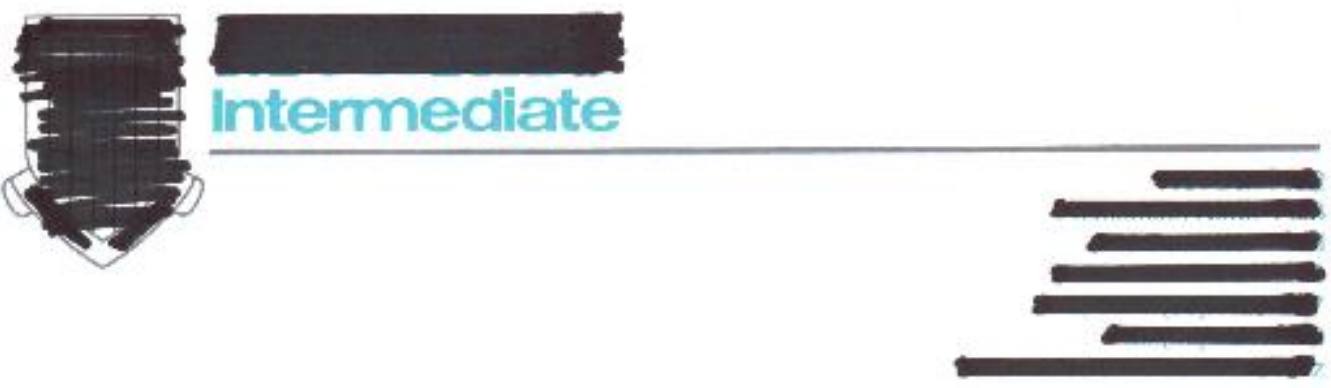

5 June 2013

Dear Parents/Caregivers

Annette Tate is a student with Victoria University in Wellington. She is visiting

termediate for three weeks studying English language learning online.

Your Child is learning English online at school, using computers, on a programme called ELLINZ.

Annette would like to talk to about what they think of learning English online. She would also like to talk to parents/caregivers about you think too.

If you are happy about this please tick the box/es below and return this nutice back to Intermediate.

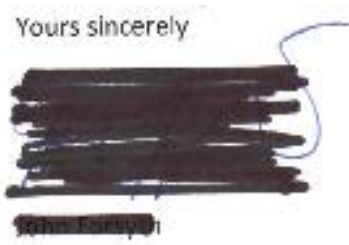

PRINCIPAL.

I give permission for to talk to Annette about learning English online

П I am happy to talk to Annette about learning English online. 
F. 'Talking sheet' for students

\section{In our talking group...}

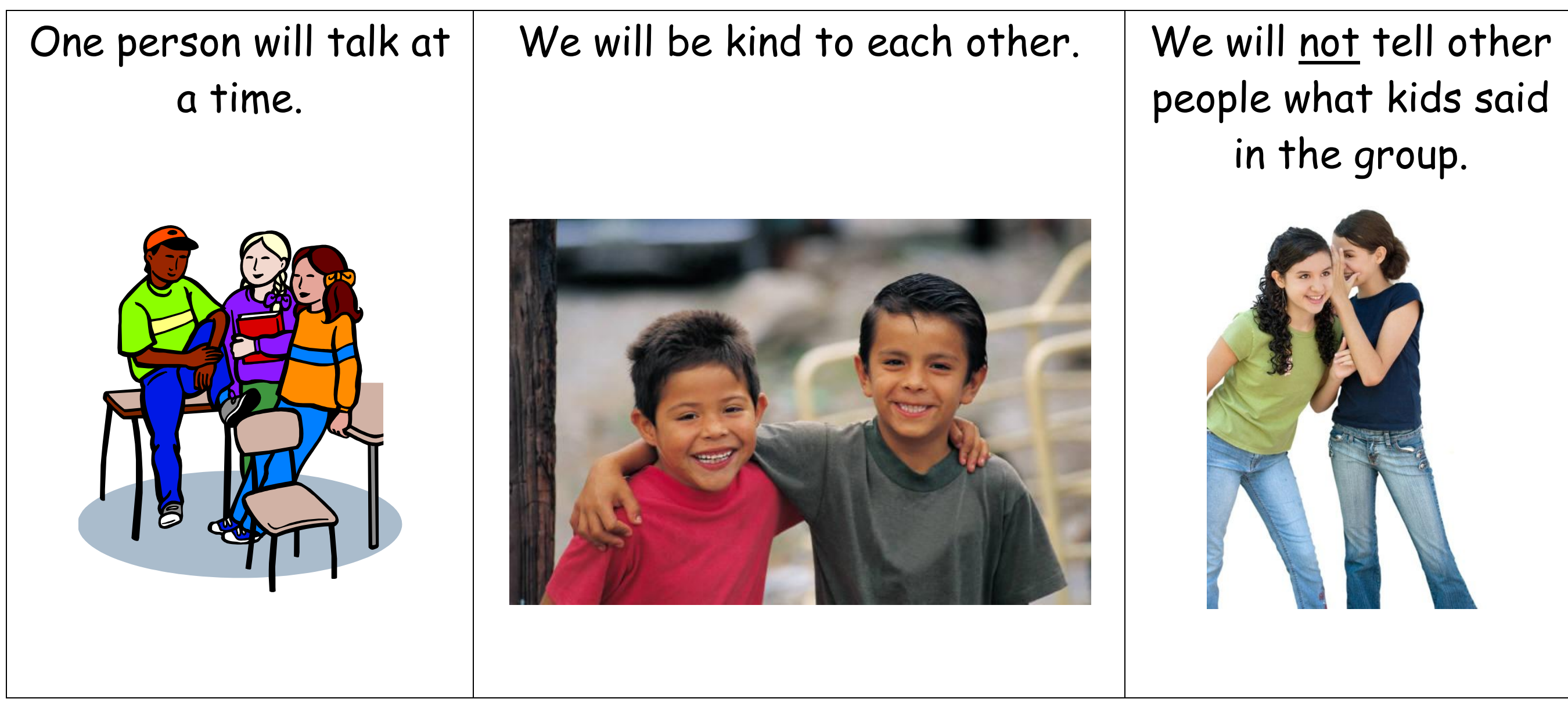

